\title{
Microglia and Stem-Cell Mediated Neuroprotection after Neonatal Hypoxia-Ischemia
}

\author{
Catherine Brégère $^{1} \cdot$ Bernd Schwendele $^{1} \cdot$ Boris Radanovic $^{1} \cdot$ Raphael Guzman $^{1}$ (D)
}

Accepted: 28 June 2021 / Published online: 11 August 2021

(C) The Author(s) 2021

\begin{abstract}
Neonatal hypoxia-ischemia encephalopathy (HIE) refers to a brain injury in term infants that can lead to death or lifelong neurological deficits such as cerebral palsy (CP). The pathogenesis of this disease involves multiple cellular and molecular events, notably a neuroinflammatory response driven partly by microglia, the brain resident macrophages. Treatment options are currently very limited, but stem cell (SC) therapy holds promise, as beneficial outcomes are reported in animal studies and to a lesser degree in human trials. Among putative mechanisms of action, immunomodulation is considered a major contributor to SC associated benefits. The goal of this review is to examine whether microglia is a cellular target of SC-mediated immunomodulation and whether the recruitment of microglia is linked to brain repair. We will first provide an overview on microglial activation in the rodent model of neonatal HI, and highlight its sensitivity to developmental age. Two complementary questions are then addressed: (i) do immune-related treatments impact microglia and provide neuroprotection, (ii) does stem cell treatment modulates microglia? Finally, the immune-related findings in patients enrolled in SC based clinical trials are discussed. Our review points to an impact of SCs on the microglial phenotype, but heterogeneity in experimental designs and methodological limitations hamper our understanding of a potential contribution of microglia to SC associated benefits. Thorough analyses of the microglial phenotype are warranted to better address the relevance of the neuroimmune crosstalk in brain repair and improve or advance the development of SC protocols in humans.
\end{abstract}

Keywords Neonatal hypoxic-ischemic brain injury $\cdot$ Cerebral palsy $\cdot$ Neuroinflammation $\cdot$ Microglia $\cdot$ Stem cell therapy $\cdot$ Neuroprotection

\section{Introduction}

Perinatal hypoxic-ischemic (HI) brain injury is the result of a decreased blood and/or oxygen supply to the brain, namely asphyxia. It can occur in preterm and term infants (see Box 1 on definitions), in which latter case the condition is termed neonatal HI encephalopathy (HIE). The risk factors of hypoxia-ischemia are multiple, and include fetal, maternal, or placental conditions [1]. The incidence of HIE is estimated to be around 1.5 per 1000 live births in developed countries [2], and it is an important cause of mortality in neonates [3]. Surviving infants, depending on the severity of HI and maturational state of the brain, may suffer lifelong neurological

Raphael Guzman

Raphael.guzman@usb.ch

1 Department of Biomedicine and Department of Neurosurgery, Faculty of Medicine, University Hospital Basel, Basel, Switzerland sequelae, such as hearing and visual impairments, sensorimotor or learning disorders, seizures, and cerebral palsy (CP) [4].

At present, therapeutic hypothermia $(\mathrm{TH})$ is the only approved intervention for term neonates diagnosed with moderate or severe HIE; it requires to be initiated within six hours after birth, and consists of either whole-body cooling or selective head cooling for up till $72 \mathrm{~h}$ to reach a body core temperature of $34 \pm 0.5^{\circ} \mathrm{C}$. Randomized controlled trials of TH demonstrate a reduction in mortality without an increase in major disabilities in surviving infants at 18-22 months [5], but the narrow time window of application and incomplete efficacy of $\mathrm{TH}$ call for the development and evaluation of complementary and/or alternative interventions.

Stem cell (SC) treatment represents such a promising therapeutic option, as it allows for a wider therapeutic window in comparison to $\mathrm{TH}[6]$, and therefore is more clinically relevant. Preclinical studies indicate that SC based therapy can ameliorate or modify diverse aspects of HI-induced cerebral damages such as infarct size, apoptosis levels, axonal sprouting, neurite outgrowth, microglial activation, and 
provide some degree of functional improvements (e.g. motor, sensorimotor and cognitive behaviors) [7-10]. The results of $\mathrm{SC}$ based clinical trials for $\mathrm{CP}$ are also encouraging and show a modest yet significant effectiveness in improving gross motor function [11]. While the underlying biological mechanisms still remain elusive, the modulation of the immune system, in the central nervous system (CNS) and/or in the periphery is often put forward as a major mechanism responsible for this therapeutic benefit. Neonatal HI indeed elicits a sterile immune response that plays a crucial role in the progression of HI-induced injury. The innate immune system is activated from the very early phases until the tertiary phase of HI. In the brain, this process involves principally microglia - the resident myeloid cells - and astrocytes, which are also immune competent cells. Mast cells have also been shown to contribute to the neuroinflammatory response $[12,13]$. A role for various peripheral innate immune cells into $\mathrm{HI}$ cerebral damage has also been demonstrated, in particular for monocytes that can infiltrate the brain parenchyma [14, 15], as well as for neutrophils [16-18] and natural killer cells [17, 19]. An adaptive immune response implicating $\mathrm{T}$ cells also seems activated after neonatal HI [17, 20,21], but it is less characterized than that of the innate immune arm. Purinergic signaling (e.g. ATP/ inflammasome axis [22]), specific cytokines, chemokines and their downstream signaling pathways also play a role in sterile inflammation and in the evolution of HI-induced cerebral injury [17, 23-32]. The complexity and multiplicity of all these inflammatory components has been the subject of recent extensive and comprehensive reviews [33-36]. Thus, to avoid redundancy, a particular emphasis is placed on discussing the microglial phenotype after neonatal $\mathrm{HI}$ in light of recent advances in the field, and the impact of developmental age at time of injury on the microglial response. The link between microglia and brain repair is then assessed by reviewing whether and how immune related treatments and stem cell therapy provide neuroprotection and impact microglia. Finally, the clinical evidence for immune modulation by SC and association with neuroprotection and neuroregeneration is discussed. The focus of this review being neuroinflammation/ microglia and SC therapy in the context of HIE, only the findings from the corresponding postnatal days (P) 7-10 rodent model will be discussed.

\section{Box 1 Definitions}

Cerebral palsy (CP) is a neurodevelopmental disorder. Its most recent definition is as follows [37]: " $\mathrm{CP}$ describes a group of permanent disorders of the development of movement and posture, causing activity limitation, that are attributed to nonprogressive disturbances that occurred in the developing fetal or infant brain. The motor disorders of cerebral palsy are often accompanied by disturbances of sensation, perception, cognition, communication, and behaviour, by epilepsy, and by secondary musculoskeletal problems."
Prematurity refers to any live birth before 37 weeks of gestation, and is further divided in moderate or late preterm ( 32 to $<37$ weeks), very preterm ( 28 to $<32$ weeks), and extremely preterm ( $<28$ weeks) [38]. Term pregnancy for singleton until recently referred to $37-42$ completed weeks of gestation. Due to heterogeneity in neonatal outcomes depending on gestational age within this five weeks' time [39], the American College of Obstetricians and Gynecologists Committee has now refined the notion of term and suggests to use "full term" for deliveries between 39 through 40 weeks of gestation [40]. This new definition of term pregnancy is not yet reflected in the clinical definition of neonatal HIE, which very often refers to term pregnancy as 36 weeks of gestation or more.

Human neonate (synonym for newborn): the neonatal period corresponds to the first 28 days of life after birth.

Human infant: corresponds to the period of time between birth and the first year.

Where the Ambiguity Starts-Definition of Rodent Age

Rodent neonate: there is a lack of consensus on the timeframe corresponding to the neonatal period. Depending on authors, the age range for a neonate is between birth and P10, or sometimes between birth and weaning, i.e. 21 days.

Rodent juvenile (synonym for adolescent): juvenility refers to the transition between "childhood" and "adulthood", during which many neurodevelopmental alterations are still occurring (maturation of cortical and limbic structures, of neurotransmitter systems); it associates with typical adolescent-like behaviors (i.e. risk-taking behavior, increased emotional reactivity). The time frame for juvenility is not strict; tentatively in rodents the time period between P28 and P42 has been suggested, but it can start before, and end after [41]. In contrast to juvenility, rodent puberty refers to the well-defined time period during which sexual maturity is achieved. It occurs at around P32-40 and P38-45 for rat females and males, respectively.

Rodents may be considered as adults if they are at least 12 weeks of age [42].

\section{Pathophysiology of Neonatal HI: A Complex and Evolving Brain Injury}

Among neural cells, neurons are the most vulnerable to HI, due to their high energetic requirements to ensure neurotransmission and maintain ionic gradients across their membrane. Specific groups of neurons and regions (cortex, thalamus and putamen) in the developing brain have been shown to be particularly sensitive, a phenomenon referred to as selective vulnerability $[43,44]$. Neuronal injury occurring after HI progresses over time, and based on investigations in animal models of neonatal $\mathrm{HI}$ and clinical observations, the following chronological phases have been proposed. The first phase is referred to as a primary energy failure (or acute phase), and immediately follows the HI insult. The drop in glucose and oxygen levels induced by HI causes a rapid reduction in ATP levels, which then leads to a failure of ATP dependent processes in neurons, in particular the transmembrane ion pumps. This energy failure triggers a cascade of toxic events, e.g. intracellular accumulation of sodium, calcium and water, brain acidosis, and eventually results in cytotoxic edema, 
extracellular accumulation of excitatory amino acids, and death of neurons, mainly through necrosis but also through apoptosis. Depending on the severity and duration of the HI episode, a latent phase may follow during which partial recovery of neuronal metabolism can occur; although its duration and exact timing is unknown, it is often considered that this phase is an appropriate time window to begin potential neuroprotective treatments, such as TH or SCs injection, in order to limit the ongoing toxic processes and prevent the progression towards the secondary phase. In the absence of intervention or if the primary phase is prolonged and severe, then the latent phase is short and a secondary delayed energy failure phase (six to $72 \mathrm{~h}$ after the insult) ensues, during which further deterioration and cell death will occur, characterized by excitotoxicity, mitochondrial failure, acute inflammation, oxidative stress, and increased seizure activity. Finally, there is evidence that some injury processes may persist over months or perhaps years, resulting in so called tertiary damages [45]; the suggested mechanisms underlying such damages include astrogliosis, persistent inflammation and epigenetic changes, all of which may lead to exacerbated cell loss and sensitization to potential second hits.

\section{Modeling HIE in Rodents: The Rice-Vannucci Model}

The most widely used experimental model to study HIE is the Rice-Vannucci model [46]. Initially developed in the immature Sprague-Dawley rat, it was later adapted to the mouse $[47,48]$, thus allowing to study the contribution of individual or combination of genes to the HI-induced pathological processes using genetically modified mice. This model combines unilateral ligation of the common carotid artery (CCA) and subsequent exposure to $8-10 \%$ oxygen/balance nitrogen (hypoxia) for a duration of between $40 \mathrm{~min}$ up to $3.5 \mathrm{~h}$. The time interval between permanent CCA ligation and subsequent exposure to hypoxia influences the development of brain injury in the rodent neonate. If initiated three to four hours after CCA ligation, hypoxia induces a discernible neurologic lesion histologically and a drop in ATP levels in the ipsilateral hemisphere. Nevertheless, the brain injury is almost absent if hypoxia is initiated $24 \mathrm{~h}$ post-ligation $[49,50]$. This is most likely because collateral compensatory blood flow occurs within $24 \mathrm{~h}$, as demonstrated in the adult rat in which one to two days and up to six weeks after CCA ligation, a significant enlargement of the anastomosis of the ipsilateral posterior communicating artery was measured [51, 52]. Hypoxia alone also does not cause obvious neuronal death, but rodent neonates exposed to global hypoxia between P7-P10 show a heightened susceptibility to provoked seizures, and develop spontaneous seizures shortly after hypoxia exposure, and during adulthood [53, 54]. Thus hypoxia-only models are valuable to study short and long-term consequences of neonatal epilepsy (reviewed in [54]).

The brain injury induced by $\mathrm{HI}$ is observed in the ipsilateral hemisphere, i.e. on the same side of carotid ligation, and generally leaves the contralateral hemisphere intact. Duration of hypoxia obviously influences the severity of lesion [55], but even when using the same exposure time to hypoxia within an experiment, animals still display variable brain damage, ranging from none, mild, moderate to almost fully infarcted ipsilateral hemisphere $[56,57]$. The lesions are commonly observed in both grey and white matter, and affected structures include the cortex, striatum, thalamus and hippocampus. This neuropathology is accompanied by short-term sensorimotor deficits [58] and long-lasting motor, learning and memory impairments [59-61]. Of note, the HI-induced sensorimotor and motor deficits are lateralized, and observed on the contralateral limbs [62].

The HI surgery in rodents is typically performed at P7 in rats, and between P7-10 days in mice. While not explicitly stated in the original publications, the choice of these days was based on the work by Dobbing and Sands [63], who reported that the peak of the brain growth spurt occurred at P7 in the rat brain and around birth in humans (see Box 2 on the brain growth spurt). There is no definitive answer as to whether the degree of maturation of the rat brain at P7 day corresponds to that of the human brain at birth, because it mainly depends on the developmental indices considered. For instance, in terms of functional cortical development (measured by the number of synapses, electrical activity and activity of some neurotransmission system), the brain of a human full-term neonate resembles that of $\mathrm{P} 12-13$ rat [64]. When white matter maturation is considered, the human brain between 30 and 36 weeks of gestation then roughly corresponds to that of a P7 rodent brain [65]. Based on these criteria and others, some authors posit that the P7 rat brain may still be premature in comparison to that of a human term infant, and argue that the P10-11 stage may be more appropriate to study HIE and potential therapies $[56,66]$. Notwithstandingly, the overwhelming majority of investigators - including ourselveshas and continues to use the classical P7 rat model and thus the prevalence of this model facilitates inter-studies comparisons (see all Tables). As models translating the timing of neurodevelopment events from humans to rodents are now available (http://translatingtime.org) [67-69], an informed choice can be made concerning the postnatal age at which $\mathrm{HI}$ is induced, keeping in mind that a three to four day shift may impact neuropathological and behavioral outcomes.

$\mathrm{HI}$ is also performed in rodent neonates younger than P7. As P1-P5, in terms of brain maturation, roughly corresponds to a human fetus between 24 to 32 weeks of gestation, HI induction at this postnatal age attempts to model brain lesions observed in the very preterm infant, in particular white matter damage and its most severe form periventricular leukomalacia 
(PVL). There is currently no single model of "encephalopathy of prematurity "[70], as the day of HI induction, the severity of hypoxia (typically $5 \% \mathrm{O}_{2}$ because $8 \% \mathrm{O}_{2}$ fails to induce neuronal damage [71]) and its duration, vary greatly between studies [72-77]. In addition, HI is sometimes combined with an inflammation trigger (e.g. LPS) [78, 79], since inflammation is thought to be a major cause of brain injury in preterm infants [80, 81]. The pattern of brain lesion overlaps to a certain extent with that of the $\mathrm{P} 7$ model, for instance alteration in cortical development and myelination can be observed, albeit with subtle differences in neuronal populations affected, and short as well as long-term sensorimotor, motor and cognitive defects are also observed [82-85]. Nevertheless, contrary to the HI-P7 model, the hippocampus is typically spared in neonates exposed to HI before P7 [71].

\section{Box 2 Age Matters/the Brain Growth Spurt}

Age is admittedly a critical factor in the field of neurosciences [86], but even more so in neurodevelopment. Why do we model a brain injury occurring at around birth in humans in seven-day-old rodents? The answer is that the relation of birth to the degree of maturation of the brain differs between species. While humans, just as rodents, are considered an altricial species, their brain maturation at birth is actually more advanced than that of rodents.

The Brain Growth Spurt

The growth of the brain, in terms of weight, is not uniform across development. If age is plotted against brain weight (expressed as percent of adult value), it yields a sigmoid curve, whichever species considered. When derivated into a velocity curve, then a peak becomes visible: it corresponds to a phase of extremely fast growth, referred to as the brain growth spurt. A major difference between species is the timing of this growth spurt in relation to birth. In humans, there is a major brain growth spurt that begins at around mid-gestation, peaks at birth, and ends at around 3 to 4 years [87]; between birth and the age of 3-4 years, the weight of the human brain quadruples, reaching almost $80 \%$ of the adult brain weight. In the rat, the brain growth spurt is postnatal only: it starts at birth, peaks at postnatal day 7 , and ends at around postnatal day 25 . The timing of the peaks, birth in humans, and P7 in rats, is the basis for the P7 rat model of neonatal HI. It is still frequent to read in the literature that the developmental stage of the rat brain at P7 roughly corresponds to that of humans at term birth. Such a statement is yet a shortcut, as other developmental aspects beyond the growth spurt can also be considered, as discussed in the main text. Thus, the decision-making concerning the time point at which an injury is induced in rodent neonates to mimic a human condition will depend on the research question and should be based on the available neurodevelopmental data.

\section{The Impact of Neonatal HI on Microglia/Macrophages}

\section{Microglial Phenotype after Neonatal HI}

In the healthy developing brain, microglia are implicated in various ongoing neural processes, such as synaptic pruning
$[88,89]$, maintenance of normal brain structure and olfaction [90], phagocytosis of dead cells and debris, but also of viable neural precursor cells in the subventricular zone (SVZ) [91], axon guidance [92], as well as neurogenesis and oligodendrogenesis [93] .

Experimental data in rodents indicate that neonatal $\mathrm{HI}$ induces early (two hours post-HI) and persisting (up until 17 days) phenotypical changes in microglia in the ipsilateral hemisphere, including an increase in cell count, a spectrum of morphological changes from a ramified to an amoeboid state, and an elevated expression of markers of microglia activation (OX-6, major histocompatibility complex II; OX-18, major histocompatibility complex I; CD68) [94, 95] (see Table 1 for an overview on microglia and other cerebral immune-related findings in the rodent model of neonatal HI). The time course of these changes is region-dependent, with the hippocampal microglia showing earlier activation than their cortical, striatal and white matter counterparts [32, 96]. There is a commonly held view that in the earlier phases of HI injury, microglia adopt a M1 "classically activated" pro-inflammatory phenotype, while later on switch to a M2 "alternatively activated" anti-inflammatory phenotype (see Boxes 3 and 4 for a historical perspective and a summary on the M1/M2 concept). Thus, a study reported that M1 microglia predominate in the ipsilateral hemisphere three hours after neonatal $\mathrm{HI}$, while at $24 \mathrm{~h}$, both M1 and M2 microglia can be detected, suggesting a switch in the inflammation state of the brain [31]. Nevertheless, a limitation in this study is that a single marker for each state was used (iNOS for M1, and CD206 for M2). A more recent study revealed a slightly more complex picture, with higher and concomitant expression of both anti-inflammatory and pro-inflammatory genes in the ipsilateral than in the contralateral hemisphere [97]. In addition, FACS analysis of the $\mathrm{CD} 11 \mathrm{~b}^{+}$population (microglia/ macrophages) for CD86 (classical) and CD206 (alternative) cell markers revealed an expanded and predominant population of $\mathrm{CD} 11 \mathrm{~b}^{+} \mathrm{CD} 86^{+} \mathrm{CD} 206^{-}$cells in the injured hemisphere over several days post injury, a relative suppression of $\mathrm{CD} 11 \mathrm{~b}^{+} \mathrm{CD} 86^{+} /-\mathrm{CD} 206^{+}$cells, and a small "non-polarized" cell population expressing neither CD86 and CD206, but expressing galectin-3, an immunomodulatory mediator. Our own investigations of the microglial phenotype in the SVZ - three and 13 days after neonatal $\mathrm{HI}$ in rat-also converge towards the same point since $\mathrm{CD} 11 \mathrm{~b}+$ microglia isolated from the ipsilateral subventricular zone (SVZ) of HI-exposed rat neonates upregulate both pro- and anti-inflammatory genes until 13 days post-injury, and do not differentially express markers of acute inflammation such as IL- $1 \beta$, IL- 6 , TNF- $\alpha$, and IFN- $\gamma$ when compared to microglia isolated from the SVZ from sham animals [98]. This underlies the specificity of the SVZ microglial response versus that observed in regions nearby the ischemic core. Further comparative analyses of our microglial gene datasets with 
Table 1 Cerebral immune-related findings in the rodent model of neonatal HI

$\begin{array}{ll}\text { Reference } \quad \text { Species and Model of HI } & \begin{array}{l}\text { Immune-related findings in the ipsilateral (Il) Conclusion(s) } \\ \text { brain in comparison to the contralateral (Cl) } \\ \text { brain }\end{array}\end{array}$

McRae A et al., WFU rat $1995 \quad$ P7

PMID: 7743644 Left CCA ligation $100 \min 7.7 \% \mathrm{O}_{2}$ Sacrifice time-points: 2-3 h, 24 h, 2-4 d and $2 \mathrm{w}$

Ohno $\mathrm{M}$ et al., Sprague-Dawley rat $1995 \quad$ P7

PMID: 7743650 Left CCA ligation $120 \min 8 \% \mathrm{O}_{2}$ Sacrifice time-points: $3,6,12,24,48$ and $72 \mathrm{~h}$ and 5 and $14 \mathrm{~d}$

Szaflarski J et al., 1995

Sprague-Dawley rat

PMID:7762028 Right CCA ligation $180 \min 8 \% \mathrm{O}_{2}$ Sacrifice time-points: $1,2,4,8,12,24$, and $48 \mathrm{~h}$

Hagberg $\mathrm{H}$ et al., Wistar rat $1996 \quad$ P7

PMID: 8888290 Left CCA ligation $70-100 \min 7.7 \% \mathrm{O}_{2}$ Sacrifice time-points: $1,3,6,10,20$, and $48 \mathrm{~h}$, and at $14 \mathrm{~d}$
Immunohistochemistry using $O X-18$ (Ab against rat MHC-Class I antigens), OX-42 (anti-CD11b/c, a component of complement receptor 3 or $C R 3$ ) and $O X-6$ (Ab against rat MHC-Class II antigens)

2-3 h:

- Corpus callosum: slight increase in OX-18 immunoreactivity.

- Thalamus: scant OX-18/OX-42 immunoreactivity.

- Cortex or striatum: absence of OX-18 ${ }^{+}$ microglia.

- No OX-6 immunoreactivity in any region. $1 \mathrm{~d}$ :

- Corpus callosum: OX-18 and OX-42 immunoreactivity increases.

- No OX-6 immunoreactivity in any region.

2-4 d:

- Cerebral cortex, striatum and corpus callosum: peak in OX-18 and OX-42 stainings.

- Thalamus: scant OX-18/OX-42 immunoreactivity.

- OX-6 immunoreactivity detected.

$2 \mathrm{w}:$

- OX-18/OX-42 immunoreactivity persists at a high level in the cortex and striatum; the immunoreactivity is lost in the corpus callosum.

- Thalamus: peak in OX-18/OX-42 immunoreactivity.

- No OX-6 immunoreactivity in any region.

Immunohistochemistry using OX-42, ED-1 (anti-CD68 Ab) and ED-2 (anti-CD163 $A b$, marker of the monocyte/macrophage lineage)

- Cerebral cortex: intense OX-42 immunoreactivity evident $24 \mathrm{~h}$ after HI.

- Maximal microglia/macrophage reaction 5 $\mathrm{d}$ after $\mathrm{HI}$.

- Positive OX-42 staining still detected in cortex and hippocampus 14 days after HI.

- CD68 ${ }^{+}$cells become visible after $48 \mathrm{~h}$.

- No change in ED-2 immunoreactivity observed in the HI brain.

$R T-P C R$

- In the Il cortex, hippocampus and striatum, a peak in IL-1 $\beta$ mRNA expression occurs $4 \mathrm{~h}$ post-HI; return to normal levels by $24 \mathrm{~h}$.

- Similar transient increase in TNF- $\alpha$ mRNA.

Cytokines/gene expression

No IL-1 bioactivity detectable in the brain from control animals.

After HI:

- In the Il hemisphere, IL-1 bioactivity is undetectable $1 \mathrm{~h}$ after the insult, increases at $3 \mathrm{~h}$, peaks at $6 \mathrm{~h}$, and remains
- The loss of MAP2 precedes microglial activation in cortex and striatum.

- The time course of microglial activation depends on the brain region considered.

- Overall, in comparison to the $\mathrm{Cl}$ hemisphere, a robust proliferation of microglia starts at $24 \mathrm{~h}$, peaks at 2-4 days, and persists up to $14 \mathrm{~d}$ post-HI.

Microglial response to HI appears to be the most prominent among glial cells.

The elevation in the gene expression of pro-inflammatory cytokines suggests a potential functional role in perinatal brain injuries.

IL-1 plays a role in the pathophysiology of neonatal $\mathrm{HI}$. 
Table 1 (continued)

Immune-related findings in the ipsilateral (Il) Conclusion(s)

brain in comparison to the contralateral $(\mathrm{Cl})$

brain
Reference Species and Model of HI

Ivacko JA et al., Sprague-Dawley rat $1996 \quad$ P7

PMID: 8825384 Right CCA ligation Sacrifice time-points: $10 \mathrm{~min}$ to $5 \mathrm{~d}$

Hudome S et al., Wistar rat 1997 P7

PMID: 9128280 Right CCA ligation $135 \min 8 \% \mathrm{O}_{2}$

0,5 , and $30 \mathrm{~min}$, and $2,4,8,18$, and $42 \mathrm{~h}$ $180 \min 8 \% \mathrm{O}_{2}$

Sacrifice time-points:

significantly higher than in $\mathrm{Cl}$ hemisphere up to $48 \mathrm{~h}$.

- IL-6 bioactivity and mRNA are also increased in response to $\mathrm{HI}$ with a similar time course to IL-1, but the changes are not as pronounced.

G. simplicifolia B4-isolectin histochemistry

- In the hippocampus, evidence of microglia activation based on morphological changes 10 min after HI.

- In the hippocampus, thalamus, cortex and striatum, increased number of activated microglia $4 \mathrm{~h}$ after $\mathrm{HI}$.

- Even more extensive microglial activation $8 \mathrm{~h}$ post-HI followed by progressive increase at 24, 48 and 72 h.ED-1 (CD68) immunohistochemistry

- No increase 10 min post-HI, but immunoreactivity detectable $4 \mathrm{~h}$ post-HI in the Il ependyma and choroid plexus. At $24 \mathrm{~h}$ post-HI, reactive cells infiltrate the pyramidal cell layer and at $48 \mathrm{~h}$, there is diffuse infiltration throughout the hippocampus.

Hemispheric myeloperoxidase (MPO) activity

MPO activity in both hemispheres of $\mathrm{HI}$-exposed animals is higher than in control animals at all times of sacrifice, with a peak between 4 and $8 \mathrm{~h}$ post-HI. There is no difference in MPO activity between $\mathrm{Il}$ and $\mathrm{Cl}$ from $\mathrm{HI}$-injured rats.

Neutrophil staining with ANS

(anti-neutrophil serum) in the brain

The count of neutrophils in HI-Il and $\mathrm{HI}-\mathrm{Cl}$ hemispheres does not differ significantly from that in normal brain tissue. Overall there are significantly more neutrophils in the Il than in the $\mathrm{Cl}$ hemisphere. Staining indicates that the majority of neutrophils are located within the leptomeningeal blood vessels on the surface of the brain or within the choroid plexus, thereby indicating that the neutrophils do not extravasate from blood to the brain parenchyma.

Ivacko JA et al., Sprague-Dawley rat $1997 \quad$ P7

PMID: 9270493 Right CCA ligation $180 \min 8 \% \mathrm{O}_{2}$

Sacrifice time-points:

- For in situ hybridization: 0, 1, 2, 4, 8, MCP-1 mRNA and protein peak within the $16,24,48$, and $120 \mathrm{~h}$

- For immunocytochemistry: $10 \mathrm{~min}$, $2.5,4,8,12,24,48$ and $120 \mathrm{~h}$
In situ hybridization and immunohistochemistry for $M C P-1$ (monocyte chemoattractant protein-1, or $\bar{C} C L 2$, a potent chemotactic factor for monocytes; the receptor is CCR2)

first $24 \mathrm{~h}$ in the lesioned hemisphere and are no longer detected after $48 \mathrm{~h}$.

G. simplicifolia B4-isolectin histochemistry

In the lesioned forebrain structures, the microglial/monocyte response (i.e. accumulation and morphological transition to an activated state characterized by cell body enlargement
- Based on lectin and ED-1 labelings, the density of microglia activation peaks between 2 and $4 \mathrm{~d}$ after HI.

- $5 \mathrm{~d}$ post-HI, microglial activation is less intense in cortex, striatum and hippocampus.

- The regional distribution of microglia activation generally corresponds to that of the histopathology.

- Overall, microglia activation occurs very early in the forebrain after $\mathrm{HI}$; it peaks around $2 \mathrm{~d}$ post-HI, and begins to wane $4 \mathrm{~d}$ post-HI.

Neutrophils may play a role in the pathogenesis of neonatal HI, via yet unclear mechanisms.

- HI induces MCP-1 gene and protein expression in the Il hemisphere within $48 \mathrm{~h}$, after which time point MCP-1 protein declines.

- MCP-1 immunoreactive cells appear to be neurons.

- Microglia express MCP-1 receptors. The microglial response is more prolonged than that of MCP-1 after HI.

-- Overall, MCP-1 may play a role in the microglial response; however it should be noted that microglial response is observed prior to detection of MCP-1 mRNA or protein. 
Table 1 (continued)

Immune-related findings in the ipsilateral (Il) Conclusion(s)

brain in comparison to the contralateral $(\mathrm{Cl})$

brain
Reference Species and Model of HI

Bona $\mathrm{E}$ et al., 1999

PMID: 10203141

Liu X et al., 1999

PMID:

10532634
Wistar rats

P7

Left CCA ligation

$70 \min 7.7 \% \mathrm{O}_{2}$

Sacrifice time-points: and $35 \mathrm{~d}$
3 h, 6 h, 12 h, 24 h, 72 h, 7 d, 14 d

and shortened, thickened cell processes) peaks at about $48 \mathrm{~h}$ after HI, plateaus from 48 to $96 \mathrm{~h}$, and then begins to wane. Many activated microglia and/or monocytes are still detectable throughout the Il cerebral hemisphere 5 to $6 \mathrm{~d}$ after lesioning.

\section{RT-PCR}

Whole Il hemisphere in comparison to $\mathrm{Cl}$ : early induction of $\alpha$ (gro and MIP-2) and $\beta$ (MIP- $1 \alpha$ and MIP-1 $\beta$ ) chemokines (within $6 \mathrm{~h}$ ); induction of TNF $\alpha$ (peak at $12 \mathrm{~h}$ ) and Il-1 $\beta$ (peak at $6 \mathrm{~h}$ ).

Hematoxylin and eosin staining

Increased neutrophil count at $12 \mathrm{~h}$ post-HI, then return to baseline levels; neutrophils found within and around vessels in the damaged gray and white matter.

Immunohistochemistry

- $3 \mathrm{~d}$ after HI, increase in CD4 expression bilaterally in corpus callosum, and in damaged regions with a peak $7 \mathrm{~d}$ post-HI; Persisting CD4 expression in injured regions up to $14-35 \mathrm{~d}$ post-HI.

- At 24 and $72 \mathrm{~h}$ post-HI, discrete increase in $\mathrm{CD} 8+$ cells in the $\mathrm{CC}$ and in the $\mathrm{HI}$ damaged regions.

- At $12 \mathrm{~h}$ post-HI, variable increase in NK+ cells immunoreactivity in the Il hemisphere, with the number of NK cells ranging from 15 to 20 to 60 . This accumulation of NK cells is observed in the infarcted area, and appears to persist up till $14 \mathrm{~d}$ post-HI.

- OX-18+ cells (microglia/macrophages) detectable as early as $3 \mathrm{~h}$ post-HI, and increase up till $72 \mathrm{~h}$ post $\mathrm{HI}$, with the most pronounced induction in the severely HI-affected brains.

- Marked increase in $\beta 2$-integrin immunoreactivity in the infarct region $7 \mathrm{~d}$ post-HI that persists up to $35 \mathrm{~d}$.

- Attenuation of HI-induced brain damage in ICE deficient mice (ICE=Interleukin-1 converting enzyme; animals are deficient in systemic IL- $1 \alpha$ and IL- $1 \beta$ ) in comparison to WT mice if animals undergo moderate $\mathrm{HI}$

- However, the degree of infarct severity in both ICE and WT mice remains the same if animals are subjected to severe HI.

$m R N A$ and protein levels of $M C P-1$, and $m R N A$ levels of its receptor CCR 2

Xu H et al., 2001 WT and ICE-deficient mice on a

PMID:

11376856 mixed 129/Sv and C57BL/6 background

P9 -P10

Right CCA ligation

$10 \% \mathrm{O}_{2}, 40 \mathrm{~min}$ (minimal) or $70 \mathrm{~min}$ (moderate) or $120 \mathrm{~min}$ (severe) HI insult

Sacrifice time-points:

$0,8,16,24$ and $48 \mathrm{~h}$
- There is an early induction of chemokine gene expression after HI that precedes immune cells activation.

- The activation of microglia/macrophages (MHC-Class I staining), CD4 lymphocytes and neutrophil accumulation persist for up to $35 \mathrm{~d}$ post-HI.

Overall, chemokines potentially play a role in initiating the inflammatory response associated with $\mathrm{HI}$.
- HI markedly stimulates MCP-1 expression both in ICE deficient mice and in wildtype mice at $8 \mathrm{~h}$ post-HI.

- In animals subjected to the mildest HI protocol, the Il hemisphere concentration of MCP-1 is substantially lower in the ICE deficient mice than in the wildtype group.
- Neonatal ICE-deficient mice are resistant to a moderate $\mathrm{HI}$ insult, but not to a severe insult.

- Overall, the activity of ICE contributes to the progression of neonatal $\mathrm{HI}$ injury to some extent.

- HI stimulates MCP-1 expression in the brain even in the absence of IL- $1 \beta$ activity.

- The activity of ICE participates to the regulation of the acute inflammatory response to $\mathrm{HI}$ brain injury in neonatal mice. 
Table 1 (continued)

Reference Species and Model of HI

Cowell RM

et al., 2002

PMID:

11872906

Hedtjärn M

et al., 2002

PMID:

12122053
Sprague-Dawley rat P7

Right CCA ligation 60 to $150 \min 8 \% \mathrm{O}_{2}$ Sacrifice time-points: $0,4,8,16,72$ and $120 \mathrm{~h}$

Wistar rat

P7

Left CCA ligation

$60 \min 7.7 \% \mathrm{O}_{2}$

Sacrifice time-points:

$1,3,6$ and $14 \mathrm{~d}$
C57BL/6 wild-type mice and IL-18 $\mathrm{KO}$ mice

P9

Left CCA ligation

$60 \min 7.7 \% \mathrm{O}_{2}$

Sacrifice time-point: $3 \mathrm{~d}$
Immune-related findings in the ipsilateral (Il) Conclusion(s)

brain in comparison to the contralateral $(\mathrm{Cl})$

brain
- The severity of the HI insult influences the magnitude of the MCP-1 response.

- CCR2 mRNA is detected only at $24 \mathrm{~h}$ post-HI, and expression is equivalent between HI-exposed ICE deficient mice and $\mathrm{HI}$-exposed wildtype mice.

Immunohistochemistry for MIP-1 $\alpha$, macrophage inflammatory protein, a monocyte chemoattractant protein that belongs to the $\beta$-chemokine family

- In normal P7 to P12 rat brain, MIP- $1 \alpha$ is found in physiologically activated microglia.

- From 8 to $120 \mathrm{~h}$ post-HI, MIP- $1 \alpha$ immunoreactive cells are detected in the injured cortex, hippocampal dentate gyrus and thalamus, but not in the corresponding $\mathrm{Cl}$ regions; they are associated with capillaries.

- No increase in immunoreactivity for the 2 receptors of MIP- $1 \alpha$, CCR 1 and CCR 5 , is detectable.

ELISA

MIP- $1 \alpha$ concentration peaks in the Il hemisphere at $16 \mathrm{~h}$ post-HI and declines thereafter.

Immunohistochemistry

- Immunoreactivity for IL-18 (member of the IL-1 family) is observed in injured areas in cortex and thalamus in the Il hemisphere at 6 and $14 \mathrm{~d}$ after $\mathrm{HI}$.

- Cells expressing IL-18 are identified as microglia and they co-localize with caspase-1 positive cells.

- IL-18R immunoreactivity is primarily found on neurons: the expression remains similar between control and HI-exposed animals, and no difference can be observed between $\mathrm{Il}$ and $\mathrm{Cl}$ hemispheres. RT-PCR

Between $3 \mathrm{~h}$ and $14 \mathrm{~d}$ post-HI, continuous and significant increase in mRNA expression of IL-18 and caspase-1 in Il versus $\mathrm{Cl}$ hemisphere of $\mathrm{HI}$-exposed animals.

Cytokines (ELISA)

- Increase in active IL-18 protein levels in the injured hemisphere 3 and $6 \mathrm{~d}$ after injury.

- In contrast, the maximal increase in IL- $1 \beta$ protein occurs $8 \mathrm{~h}$ post-HI, earlier than the peak in caspase- 1 and IL-18 protein expression, and then a secondary rise occurs at 6-14 d after HI.

Immunohistochemistry

- The area of infarction measured as lack of MAP2 immunoreactivity is significantly reduced in IL-18 KO compared to wildtype mice.

- The neuropathological scoring of HI brain injury is also lower in IL-18 KO mice.
- Neonatal HI induces expression of MIP- $1 \alpha$ in the monocyctic/macrophage lineage.

- Overall, MIP- $1 \alpha$ contributes to neonatal HI-induced inflammation.

The relative resistance of IL-18 deficient mice to HI injury suggests the involvement of IL-18 in the pathogenesis of neonatal $\mathrm{HI}$. 
Table 1 (continued)

Reference Species and Model of HI
Immune-related findings in the ipsilateral (Il) Conclusion(s)

brain in comparison to the contralateral $(\mathrm{Cl})$

brain

\begin{tabular}{cl}
\hline $\begin{array}{c}\text { Hedtjärn M } \\
\text { et al., 2004 }\end{array}$ & P57BL/6 wild-type mice \\
PMID:15625408 & Left CCA ligation \\
& 60 min $10 \% \mathrm{O}_{2}$ \\
& Sacrifice time-points: \\
& $2,8,24$, and $72 \mathrm{~h}$
\end{tabular}

Hedtjärn M

et al., 2005

PMID: 16046848

C57BL $/ 6$ mice

IL-1 $\beta 18$ double-knockout mice and mice lacking the gene for IL- $1 \beta$ while being heterozygous for IL-18 IL- $1 \alpha \beta$ double knockout mice P9

Left CCA ligation

$60 \min 10 \% \mathrm{O}_{2}$

Sacrifice time-point: $1 \mathrm{w}$

$\begin{array}{cl}\text { Van Den Tweel } & \text { Wistar rat } \\ \text { ER et al., } & \text { P12 } \\ 2006 & \text { Right CCA ligation } \\ \text { PMID: } & 90 \text { min } 8 \% \mathrm{O}_{2} \\ 16492985 & \text { Sacrifice time-points: } \\ & 30 \text { min to } 48 \mathrm{~h}\end{array}$

Jin Y et al., 2009 Wistar rat

PMID: P7

$19520991 \quad$ Right CCA ligation

$75 \min 8 \% \mathrm{O}_{2}$

Sacrifice time-points:

$0,1,2,4,24$ and $48 \mathrm{~h} ; 1,2$ and $4 \mathrm{w}$

$\begin{array}{cl}\text { Winerdal M } & \text { C57/bl6 mice } \\ \text { et al., 2012 } & \text { P10 } \\ \text { PMID: } & \text { Right CCA ligation } \\ \text { 22567156 } & 60 \text { min } 10 \% \mathrm{O}_{2} \\ & \text { Sacrifice time-points: }\end{array}$

Microarray global inflammatory gene expression analysis in the developing brain

- 148 inflammatory genes are differentially expressed 2 to $72 \mathrm{~h}$ after HI; $97 \%$ of the genes are up-regulated.

- The differentially regulated genes are divided in 9 functional categories based on function and cellular expression: chemokines, complement-related genes, genes expressed by leukocytes, macrophage related genes, genes related to $\mathrm{B}$ and T-lymphocytes, genes induced or regulated by interferons, MHC class I- and II related genes, others genes involved in immune and inflammatory responses and genes related to adhesion.

- When overall brain injury is measured, mice deficient in IL- $1 \beta$ in combination with IL-18 are moderately protected.

- Mice deficient in either IL- $1 \beta$, or IL- $1 \beta$ in combination with IL- $1 \alpha$, are not protected against neonatal $\mathrm{HI}$.

Cytokines

- The mRNA of TNF- $\alpha$, TNF- $\beta$, and IL- $1 \beta$ are detected $6 \mathrm{~h}$ post-HI and peak $24 \mathrm{~h}$ after $\mathrm{HI}$.

- After 48 h, mRNA expression for the cytokines return to the levels measured at $6 \mathrm{~h}$.

- A large individual variation in the cytokine levels after HI is noted.

- No significant differences are observed between expression of the cytokines in the $\mathrm{Il}$ and $\mathrm{Cl}$ hemispheres.

- Hypoxia alone induces an increase in IL-1 $\beta$ mRNA expression in both hemispheres.

Immunohistochemistry for CD68

- The number of CD68+ cells in the Il hemisphere starts to increase at $12 \mathrm{~h}$ and continues to rise until $48 \mathrm{~h}$ post-HI.

- No change in the number of CD68+ cells in the CL hemisphere is observed.

Toluidine blue histology to identify mast cells (MCs)

- Rapid increase in MCs in the Il hemisphere in comparison to both control and $\mathrm{Cl}$ hemispheres immediately after $\mathrm{HI}$ and throughout the initial $48 \mathrm{~h}$ period.

Impact of cromolyn treatment, a MC stabilizer

FACS

- In comparison to sham and $\mathrm{Cl}$ hemisphere, the number of $\mathrm{CD} 1 \mathrm{bb}^{+} / \mathrm{CD} 86^{+}$increases 1 $\mathrm{d}$ post $\mathrm{HI}$, then declines, peaks again $7 \mathrm{~d}$
- The immune-related response in the brain after neonatal $\mathrm{HI}$ is complex and involves many immune cells, microglia macrophages, T and B-cells, NK cells, mast cells dendritic cells and leukocytes. - Both pro-inflammatory and anti-inflammatory cytokines are induced.

IL-18, but not IL- $1 \alpha$ and IL-1 $\beta$, contributes to neonatal HI-induced neuronal injury.

- There are bilateral increases in mRNA of cytokines after HI, thus indicating that hypoxia alone is sufficient to induce these changes.

- It is suggested that changes that occur bilaterally are not toxic per se, but require the ischemic milieu to exert neurotoxic effects.
Mast cells appear to contribute to the inflammatory response to neonatal $\mathrm{HI}$ and could be the initiators of the immune response.

\footnotetext{
- After neonatal HI, the first immune activation is that of $C D 11 b^{+}$cells in the brain and correspond to microglia.
} 
Table 1 (continued)

Reference Species and Model of HI

$1,2,7,14,90$ and $190 \mathrm{~d}$

Bonestroo $\mathrm{H}$

et al., 2013

PMID:

23689428
Wistar rat

P7

Right CCA ligation

$90 \mathrm{~min} 8 \% \mathrm{O}_{2}$

Sacrifice time-points:

3 or $24 \mathrm{~h}$
Immune-related findings in the ipsilateral (Il) Conclusion(s)

brain in comparison to the contralateral $(\mathrm{Cl})$

brain
post-HI and then returns to control levels 2 w post-HI.

- MHC-II expression in CD11 $\mathrm{b}^{+}$cells is increased $1 \mathrm{~d}$ post-HI, then declines until peaking again 3 mo post-HI and returns thereafter to baseline levels.

- Two peaks of CD4 ${ }^{+} \mathrm{T}$-lymphocytes influx in the HI hemisphere are observed, one at $1 \mathrm{w}$ post-HI and the second one at $2 \mathrm{w}$ post-HI.

- An influx of CD8 ${ }^{+}$cytotoxic T-cells is observed $2 \mathrm{w}$ post-HI, elevated numbers are still present at $3 \mathrm{mo}$ and then return to baseline levels at 7 mo post-HI.

- The T cells entering the injured brain hemisphere $1 \mathrm{w}$ after $\mathrm{HI}$ express the naïve $\mathrm{T}$ cell marker CD45rb, but only few $\mathrm{CD}_{4} 5 \mathrm{rb}^{+}$cells are observed 3 mo post-HI.

- The expression of CD69 and CD25 (activation markers of lymphocytes) increases both in $\mathrm{CD}^{+}$and $\mathrm{CD} 8^{+}$ $\mathrm{T}$-lymphocytes to reach maximum levels 3 mo post-HI.

- A subpopulation of $\mathrm{CD} 4^{+} \mathrm{CD} 8^{+}$double positive T-cells, not seen in shams, is present in the $\mathrm{HI}$ hemisphere at 3 mo but disappears at $7 \mathrm{mo}$.

Immunohistochemistry in the brain

- iNOS+-Ibal+ cells: $3 \mathrm{~h}$ post-HI, small number in cortical regions and $24 \mathrm{~h}$ post-HI, significant increase in the number of these cells throughout the Il cortex, striatum, thalamus and small increase in the hippocampus.

- CD206+-Iba1+ cells: no significant increase $3 \mathrm{~h}$ post-HI, but significant increase $24 \mathrm{~h}$ post-HI in the cortex, thalamus and hippocampus.

MPO activity assay in the brain as a measure of neutrophil influx

- $3 \mathrm{~h}$ post-HI, slight and nonsignificant increase in neutrophils within meninges and cortex.

- $24 \mathrm{~h}$ post-HI, significant increase in neutrophils throughout cortical and hippocampal parenchyma.

Gene expression

$3 \mathrm{~h}$ post-HI in the brain:

Upregulation of the pro-inflammatory cytokines TNF- $\alpha$ and IL- $1 \beta$ in the Il hemisphere in comparison to levels in sham animals; the anti-inflammatory cytokine IL-10 is significantly upregulated; also increase in CINC-1 and MCP-1; no change in TGF- $\beta$, IL-4 or IL-6.

$3 \mathrm{~h}$ post-HI in the liver:

Downregulation of TNF- $\alpha$ and IL-1 $\beta$ compared to levels in sham animals. Trend towards IL-10 upregulation; increase in
- Neonatal HI induces early pro-inflammatory response in the brain with a concomitant increase in influx of neutrophils; microglia show a "M1-like phenotype " 3 and 24 h post-HI.

- The inflammatory state of the brain may change $24 \mathrm{~h}$ post-HI: the anti-inflammatory cytokine TGF- $\beta$ increases and macrophages/microglia may adopt the "M2-like phenotype".

- The nature of the inflammation induced by $\mathrm{HI}$ in the liver differs from that observed in the brain: a downregulation of pro-inflammation mediators is observed $3 \mathrm{~h}$ post HI; $24 \mathrm{~h}$ post-HI, the hepatic cytokine/chemokine expression levels are back to these measured in control animals. - Overall, the authors suggest that the cerebral inflammation induced by $\mathrm{HI}$ is responsible for the downregulation of the hepatic pro-inflammatory cytokine response. 
Table 1 (continued)

Reference Species and Model of HI
Immune-related findings in the ipsilateral (Il) Conclusion(s)

brain in comparison to the contralateral $(\mathrm{Cl})$

brain

\begin{tabular}{|c|c|}
\hline $\begin{array}{l}\text { Furukawa S } \\
\text { et al., } 2014\end{array}$ & $\begin{array}{l}\text { Wistar rat } \\
\text { P7 }\end{array}$ \\
\hline $\begin{array}{l}\text { PMID: } \\
24680905\end{array}$ & $\begin{array}{l}\text { Left CCA ligation } \\
120 \text { min } 8 \% \mathrm{O}_{2} \\
\text { Sacrifice time-points: } \\
24,48 \text { and } 72 \mathrm{~h}\end{array}$ \\
\hline Hellström & C57BL/6 mice \\
\hline $\begin{array}{l}\text { Erkenstam N } \\
\text { et al., } 2016\end{array}$ & $\begin{array}{l}\text { P9 } \\
\text { Left CCA ligation }\end{array}$ \\
\hline $\begin{array}{l}\text { PMID: } \\
\quad 28018179\end{array}$ & $\begin{array}{l}50 \text { min } 10 \% \mathrm{O}_{2} \\
\text { Sacrifice time-points: } \\
6 \mathrm{~h}, 1,3 \text { and } 7 \mathrm{~d}\end{array}$ \\
\hline
\end{tabular}

CINC-1, but decrease in MCP-1; no change in TGF- $\beta$, IL- 4 or IL- 6 .

$24 \mathrm{~h}$ after insult in the brain:

TNF- $\alpha$, MCP-1 and CINC- 1 still elevated in the Il hemisphere compared to levels in sham animals; IL-1 $\beta$ and IL-10 normalized $24 \mathrm{~h}$ after $\mathrm{HI}$; no significant changes in IL-4 or IL-6.

$24 \mathrm{~h}$ after insult in the liver:

Significant decrease in IL-10 and MCP-1, but no other difference between $\mathrm{HI}$ and sham animals.

Immunohistochemistry using tomato (Lycopersicon esculentum) lectin

- In the hippocampus, activation of microglia is strong for the first $48 \mathrm{~h}$ after $\mathrm{HI}$ and then decreases.

- In the cortex and white matter, activation of microglia is weak at $24 \mathrm{~h}$ and then becomes strong over 48 and $72 \mathrm{~h}$.

ELISA for TNF- $\alpha$ in Il hemisphere

At all time points examined after HI, TNF- $\alpha$ concentration remains low and unchanged.

qRT-PCR of total cortical homogenates

- $6 \mathrm{~h}$ after HI, concurrent upregulation of genes related to classical (CD86, IL-6, IL-1 $\beta, \operatorname{Cox} 2$, iNOS) and alternative (CD206, IL-10, Fizz1, Arg1) activation. No significant upregulation in these genes at later time points.

FACS analysis of the CD1 $1 b^{+}$populations

- In the Il hemisphere, the total population of

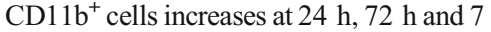
$\mathrm{d}$ after HI, with the largest increase occurring at $24 \mathrm{~h}$.

- Similarly, the different CD11 ${ }^{+}$cell populations expand at the same time points, with the largest expansion also observed at $24 \mathrm{~h}$.

- The pool of classically polarized-like cells $\left(\mathrm{CD} 11 \mathrm{~b}^{+} \mathrm{CD} 86^{+} \mathrm{CD} 206^{-}\right)$is the dominant cell type at $24 \mathrm{~h}$ post-HI.

- The proportion of alternatively polarized-like cells $\left(\mathrm{CD} 11 \mathrm{~b}^{+} \mathrm{CD} 86^{ \pm}\right.$ $\mathrm{CD} 206^{+}$) cells never exceeds $8 \%$ of the total $\mathrm{CD} 11 \mathrm{~b}^{+}$population, in either the $\mathrm{Cl}$ or the Il hemisphere, at any time point examined.

- In the $\mathrm{Cl}$ hemisphere, the unpolarized $\mathrm{CD} 11 \mathrm{~b}^{+} \mathrm{CD} 86^{-} \mathrm{CD} 206^{-}$population is the largest population (approximately $80 \%$ of all $\mathrm{CD} 11 \mathrm{~b}^{+}$cells).

Immunoassay for Galectin-3 protein expression in lysates of FACS sorted cell populations

- The 3 different CD $11 b^{+}$cell populations show increased galectin-3 expression at different time points post-HI: at 1 and $3 \mathrm{~d}$ for the $\mathrm{CD} 86^{-} \mathrm{CD} 206^{-}$population, at $7 \mathrm{~d}$
The temporality of microglia activation after neonatal $\mathrm{HI}$ is region-specific:

hippocampal microglia appear to respond first, followed by white matter and cortical microglia.

- The data illustrate that the traditional concept of "classical" versus "alternative" activation of microglia/macrophages cannot be applied to the complex phenotype observed in vivo after neonatal HI.

- It is the unpolarized population of CD $11 b^{+}$ cells that express the most galectin- 3 , an immunomodulatory factor. These cells may play a role in the recruitment of cells in the brain and in the immune response after neonatal HI. 
Table 1 (continued)

Reference Species and Model of HI
Immune-related findings in the ipsilateral (Il) Conclusion(s)

brain in comparison to the contralateral $(\mathrm{Cl})$

brain

$\begin{array}{cc}\begin{array}{c}\text { Smith P et al., } \\ 2018\end{array} & \begin{array}{c}\text { Lys-EGFP-ki mouse: marking of } \\ \text { peripheral mature myeloid cells } \\ \text { (monocytes, monocyte-derived }\end{array} \\ \text { PMID: } & \text { macrophages and granulocytes) } \\ 30376851 & \text { P9 } \\ & \text { Left CCA ligation } \\ & 50 \text { min } 10 \% \mathrm{O}_{2} \\ & \text { Sacrifice time-points: } \\ & 6 \mathrm{~h}, 1,3,7,14 \text { and } 28 \mathrm{~d}\end{array}$

Fisch U et al., Sprague-Dawley rat 2020

PMID:

31954397
P7

Right CCA ligation

40 min $8 \% \mathrm{O}_{2}$

Sacrifice time-points:

3,13 and $33 \mathrm{~d}$ for the $\mathrm{CD} 86^{+} \mathrm{CD} 206^{-}$population, and at $3 \mathrm{~d}$ for the $\mathrm{CD} 86^{ \pm} \mathrm{CD} 206^{+}$population.

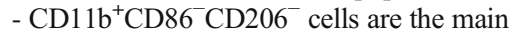
source of increased galectin-3 protein in the injured hemisphere at all three time points.

Flow cytometry

- CD11b+EGFP+ infiltrating myeloid cells are significantly increased in the ipsilateral compared with the $\mathrm{Cl}$ hemisphere at $1 \mathrm{~d}, 7$ $\mathrm{d}$ and $14 \mathrm{~d}$ after HI; they represent respectively $\sim 48 \%, 19 \%$ and $9 \%$ of the injured hemisphere's total CD11b+cell population.

- The temporal pattern of peripheral leukocyte influx is biphasic, i..e it is characterized by peak accumulation of inflammatory cells (inflammatory monocytes and granulocytes) at $1 \mathrm{~d}$, relative quiescence at $3 \mathrm{~d}$ and renewed infiltration at $7 \mathrm{~d}$ post-HI.

Immunohistochemistry with EGFP and IbaI

- At $1 \mathrm{~d}$ post-HI, infiltration is disperse and observed in the hippocampus, thalamus and striatum, while at $7 \mathrm{~d}$ post-HI, the infiltration is dense and limited to hippocampus and white matter in the thalamus; cortical infiltration is observed at both time points but only in the case of severe HI injury.

Cytokines

- Inflammatory cytokine levels (e.g. IL- $1 \alpha$, IL-1 $\beta$ and IL-6) are elevated in the Il hemisphere in comparison to the $\mathrm{Cl}$ hemisphere at $6 \mathrm{~h}, 1,3$ and $14 \mathrm{~d}$ post-HI, but not at the $7 \mathrm{~d}$ time point.

- Chemokine levels (MCP1, MIP1a) are elevated in the Il hemisphere in comparison to the $\mathrm{Cl}$ hemisphere, are reduced to sham levels within 1-3 and remain so for $2 \mathrm{w}$ post-HI, except for $\mathrm{KC}$ which increases again markedly at $14 \mathrm{~d}$ post-HI.

Depletion of myeloid cells via repeated, systemic administration of an antibody RB6-8C5

Antibody treatment expectedly diminishes myeloid cell infiltration after neonatal $\mathrm{HI}$; $14 \mathrm{~d}$ post-HI, the neuronal injury is reduced only in males, but not in females.

The antibody treatment does not improve the loss in myelinated areas after $\mathrm{HI}$ in either sex.

Immunohistochemistry

- In comparison to sham, the density of $\mathrm{Iba1}^{+}$ microglia in the HI-Il SVZ remains elevated at P10, P20 and P40.

- The proportion of activated microglia $\left(\mathrm{Iba}^{+}{ }^{+} \mathrm{CD} 68^{+} / \mathrm{Iba}^{+}\right)$in the Il SVZ is significantly increased at P10 and P20.
- The infiltration of inflammatory monocytes and granulocytes after neonatal $\mathrm{HI}$ follows a temporal biphasic pattern, with the highest levels of invading cells at $1 \mathrm{~d}$ post-HI and a second wave of invasion occurring $7 \mathrm{~d}$ post-HI.

- Antibody mediated depletion of myeloid cell infiltration after neonatal HI appears neuroprotective in males, but not in females.
- Neonatal HI induces significant changes in the density, proliferation status and morphology of microglia in the SVZ for a prolonged period of time, and these parameters are less affected in adjacent regions i.e. cortex and corpus callosum. 
Table 1 (continued)

\begin{tabular}{|c|c|c|c|}
\hline Reference & Species and Model of $\mathrm{HI}$ & $\begin{array}{l}\text { Immune-related findings in the ipsilateral (Il) } \\
\text { brain in comparison to the contralateral (Cl) } \\
\text { brain }\end{array}$ & Conclusion(s) \\
\hline & & $\begin{array}{l}\text { - The proportion of proliferating microglia } \\
{\text { (Iba } 1^{+} \mathrm{BrdU} \mathrm{U}^{+} / \mathrm{Iba} 1^{+} \text {) is augmented in the Il }} \mathrm{SVZ} \text { only at P10. } \\
\text { - Morphologically, the proportion of } \\
\text { amoeboid microglia in the Il SVZ rises } \\
\text { significantly at P10, but not thereafter. } \\
\text { Nevertheless, the number of } \\
\text { ball-and-chain buds detected in Iba1 }{ }^{+} \\
\text {microglia is higher at P40 in the Il SVZ } \\
\text { than in the sham SVZ. } \\
\text { Microarray analyses of Cd1 } 1 b^{+} \text {microglia } \\
\text { micro-dissected from the SVZ } \\
\text { - After neonatal HI, both pro- and } \\
\text { anti-inflammatory related genes as well as } \\
\text { neurotrophic genes (Igf-1) are upregulated } \\
\text { at P10 and P20. } \\
\text { - KEGG pathway analysis of differentially } \\
\text { expressed genes of HI and sham SVZ } \\
\text { microglia reveals an enrichment of } \\
\text { pathways associated with } \\
\text { neurodegenerative diseases in P10-HI } \\
\text { SVZ microglia. }\end{array}$ & $\begin{array}{l}\text { - Overall there is a SVZ-specific response of } \\
\text { microglia to neonatal HI, associated with a } \\
\text { complex immunomodulatory and } \\
\text { potential neurotrophic gene expression } \\
\text { pattern. }\end{array}$ \\
\hline
\end{tabular}

All sacrifice time-points are given in post-HI

published ones revealed that, three days after neonatal HI, the transcriptome of the SVZ microglia from HI-exposed animals does not fit a M1 or M2 state, but rather present similarities with that of primed microglia isolated from mouse models for aging and neurodegenerative diseases, characterized by an altered immune profile associated with phagocytic clearance and possibly neurotrophic features [99]. Thus the concept of "disease-associated microglia" may apply beyond the neurodegenerative environment [100, 101]. Altogether, these data uncover a previously unrecognized microglial diversity/ complexity after neonatal HI that surpasses the traditional M1/M2 frame of thought [102, 103].

This reinforces the idea that the M1/M2 concept, as currently applied to microglia should be questioned, if not abandoned [104, 105]. With the advent of RNA-sequencing (RNA-Seq) analyses of microglia, an extraordinary complexity and unique microglial signature during physiological development has been revealed. Thus, mouse microglia harvested between embryonic day E14.5 and P9 harbor a transcriptomic signature distinct from earlier embryonic stages or adult microglia, and these so called "pre-microglia" express of a common cluster of genes involved in neural migration, neurogenesis and cytokine secretion [106]. Further refining these observations, single-cell RNA-sequencing (scRNA-Seq) of murine microglia at E14.5 and P5 reveals a greater diversity of microglial subpopulations at these ages than at juvenile, adult or old stages [107]. Collectively these data highlight the peculiarity of the microglial phenotype during development, the regional and temporal specificities, and agrees with the reported heterogenous functions in the developing brain.

\section{Does Age at Time of Injury Influence the Ischemic-Induced Microglial Response? If So, how?}

Six studies have directly compared the cerebral immune response after induction of $\mathrm{HI}$ at different postnatal ages, out of which three were conducted by the same laboratory (see Table 2). In these reports, the intensity of the microglial and cytokine response after neonatal HI (P9 mice or P12 rats) was compared to that after $\mathrm{HI}$ in newborn rats (P1), juvenile mice (P21 or P30) or adult mice (three months of age). While HI-induced microglia proliferation (five weeks post-HI) and brain expression of IL-18 and MCP-1 (three days post-HI) appeared more pronounced in the ipsilateral hippocampus of mice subjected to $\mathrm{HI}$ at P21 than in mice subjected to HI at P9, opposite results were documented in studies comparing neonatal HI to older juvenile or adult HI. In particular HI-associated elevation in hippocampal microglial population $\left(\mathrm{CD} 11 \mathrm{~b}^{\text {thigh }} / \mathrm{CD} 45^{+ \text {low }}\right)$ and in pro-inflammatory cytokines (TNF- $\alpha$, IL-1 $\beta$ ) two days after lesioning was significantly more robust in P9 than in P30 mice. Morphological analyses of microglia at the same time point post-HI corroborated these findings, with microglia displaying a more activated phenotype in P9 than in P30 
Table 2 Impact of age on ischemic-induced neuroinflammation-Comparative studies

Reference Species and Model of HI Immune-related findings in the ipsilateral (Il) brain Conclusion(s) in comparison to the contralateral $(\mathrm{Cl})$ brain

\begin{tabular}{|c|c|c|c|}
\hline $\begin{array}{l}\text { Qiu L et al., } \\
\text { 2007 } \\
\text { PMID: } \\
16926844\end{array}$ & $\begin{array}{l}\text { C57/BL6 male mice } \\
\text { - P9 "P9 immature } \\
\text { mice/brain" } \\
\text { Left CCA ligation } \\
35 \text { min } 10 \% \mathrm{O}_{2} \\
\text { - P21 "P21 juvenile } \\
\text { mice/brain" } \\
\text { Left CCA ligation } \\
30 \text { min } 10 \% \mathrm{O}_{2} \\
\text { Sacrifice time points: } \\
5 \text { w for BrdU studies (i.e. } \\
\text { P45 for P9 mice, and } \\
\text { P57 for P21 mice) } \\
3 \text { d for IL-18 and MCP-1 }\end{array}$ & 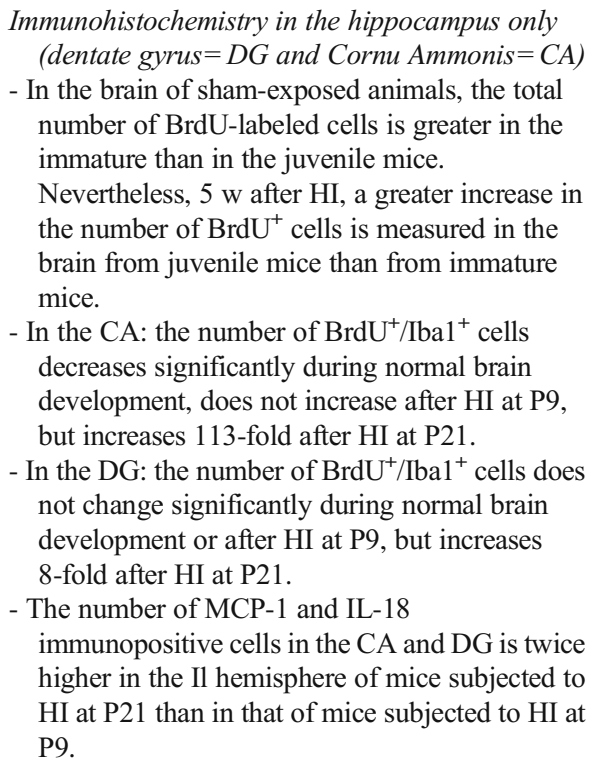 & $\begin{array}{l}\text { The post-ischemic hippocampal inflammation } \\
\text { evaluated in terms of microglia proliferation and } \\
\text { expression of IL-18 and MCP-1 is more pro- } \\
\text { nounced in the hippocampus from mice sub- } \\
\text { jected to HI at the juvenile stage than from mice } \\
\text { subjected to HI at the neonatal stage. }\end{array}$ \\
\hline $\begin{array}{l}\text { Ferrazzano P } \\
\text { et al., } 2013 \\
\text { PMID: } \\
23469850\end{array}$ & $\begin{array}{l}\text { C57BL/6 J mice } \\
\text { - } \mathrm{P9} \text { "P9 neonatal } \\
\text { mice/brain" } \\
\text { Left CCA ligation } \\
50 \text { min } 10 \% \mathrm{O}_{2} \\
\text { Sacrifice time points: } \\
\text { P10, P11, P12, P16, P18, } \\
\text { P21 and P26 } \\
\text { - P30 "P30 juvenile } \\
\text { mice/brain" } \\
\text { Left CCA ligation } \\
50 \text { min } 10 \% \mathrm{O}_{2} \\
\text { Sacrifice time points: } \\
\text { P32, P39 and P47 }\end{array}$ & 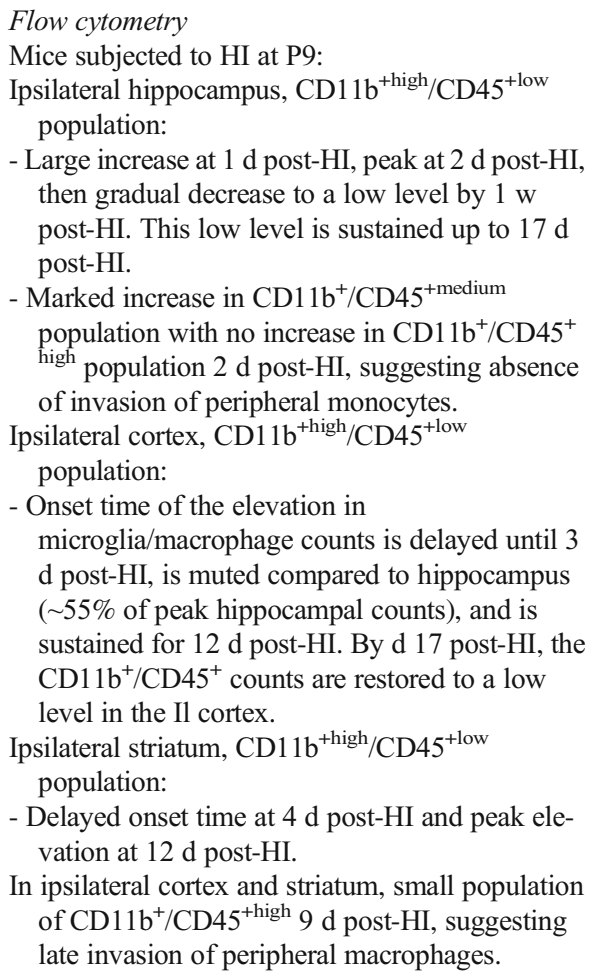 & $\begin{array}{l}\text { - In the neonatal P9 brain, the microglial response } \\
\text { in the hippocampus occurs earlier (peak on } \mathrm{d} 2 \\
\text { post-HI) than in the striatum and cortex (peak on } \\
\text { d } 9 \text { post-HI). } \\
\text { - The microglial proliferation and } \\
\text { pro-inflammatory cytokine responses in P9 } \\
\text { brains after HI are more robust in comparison to } \\
\text { P30 brains. } \\
\text { - Such differential inflammatory response induced } \\
\text { by HI at the two postnatal stages may have } \\
\text { implications for tissue repair. }\end{array}$ \\
\hline $\begin{array}{l}\text { Ferrazzano P } \\
\text { et al., } 2013 \\
\text { PMID: } \\
23469850\end{array}$ & & $\begin{array}{l}\text { Mice subjected to HI at P30: } \\
\text { - Overall smaller increases in } \\
\text { microglia/macrophage counts while similar re- } \\
\text { gional time-course of microglia responses is } \\
\text { observed. } \\
\text { - Ipsilateral hippocampus: transient elevation of } \\
\mathrm{CD} 11 \mathrm{~b}^{+} / \mathrm{CD} 45^{+} \text {population at } 2 \mathrm{~d} \text { post-HI. } \\
\text { - Ipsilateral cortex and striatum: delayed increase in } \\
\text { microglia response, } \mathrm{CD} 11 \mathrm{~b}^{+} / \mathrm{CD} 45^{+} \text {peak at } 9 \mathrm{~d} \\
\text { post-HI and sustained increase until } 17 \mathrm{~d} \\
\text { post-HI. }\end{array}$ & \\
\hline
\end{tabular}


Table 2 (continued)

Reference Species and Model of HI Immune-related findings in the ipsilateral (Il) brain Conclusion(s)

in comparison to the contralateral $(\mathrm{Cl})$ brain

\begin{tabular}{|c|c|c|c|}
\hline $\begin{array}{l}\text { Umekawa T } \\
\text { et al., } 2015 \\
\text { PMID: } \\
26179283\end{array}$ & $\begin{array}{l}\mathrm{Cx} 3 \mathrm{cr} 1^{\mathrm{GFP} /+} \mathrm{Ccr} 2^{\mathrm{RFP} /+} \\
\text { double transgenic mice. } \\
\mathrm{Cx} 3 \mathrm{cr} 1^{\mathrm{GFP} /+} \text { : marking of } \\
\text { resident microglia } \\
\mathrm{Ccr} 2^{\mathrm{RFP} /+} \text { : marking of } \\
\text { blood-derived macro- } \\
\text { phages } \\
\text { - P9 } \\
\text { Right CCA ligation } \\
50 \text { min } 10 \% \mathrm{O}_{2} \\
\text { - Adult }(3 \text { months of age }\end{array}$ & $\begin{array}{l}\text { - No CD } 11 \mathrm{~b}^{+} / \mathrm{CD} 45^{+ \text {high }} \text { cells in any region at any } \\
\text { time point post-HI. } \\
\text { Cytokines } \\
\text { Mice subjected to HI at P9: } \\
\text { - Ipsilateral hippocampus: transient elevation of } \\
\text { TNF- } \alpha \text {, IL-1 } \beta \text { at } 2 \mathrm{~d} \text { post-HI, then return to the } \\
\text { contralateral levels at } 9 \mathrm{~d} \text { post-HI; elevation of } \\
\text { IL-10 at } 2 \mathrm{~d} \text { up until } 9 \mathrm{~d} \text { post-HI. } \\
\text { - Ipsilateral cortex: delayed expression of TNF- } \alpha \\
\text { and IL1- } \beta \text { at } \mathrm{d} 9 \text { post-HI. } \\
\text { Mice subjected to HI at P30: } \\
\text { - Smaller rise in TNF- } \alpha \text { and IL-1 } \beta \text { at } 2 \mathrm{~d} \text { post-HI } \\
\text { than that in the P9 hippocampus. } \\
\text { - The ipsilateral P30 cortex and striatum also show } \\
\text { a smaller increase in TNF- } \alpha \text { and IL-1 } \beta \text { expres- } \\
\text { sion. } \\
\text { - IL-10 levels are elevated at } 2 \mathrm{~d} \text { post-HI in P30 } \\
\text { hippocampus at levels similar to the P9 } \\
\text { hippocampus, and remain elevated at } 9 \mathrm{~d} \\
\text { post-HI. } \\
\text { - In P30 cortex and striatum, IL-10 levels are in- } \\
\text { creased at } 9 \mathrm{~d} \text { post-HI. } \\
\text { - No significant differences in mortality rates or } \\
\text { neuropathological scores between P9 and } 3 \text { mo } \\
\text { mice at any time point after HI. } \\
\text { Immunohistochemistry in the hippocampus only } \\
\text { - The Cx3cr1-GFP }{ }^{+} \text {cells increase } 1 \mathrm{~d} \text { after HI in } \\
\text { the DG and the CA regions of the P9 pups, } \\
\text { whereas they increase } 7 \mathrm{~d} \text { after HI in the CA } \\
\text { region of the } 3 \text { mo mice. } \\
\text { - } 1 \mathrm{~d} \text { post-HI, Ccr2-RFP }{ }^{+} \text {cells appear in the } \\
\text { hippocampus of the P9 pups, whereas they are } \\
\text { very few in the } 3 \text { mo mice. Then, they increase in }\end{array}$ & $\begin{array}{l}\text { - First report that demonstrates age-dependent dif- } \\
\text { ferences in the activation of resident microglia } \\
\text { and infiltrating blood-derived macrophages in } \\
\text { the hippocampus after HI brain injury. } \\
\text { - The inflammatory response appears more } \\
\text { pronounced in the immature brain. } \\
\text { - Overall, the resident microglia, rather than } \\
\text { infiltrating blood-derived macrophages, prolif- } \\
\text { erate and are activated earlier in the immature } \\
\text { than in the adult hippocampus, but remain in- } \\
\text { creased longer in the adult brain. }\end{array}$ \\
\hline
\end{tabular}

Right CCA ligation $75 \min 10 \% \mathrm{O}_{2}$ (to produce similar extent of brain injury)

Sacrifice time points: $1,3,7$ and $28 \mathrm{~d}$ the $\mathrm{DG}$ and the $\mathrm{CA}$ regions, peak $3 \mathrm{~d}$ after $\mathrm{HI}$ in both the $\mathrm{P} 9$ neonates and the 3 mo mice, and then decrease gradually.

- $\mathrm{GFP}^{+} /$galectin- $3^{+}$cells (activated microglia) are increased 1 and $3 \mathrm{~d}$ after $\mathrm{HI}$ in the $\mathrm{P} 9$ pups, whereas they reach a peak 3 and $7 \mathrm{~d}$ after $\mathrm{HI}$ in the 3 mo mice. The number of $\mathrm{GFP}^{+} /$galectin- $3^{+}$ cells is nine time greater in the immature than in the adult hippocampi.

- $\mathrm{RFP}^{+} /$galectin- $3^{+}$cells (activated macrophages) in the DG and the CA regions increase transiently 3 $\mathrm{d}$ after $\mathrm{HI}$ in both the $\mathrm{P} 9$ pups and the 3 mo mice.

- The number of $\mathrm{Cx} 3 \mathrm{cr} 1-\mathrm{GFP}^{+} / \mathrm{CD} 16 / 32^{+}$ "pro-inflammatory-M1 "cells briefly increases 3 $\mathrm{d}$ after $\mathrm{HI}$ in the $\mathrm{P} 9$ hippocampus, whereas in the 3 mo mice, these cells increase at $3 \mathrm{~d}$ and remain at the same level for up to $7 \mathrm{~d}$ after HI.

- The number of $\mathrm{Cx} 3 \mathrm{cr} 1-\mathrm{GFP}^{+} / \mathrm{CD} 206^{+}$ "anti-inflammatory-M2 "cells increase transiently $3 \mathrm{~d}$ after $\mathrm{HI}$ in the DG region of both the $\mathrm{P} 9$ pups and the $3 \mathrm{mo}$ mice.

- The number of $\mathrm{RFP}^{+} / \mathrm{CD} 16 / 32^{+}$in the DG increase $3 \mathrm{~d}$ after $\mathrm{HI}$ in both the $\mathrm{P} 9$ pups and the 3 mo mice; same observation for the number of $\mathrm{RFP}^{+} / \mathrm{CD} 206^{+}$cells.

ELISA

- The concentration of CCL2 (MCP-1) at $1 \mathrm{~d}$ post-HI is 3 times higher in the ipsilateral 
Table 2 (continued)

Reference Species and Model of HI Immune-related findings in the ipsilateral (Il) brain Conclusion(s)

in comparison to the contralateral $(\mathrm{Cl})$ brain

\begin{tabular}{|c|c|c|c|}
\hline & & $\begin{array}{l}\text { hippocampus of the } \mathrm{P} 9 \text { pups compared with the } \\
3 \text { mo mice. }\end{array}$ & \\
\hline $\begin{array}{l}\text { Cikla U et al., } \\
2016 \\
\text { PMID: } \\
26857490\end{array}$ & $\begin{array}{l}\text { C57BL/6 J mice } \\
\text { - } \mathrm{P9} \text { "P9 neonatal } \\
\text { mice/hippocampus" } \\
\text { • } \mathrm{P} 30 \text { "P30 juvenile } \\
\text { mice/hippocampus" } \\
\text { Left CCA ligation } \\
50 \text { min } 10 \% \mathrm{O}_{2} \\
\text { Sacrifice time points: } \\
2 \text { and } 9 \mathrm{~d} \text { for brain } \\
\text { analyses and } 60 \mathrm{~d} \text { for } \\
\text { behavior assessment }\end{array}$ & $\begin{array}{l}\text { Flow cytometry } \\
-2 \mathrm{~d} \text { after HI, robust increase in } \mathrm{CD} 11 \mathrm{~b}^{+} / \mathrm{CD} 45^{+} \\
\text {microglia counts (ratio } \mathrm{Il} / \mathrm{Cl}) \text { in } \mathrm{P} 9(\sim 9.5 \mathrm{fold}) \\
\text { and in } \mathrm{P} 30 \text { hippocampus, although less } \\
\text { pronounced ( } \sim 5.7 \text { fold); modest increase in } \\
\text { microglia counts in cortex and striatum. } \\
\text { - } 9 \mathrm{~d} \text { after HI, decline in microglia counts in } \\
\text { hippocampus, and dramatic increase in } \\
\text { microglia counts in cortex and striatum in both } \\
\text { P9 and P30 mice. } \\
\text { - Minocycline reduces microglia counts in P9 mice } \\
\text { at } 2 \text { and } 9 \text { d post-HI in all regions, but is inef- } \\
\text { fective at reducing microglia counts } 9 \mathrm{~d} \text { post-HI } \\
\text { in P30 cortex and striatum. } \\
\text { Iba1 immunohistochemistry } \\
\text { - In the hippocampus, with minocycline treatment, } \\
\text { microglia retain a ramified morphology at } 2 \mathrm{~d} \\
\text { post-HI in both P9 and P30 mice. } \\
\text { - In the cortex and striatum of minocycline-treated } \\
\text { P9 mice, microglia demonstrate a ramified } \\
\text { morphology in the cortex and striatum at } \mathrm{d} 9 \\
\text { post-HI. } \\
\text { - However, in minocycline-treated P30 mice, mi- } \\
\text { croglia in Il cortex and striatum display activated } \\
\text { morphology similar to that seen in the } \\
\text { vehicle-treated controls at d } 9 \text { post-HI. }\end{array}$ & $\begin{array}{l}\text { - Despite early improvement in neurological } \\
\text { damage (assessed by MAP2 } \\
\text { immunohistochemical staining) and in microglia } \\
\text { parameters in minocycline-treated P9 mice, no } \\
\text { improvement in cerebral atrophy (measured by } \\
\text { MRI) or hippocampus learning behavior evalu- } \\
\text { ated } 60 \mathrm{~d} \text { post-HI are detected. } \\
\text { - Conversely, minocycline does not reduce } \\
\text { neurological damage in P30 HI-exposed mice; } \\
\text { yet } 60 \text { d post-HI, the treatment results in less } \\
\text { cerebral atrophy and is accompanied by im- } \\
\text { proved hippocampal learning. } \\
\text { - Minocycline has a differential impact depending } \\
\text { on the age at which HI is inflicted. The } \\
\text { mechanisms remain unclear but late microglial } \\
\text { activation could have a beneficial role. }\end{array}$ \\
\hline $\begin{array}{l}\text { Cengiz P et al., } \\
2019 \\
\text { PMID:30639264 }\end{array}$ & $\begin{array}{l}\text { C57BL/6 J mice } \\
\text { - } \mathrm{P9} \text { "P9 neonatal } \\
\text { mice/hippocampus" } \\
\text { - } \mathrm{P} 30 \text { "P30 juvenile } \\
\text { mice/hippocampus" } \\
\text { Left CCA ligation } \\
50 \text { min } 10 \% \mathrm{O}_{2} \\
\text { Sacrifice time points: } \\
2 \mathrm{~d}\end{array}$ & $\begin{array}{l}\text { Ibal immunohistochemistry in the Il hippocampus } \\
\text { (in comparison to Cl hippocampus) } \\
\text { - In mice subjected to HI at P9, microglia } \\
\text { demonstrate a significant decrease in branching } \\
\text { measures and an increase in cell body volume, } \\
\text { reflecting intense microglia activation. } \\
\text { - In mice subjected to HI at P30, microglia show a } \\
\text { much more moderate decrease in branching } \\
\text { morphology } 2 \mathrm{~d} \text { post-HI, and overall retain a } \\
\text { highly ramified morphology. } \\
\text { Gene expression in CD1 } 1 b^{+} \text {microglia isolated } \\
\text { from hippocampus } \\
\text { - In mice subjected to HI at P9, a significant } \\
\text { reduction in TGF- } \beta \text { receptor expression, but an } \\
\text { increase in Serpine } 1 \text { (part of the TGF- } \beta \text { receptor } \\
\text { signaling pathway) expression are observed. } \\
\text { Also, there is a significant reduction in MerTK } \\
\text { (Mer Tyrosine Kinase, phagocytic receptor) and } \\
\text { SOCS3 (suppressor of cytokine signaling, com- } \\
\text { ponent of the MerTK pathway) expression. } \\
\text { - In mice subjected to HI at P30, the expression of } \\
\text { TGF- } \beta \text { receptor is also significantly reduced; } \\
\text { Serpine1 expression is not changed } 2 \mathrm{~d} \text { after HI, } \\
\text { but its expression remains dramatically elevated } \\
\text { compared to P9. As in P9 mice after HI, there is } \\
\text { a reduction in MerTK and SOCS3 expression; } \\
\text { but the expression of both is significantly higher } \\
\text { in the Il P30 compared to Il P9 hippocampus. }\end{array}$ & $\begin{array}{l}\text { - During physiological development (between P2 } \\
\text { and P60), microglia in the hippocampus undergo } \\
\text { significant changes in morphology, reaching a } \\
\text { mature phenotype by P30. These morphological } \\
\text { changes are accompanied by increases in the } \\
\text { expression of members of the TGF- } \beta \text { receptor } \\
\text { and MerTK signaling pathways. } \\
\text { - Based on morphological evaluation, } 2 \mathrm{~d} \text { after HI, } \\
\text { there is an intense activation of microglia in the } \\
\text { Il hippocampus of P9 mice, but not in the P30 } \\
\text { mice. } \\
\text { - The age-related differences in the microglial re- } \\
\text { sponse to neonatal HI may be linked in part to } \\
\text { the age-associated changes in the TGF- } \beta \text { recep- } \\
\text { tor and MerTK signaling pathways. }\end{array}$ \\
\hline
\end{tabular}

All sacrifice time-points are given in post-HI 
mice. The acute neuroinflammatory response ( $48 \mathrm{~h}$ ) after HI was also much stronger in $\mathrm{P} 12$ rats than in rats subjected to $\mathrm{HI}$ at $\mathrm{P} 1$ [79]. Using $\mathrm{Cx} 3 \mathrm{cr} 1^{\mathrm{GFP} /+} \mathrm{Ccr} 2^{\mathrm{RFP} /+}$ double transgenic mice to allow differential labeling of resident microglia $\left(\mathrm{GFP}^{+}\right)$and blood derived macrophages $\left(\mathrm{RFP}^{+}\right)$, Umekawa et al. [14] showed that the increase in the total number of hippocampal microglia after HI was approximately the same in P9 and adult mice, but (i) it occurred later in adult mice and (ii) the proportion of activated microglia (GFP and galectin-3 double positive) was much higher in the immature than in the adult brain. In addition, one day after HI, the concentration of the pro-inflammatory chemokine CCL2 was around three times higher in the ipsilateral hippocampus of the $\mathrm{P} 9$ neonates than in the adult mice. Altogether the majority of the studies indicate that the intensity of the microglial response after $\mathrm{HI}$ is stronger in the immature rodent brain equivalent to a term-like human brain than in a less (P1 or preterm-like human brain) or more developed juvenile or adult brain. While the time course of HI-induced microglial activation is similar in neonatal and P30 brain, it seems delayed in the adult brain in comparison to the neonatal brain. These age-related differences may also impact response to treatment, as suggested by report of Cikla et al. [108] and detailed in next section. Overall, it is very likely that the microglial heterogeneity at the transcriptional level described during development [103] contributes to this differential response to $\mathrm{HI}$ and treatment, but exactly which signaling pathway(s) is (are) involved remain to be investigated.

Box 3 the Fundamental Breakthroughs in Immunology that Led to the M1/M2 Concept

Mackaness, in his fundamental work between 1962-1970 [109-112] (for an in-depth explanation of his work, see Van Epps [113]) introduced first the term "activated macrophage". Using a mouse model of infection with the intracellular bacteria Listeria monocytogenes, he demonstrated that the mechanism of "acquired cellular resistance" - the fact that after a primary infection, mice become temporally resistant to a subsequent reinfection with the same or unrelated intracellular pathogen - was dependent upon a change into the host macrophages that became "activated". He further showed that macrophage activation depended on a soluble factor released by lymphocytes - now recognized as a specific subset of Thelper $\mathrm{CD}^{+}$cells - exposed to an antigen [111]. He defined the activated macrophage as "larger and much more complex morphologically; it has a marked propensity to spread on glass, a property which is related to its enhanced capacity for phagocytosis. The content of acid hydrolases, the digestive capacity, the respiratory rate and the mitotic rate of activated macrophages are all conspicuously raised." [112].

The major cytokine responsible for the observed macrophage activation (now referred to as "classical" activation) was thereafter identified as IFN- $\gamma$ [114]. Further studies on the effect of different cytokines on macrophage activation showed that IL-4 [115] and IL-13 [116] caused a macrophage phenotype distinct from that induced by IFN- $\gamma$. This "alternative" activation was characterized, among others, by a downregulation of IFN- $\gamma$ mediated bactericide signals such as NO production, a reduction in the release of inflammatory cytokines, and an increased expression of an endocytic receptor, namely mannose receptor (or CD206).

Amidst the work on macrophage activation, a major step in the understanding of immune regulation was brought about by the $\mathrm{T}$ helper type 1 (TH1)-TH2 hypothesis, proposed by Coffman \& colleagues in $1986[117,118]$. Further insight into the model and its historical context can be found in $[119,120]$. In essence, it provided an invaluable framework to describe how an organism responds to different pathogens (e.g. intracellular vs extracellular). The TH1 and $\mathrm{TH} 2$ clones were distinguished by the pattern of cytokine release, with TH1 clones secreting mainly IFN- $\gamma$, and TH 2 clones IL-4, IL-5, and IL-13. In general, TH1 and TH2 responses are associated with cellular and humoral immunity, respectively.

Box 4 the M1/M2 Concept of Macrophage/Microglia Activation

Mills in 2000 applied the TH1/ TH2 nomenclature to define macrophage activation, hence proposing the concept of M1/M2 macrophage activation [121]. The M1/M2 model stemmed from the main following in vitro data: (i) macrophages from $\mathrm{C} 57 \mathrm{BL} / 6$ and Balb/c mice, described to be prototypical Th1 and Th2 strains respectively, respond from a metabolic point of view, i.e. in terms of NO and ornithine production, differently to the same Th1-like stimuli, namely IFN- $\gamma$, LPS, or IFN- $\gamma+$ LPS. In particular, while stimulated macrophages from C57BL/6 produce predominantly NO (iNOS or kill pathway), macrophages from $\mathrm{Balb} / \mathrm{c}$ produce predominantly ornithine/urea (arginase or Heal pathway). (ii) The same observation was made for macrophages isolated from SCID or NUDE C $57 \mathrm{BL} / 6$ or Balb/c mice, in which lymphocytes are reduced or absent. This led Mills to hypothesize that macrophages have an inherent capability to display a classical M1 or alternative M2 phenotype, and do not necessarily need "instruction" from lymphocytes. He further proposed that macrophages are in fact the first line of defense cells that can then direct the nature of the adaptive immune response of the $\mathrm{T}$ lymphocytes, i.e. TH1, TH2 or other [122-124]. This latter view remains nevertheless contested by immunologists who consider the lymphocytes and the cytokines they release as the orchestrators of macrophage activation [125]. A notable difference between the Th1/Th2 and the M1/M2 hypotheses is that M1/M2 polarized macrophages do not constitute separate clones, like Th1/Th2 cells, but rather represent the extremes of a spectrum of different phenotypes depending on stimulus/environment.

The M1/M2 nomenclature was then enlarged, with the introduction of M2a, M2b, M2c [126] and M2d subgroups [127, 128], defined by partially overlapping or distinct transcriptional profiles/signaling cascades induced by specific stimuli. Immunologists now suggest to use a more precise polarization nomenclature that includes the source of macrophage, the stimulus used and corresponding set of activation markers [125]. Thus, while the value of the M1/M2 framework is acknowledged, it is also recognized that it does not fully capture the complexity of macrophage responses especially in in vivo settings, as now revealed by the numerous analyses of macrophage transcriptomes via high-throughput RNA sequencing-bulk, single cell or single nucleus - methodologies in diverse pathological conditions (for reviews, see [129, 130]).

Even though it may only seem natural that the M1/M2 concept was also applied to microglia, the brain resident macrophages, neuro/immunologists are reconsidering the use and the validity of such concept $[104,105,131]$. As for macrophages, microglial gene expression profiles typically cannot be fitted into M1- or M2-like subphenotypes, as observed in rat models of adult ischemic stroke [132] or neonatal HI [98], in rodent models of neurodegenerative 
disorders $[100,107,133,134]$ and in human microglia isolated from Alzheimer's patients $[135,136]$. There again, the complexity of microglia cannot be reflected into the M1/M2 concept.

\section{Modulation of the Immune Response and Neuroprotection-Correlative or Causal Crosstalk?}

Treatments known to confer some degree of neuroprotection can modulate aspects of HI-induced inflammation. For instance, hypothermia can reduce infarct size, improve behavioral outcome and these effects are concomitant with a decrease in cytokine expression in the injured hemisphere (IL-18, IL-6, TNF- $\alpha$ ), and a reduction in the number of amoeboid microglia in cortex and corpus callosum [137-139]. But whether the direct modulation of the immune response associates with neuroprotection is a challenging question, because anti-inflammatory agents/treatments can have biological actions unrelated to inflammation, for instance on angiogenesis, cell proliferation and apoptosis. Such broad effects are documented for erythropoietin [140], cyclooxygenase-2 (COX-2) inhibitors [141], doxycycline and minocycline [142].

\section{General considerations.}

Twelve immune-related therapies have been tested in the rodent model of neonatal HI (see Table 3). Among them, only EPO has been used in clinical trials for neonates with HIE (reviewed in [143]); seven are in clinical use for other human conditions (recombinant human interleukin-1 receptor antagonist, platelet-activating factor antagonists, minocycline, doxycycline, cromolyn, etanercept and fingolimod); one is going out of clinic due to cardiac side effects (COX-2 inhibitor); and three are for preclinical testing only (anti-rat neutrophil serum (ANS), IKK/NF- $\mathrm{kB}$ inhibitor and JNK inhibitor). Regardless of clinical use, testing in animal models remains invaluable because it provides fundamental knowledge on the molecular or cellular inflammatory components contributing to the pathogenesis of neonatal $\mathrm{HI}$, and on the phase of injury post-HI these components may be involved in.

Eleven out of these twelve treatments conferred neuroprotection, but with highly variable degrees (see Table 3 ). Putative factors contributing to such variability for different or sometimes same treatments are listed in Fig. 1A. Studies in which minocycline was evaluated illustrate this point. In a rat model of neonatal $\mathrm{HI}$, a single intraperitoneal dose of minocycline ( $45 \mathrm{mg} / \mathrm{kg}$ body weight $\mathrm{BW}$ ) injected before or immediately after hypoxia induced a near complete neuroprotection at seven days post-HI. Nevertheless, if administered three hours post-HI, neuroprotection was almost lost. A lower dose $(22.5 \mathrm{mg} / \mathrm{kg} \mathrm{BW})$ given before or immediately after hypoxia did not provide significant neuroprotection [144]. In a mouse model of neonatal HI, two intraperitoneal injections of minocycline $(40 \mathrm{mg} / \mathrm{kg} \mathrm{BW})$ at two and $24 \mathrm{~h}$ after HI improved neurological injury two and nine days later, but the cerebral atrophy, measured with T2-weighed MRI nine and 60 days post-HI was similar to that of non-treated HI-exposed mice. Assessment of cognitive performance 60 days post-HI revealed no significant difference between treated and untreated HI mice. In that study, authors report that the same minocycline treatment protocol applied to juvenile mice subjected to $\mathrm{HI}$ at $\mathrm{P} 30$ ameliorated cognitive performance and cerebral atrophy measured 60 days after HI [108]. These two studies demonstrate how several parameters may ultimately influence response to treatment, namely (i) species, (ii) timing of administration, (iii) dosage, (iv) age at surgery, (v) time and methodology for evaluation of neuroprotection. Differing degrees of neuroprotection were also reported for recombinant human interleukin-1 receptor antagonist (rhIL-1ra, anakinra), namely $>50 \%$ in Martin et al. [145] and only $\sim 24 \%$ in Hagberg et al. [24]. Here the contributing factors to variability include the route of administration (subcutaneous-s.c. versus intracerebral-i.c.), the treatment protocol (multiple versus single injection), and dosage (multiple s.c. doses of $\sim 1.5 \mathrm{~g}$ per rat in Hagberg's report, versus a single intracerebral dose of 3.3 or $5 \mu \mathrm{g}$ per rat in Martin's study).

The role of dosage was documented for NS398, a COX-2 inhibitor for which a higher dose was better than a lower dose [146], while the platelet-activating factor antagonist BN 52021 exerted beneficial impact in a dose-independent manner [147].

A common feature between these studies is that all the immune-related therapies were either administered before hypoxia or within few hours after HI. Four out of five studies in which impact of treatment was tested prophylactically (before the onset of hypoxia, anakinra, PAF antagonist, minocycline, ANS) reported superior neuroprotective outcome in comparison to that with post-HI treatment, which could be of interest for at risk pregnancies. Of note, only one study reported worsening of infarct severity upon treatment (i.e., with Fingolimod, [21]). This potential bias towards publishing only beneficial outcomes may be counterproductive, as any "detrimental" treatment actually reveals the key involvement of the targeted pathway in mitigating the injury, a fact that could be harnessed further in therapies. Overall, based on these studies, the following cells and molecular pathways have been identified to play a role in the pathogenesis of neonatal HI in the acute phase: neutrophils, mast cells, platelet-activating factor, IKK/NF- $\mathrm{KB}$ signaling, and cyclooxygenase-2 since inhibiting them confer neuroprotection. No or a limited role in neuroprotection post-HI was reported for TNF- $\alpha$ and JNK pathway, while a beneficial role was documented for peripheral lymphocytes. The role of IL-1 
Table 3 Effects of immune-related treatments in the rodent model of neonatal HI

$\begin{array}{ll}\text { Reference } & \begin{array}{l}\text { Species and Model Immune-related treatment } \\ \text { of HI }\end{array}\end{array}$

of $\mathrm{HI}$

Degree of neuroprotection ${ }^{\dagger}$, neuroinflammation, conclusion (s)

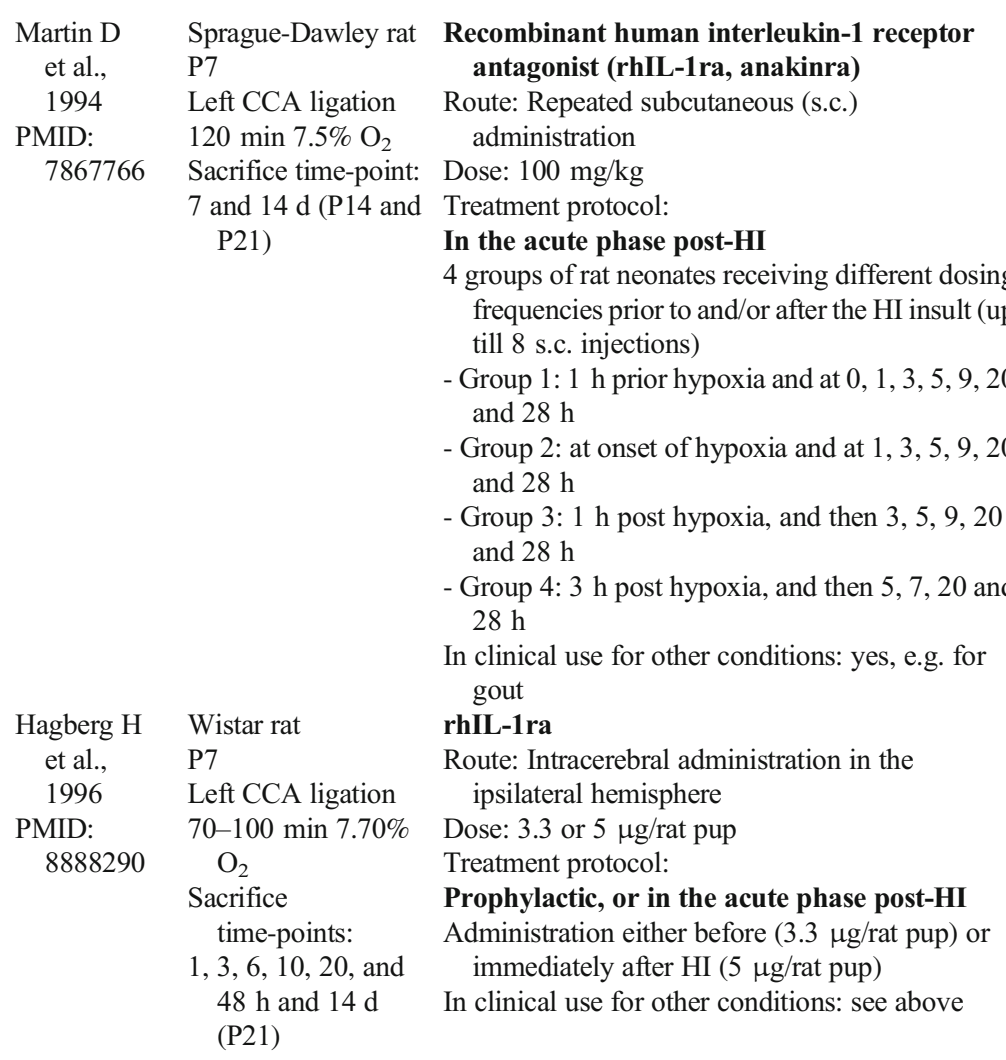

Liu X et al., Sprague-Dawley rat Platelet-activating factor (PAF) antagonist 1996

\section{P7}

PMID: $\quad$ Right CCA ligation

$8947953 \quad 150-195 \min 8 \%$

$\mathrm{O}_{2}$

Sacrifice time-point:

$5 \mathrm{~d}(\mathrm{P} 12)$

\section{BN52021}

Route: intraperitoneal (i.p.) injection

3 treatment protocols:

Prophylactic, or in the acute phase post-HI

- Pretreatment: 2 serial injections ( $25 \mathrm{mg} / \mathrm{kg} /$ injection), 1 immediately before the onset of hypoxia, and a second one $1 \mathrm{~h}$ after the end of hypoxia

- Post-treatment: 2 serial injections (25 mg/kg/injection), 1 immediately after the end of hypoxia, and then $2 \mathrm{~h}$ later

- Post-treatment-dose effect: 2 injections, immediately and $2 \mathrm{~h}$ after the end of hypoxia- different doses tested $(12.5,25$ or $50 \mathrm{mg} / \mathrm{kg} /$ injection)

In clinical use for other conditions: PAF antagonists are a heterogenous group of medication, some of which are used for different diseases

Anti-rat neutrophil serum (ANS) compared to allopurinol

Hudome
et al.,

Wistar rat

et al.,
1997

P7

Right CCA ligation

$135 \min 8 \% \mathrm{O}_{2}$
Degree of neuroprotection

$7 \mathrm{~d}$ post-HI, assessment of right and left hemisphere dry weights disparities:

- Group 1: 55\% neuroprotection (*).

- Group 2: $\sim 95 \%$ neuroprotection (**).

- Group 3: $80 \%$ neuroprotection (**).

- Group 4: $\sim 54 \%$ neuroprotection (NS).

$14 \mathrm{~d}$ post-HI, evaluation of loss of striatal neurons in cresyl violet stained brain slices only in group 1 :

- $\sim 65 \%$ neuroprotection (*).

Cerebral inflammation post-treatment

Not examined

Conclusion

IL-1 receptor activation plays a role in the pathogenesis of neonatal $\mathrm{HI}$ brain injury.

Degree of neuroprotection

$14 \mathrm{~d}$ post-HI, assessment of right and left hemisphere dry weights disparities:

- HI duration of 100 min and IL-1ra pretreatment: 24\% neuroprotection $(* *)$

- HI duration of 70 min and IL-1 ra post-treatment: no change in mean injury

Cerebral inflammation post-treatment

Not examined

Conclusion

rhIL-1ra mediated neuroprotection, despite being moderate, suggests the pathophysiological significance of IL-1 in neonatal $\mathrm{HI}$

Degree of neuroprotection

$5 \mathrm{~d}$ post-HI, assessed on cresyl violet stained brain slices:

- Incidence of infarction

$90 \%$ in vehicle-treated rats vs $33 \%$ in BN52021-pretreated rats (**) and 30\% in BN52021-post-treated rats (*).

- Neuroprotection per region

- Pretreatment: $82 \%$ in cortex, $74 \%$ in striatum, $90 \%$ in hippocampus.

- Post-treatment: $72 \%$ in cortex, $46 \%$ in striatum, $73 \%$ in hippocampus.

$5 \mathrm{~d}$ post-HI, assessed by interhemispheric weight differences for the post-treatment dose-effect study:

$18.9 \%(\mathrm{NS}), 44.8 \%(*)$ and $32.5 \%(*)$ neuroprotection observed in rats treated with $12.5,25$ or $50 \mathrm{mg} / \mathrm{kg} /$ dose compared with controls; differences in neuroprotection among the three doses not statistically different.

Cerebral inflammation post-treatment

Not examined

Conclusion

PAF appears to be one of the acute inflammatory factor mediating perinatal $\mathrm{HI}$ brain injury; PAF antagonists may represent a pharmacologic approach to attenuate the severity of HI-brain injury.

Degree of neuroprotection

$42 \mathrm{~h}$ post-HI, assessed by quantifying brain swelling (wet vs dry weight of posterolateral half of each cerebral hemisphere): 
Table 3 (continued)

Reference Species and Model Immune-related treatment of HI

\begin{tabular}{|c|c|c|}
\hline $\begin{array}{l}\text { PMID: } \\
\quad 9128280\end{array}$ & $\begin{array}{l}\text { Sacrifice } \\
\text { time-points: } \\
0,5 \text {, and } 30 \mathrm{~min} \text {, } \\
\text { and } 2,4,8,18, \\
\text { and } 42 \mathrm{~h}\end{array}$ & $\begin{array}{l}\text { comparison to allopurinol, a drug that reduces } \\
\text { neutrophil accumulation, and a known neuro- } \\
\text { protective agent } \\
\text { Route: i.p. for ANS and s.c. for allopurinol } \\
\text { Dose: Allopurinol } 135 \mathrm{mg} / \mathrm{kg} \\
\text { Treatment protocol: } \\
\text { In the acute phase post-HI } \\
\text { - } 4 \text { treatment groups: allopurinol, neutropenic, both } \\
\text { and none } \\
\text { - ANS is injected i.p. at time of surgery } \\
\text { - Allopurinol is injected } 15 \text { min post-hypoxia } \\
\text { In clinical use for other conditions: no, ANS is } \\
\text { experimental only }\end{array}$ \\
\hline $\begin{array}{l}\text { Arvin K } \\
\quad \text { et al., } \\
2002 \\
\text { PMID: } \\
\text { 12112047 }\end{array}$ & $\begin{array}{l}\text { Sprague-Dawley rat } \\
\text { P7 } \\
\text { Left CCA ligation } \\
150 \text { min } 8 \% \mathrm{O}_{2} \\
\text { Sacrifice } \\
\quad \text { time-points: } \\
24 \mathrm{~h} \text { and } 1 \mathrm{w}\end{array}$ & $\begin{array}{l}\text { Minocycline } \\
\text { Route: i.p. } \\
\text { Dose: } 45 \mathrm{mg} / \mathrm{kg} \\
\text { Treatment protocol: } \\
\text { Prophylactic, or in the acute phase post-HI } \\
\text { Single injection immediately before placement in } \\
\text { hypoxic chamber, or immediately after removal } \\
\text { from hypoxic chamber } \\
\text { In clinical use for other conditions: yes, for various } \\
\text { infections }\end{array}$ \\
\hline
\end{tabular}

Degree of neuroprotection ${ }^{\dagger}$, neuroinflammation, conclusion (s)
- 70\% (**) reduction in brain swelling by ANS-induced neutropenia and allopurinol. The application of both treat- ments confers no synergistic effect.
Cerebral inflammation post-treatment
Not examined.
Conclusion by study authors
Neutropenia before the insult is neuroprotective, thus neutrophils may play a role in the pathogenesis of neonatal $\mathrm{HI}$, although the mechanisms remain unclear.

Degree of neuroprotection

$7 \mathrm{~d}$ post-HI, measurement of the amount of surviving tissue in cresyl violet stained brain slices, and calculation of \% tissue loss in HI-IL vs HI-CL hemisphere:

- Minocycline $45 \mathrm{mg} / \mathrm{kg}$ before hypoxia: $72 \%$ (****), 100\% $(* * *)$ and $85 \%(* * * *)$ protection in striatum, hippocampus, and cortex.

- Minocycline $22.5 \mathrm{mg} / \mathrm{kg}$ before hypoxia: $61 \%$ (NS), $72 \%$ (NS) and $71 \%(*)$ protection in striatum, hippocampus, and cortex.

- Minocycline $45 \mathrm{mg} / \mathrm{kg}$ immediately after hypoxia: similar results as when given before hypoxia.

- Minocycline $45 \mathrm{mg} / \mathrm{kg} 3 \mathrm{~h}$ after hypoxia: $28 \%$ (NS), $9 \%$ (NS) and $22 \%$ (NS) protection in striatum, hippocampus, and cortex.

Cerebral inflammation post-treatment

Not examined

Conclusion

Minocycline at $45 \mathrm{mg} / \mathrm{kg}$ provides near complete neuroprotection after neonatal $\mathrm{HI}$ only if given immediately before or after HI. Administration $3 \mathrm{~h}$ post-HI is not neuroprotective.

Degree of neuroprotection

$42 \mathrm{~h}$ post-HI, measurement of brain swelling:

- In the before HI group, neutropenia reduces brain swelling by $75 \%(* * *)$.

- In the after HI group, no reduction in brain swelling.

- $14 \mathrm{~d}$ post-HI, measurement of brain atrophy:

- In the before HI group, neutropenia reduces IL hemisphere atrophy by $61 \%(*)$.

- In the after HI group, neutropenia is not protective.

Cerebral inflammation post-treatment

Not examined

Conclusion

Neutrophils play a role in early HI-induced neuropathogenesis. Anti-neutrophil strategies should be applied very early after $\mathrm{HI}$ to be neuroprotective.

Degree of neuroprotection

$7 \mathrm{~d}$ post-HI, assessment of NeuN immunoreactivity:

In CA1 hippocampus, the average cell loss is $\sim 30 \%$ in control animals, whereas it is $\sim 10 \%$ in animals treated with DOXY, regardless of injection time-points, which means a $\sim 70 \%$ neuroprotection.

Cerebral inflammation post-treatment

At $7 \mathrm{~d}$ post-HI, trend towards a reduction in the number of ED- $1^{+}$cells in the IL hippocampus, thalamus and cortex, 
Table 3 (continued)

Reference Species and Model Immune-related treatment of $\mathrm{HI}$
Degree of neuroprotection ${ }^{\dagger}$, neuroinflammation, conclusion (s)

In clinical use for other conditions: yes, for various infections

Can cross BBB

Sun Y et al., Sprague-Dawley rat recombinant human Erythropoietin (rh-EPO) ${ }^{\S}$ 2005 P7 Route: i.p.

PMID: Right CCA ligation Dose: $5 \mathrm{U} / \mathrm{g}$ body weight

$16040592150 \min 8 \% \mathrm{O}_{2} \quad$ Treatment protocol:

Sacrifice

time-points:

$3,7,14$, and $21 \mathrm{~d}$

\section{In the acute and subacute phase post-HI}

3 injections, namely injection at $24 \mathrm{~h}$ post-HI and - rh-EPO abolishes HI-induced rise in IL- $1 \beta$ protein levels in for 2 additional days

In clinical use for other conditions: yes, and in clinical trials for infants with CP (NCT\# 02811263)

Can cross a dysfunctional blood-brain barrier

with a greater extent when DOXY is administered before HI.

Conclusion

DOXY protects the neonatal brain from HI when applied in a short time window post-HI.

Degree of neuroprotection

7, 14 and $21 \mathrm{~d}$ post-HI, assessed by measurement of IL and CL wet weight disparities:

47-77\% (***) protection at these 3 time-points.

Cerebral inflammation post-treatment the ipsilateral hemisphere 3,7 , and $14 \mathrm{~d}$ post-injury, but does not affect mRNA levels of TNF- $\alpha$ between 3 and $14 \mathrm{~d}$ post-HI.

- It limits HI-induced leukocyte infiltration in the parieto-occipital cortex, observed with CD4 and CD68 IHC stainings.

Conclusion

3 doses of rh-EPO is neuroprotective after HI. A potential mechanism of neuroprotection may be through reducing HI-associated elevation in IL-1 $\beta$ and through limiting leukocyte infiltration.

$\begin{array}{cl}\text { Nijboer C } & \text { Wistar rat } \\ \text { et al., } & \text { P7 } \\ \text { 2008 } & \text { Right CCA ligation } \\ \text { PMID: } & 120 \text { min } 8 \% \mathrm{O}_{2} \\ \text { 18420952 } & \text { Sacrifice } \\ & \text { time-points: } \\ & 1 \mathrm{~h}, 3 \mathrm{~h}, 6 \mathrm{~h}, 12 \mathrm{~h}, \\ & 48 \mathrm{~h} \text { and } 6 \mathrm{w}\end{array}$

TAT-NBD, IKK/NF-кB inhibitor

- TAT-NBD: peptide inhibitor of the IKK complex, the NEMO Binding Domain (NBD)-peptide coupled to the protein transduction sequence of HIV-TAT to facilitate cerebral uptake

- mutant TAT-NBD

- biotinylated TAT-NBD

Route: i.p.

Dose: $20 \mathrm{mg} / \mathrm{kg}$

Treatment protocol:

In the acute phase post-HI

administration at various time points post-HI: 0,3 , 6,9 and $12 \mathrm{~h}$ after $\mathrm{HI}$

In clinical use for other conditions: no specific $\mathrm{NF}-\mathrm{KB}$ inhibitor in use yet, but unrelated drugs may target this signaling pathway

Can cross BBB

Jin Y et al., Wistar rat

cromolyn, mast cell stabilizer

2009 P7 Route: s.c.

PMID: $\quad$ Right CCA ligation Dose: $50 \mathrm{mg} / \mathrm{kg}$ body weight

$1952099175 \mathrm{~min} 8 \% \mathrm{O}_{2} \quad$ Treatment protocol:

Sacrifice In the acute phase post-HI

time-points: $\quad 3$ injections, i.e. immediately after $\mathrm{HI}$, and 1 and

$0,1 \mathrm{~h}, 2 \mathrm{~h}, 4 \mathrm{~h}$,

$24 \mathrm{~h}, 48 \mathrm{~h}$ and 4 In clinical use for other conditions: yes, for asthma W
Degree of neuroprotection

$48 \mathrm{~h}$ and $6 \mathrm{w}$ post-HI, assessed by MAP2 staining and hematoxylin-eosin respectively:

- $\sim 40-56 \%(* *)$ protection at $48 \mathrm{~h}$ post-HI if TAT-NBD administered 0/3 h after HI, $\sim 35 \%$ (*) if administered $6 \mathrm{~h}$ after HI.

- $75 \%$ (***) protection at $6 \mathrm{w}$ post-HI if administered $0 / 3 \mathrm{~h}$ after HI.

- Administration of TAT-NBD at 9 or $12 \mathrm{~h}$ post-HI is not neuroprotective.

Cerebral inflammation post-treatment

TAT-NBD treatment immediately after HI does not induce any changes in the HI-induced increase in mRNA levels of cytokine (TNF- $\alpha$, IL-1 $\beta$, IL-4, IL-10 and IL-1RA) at $3 \mathrm{~h}$ post-HI, even though NF- $\mathrm{BB}$ activity is fully inhibited at this time point.

Conclusion

Inhibition of the cerebral IKK/NF-kB pathway early after HI is neuroprotective, but does not involve abrogation of early cytokine expression. This early cytokine induction by neonatal HI may contribute to neuroprotection.

Degree of neuroprotection

1, 2 and $4 \mathrm{w}$ post-HI, scoring of Fluoro-Jade B stainings, and measurement of IL/CL hemisphere ratio on $\mathrm{H} \& \mathrm{E}$ stained brain slices:

- $61-75 \%(*)$ improvement in score of brain damage at the time-points examined.

- Cavitation is absent in all cromolyn treated rats, whereas it is present in $30 \%$ and $50 \%$ of vehicle-treated animals at 2 and $4 \mathrm{w}$ post-HI, respectively.

- IL/CL ratio restored to normal in cromolyn treated rats $(*)$. Cerebral inflammation post-treatment

Astrocytic and microglial activation, scored with GFAP and OX-42 antibodies respectively, are significantly reduced at the time points examined.

Conclusion

Mast cells appear to contribute to the inflammatory response to neonatal $\mathrm{HI}$ and could be the initiators of the immune response. 
Table 3 (continued)

Reference Species and Model Immune-related treatment
of HI

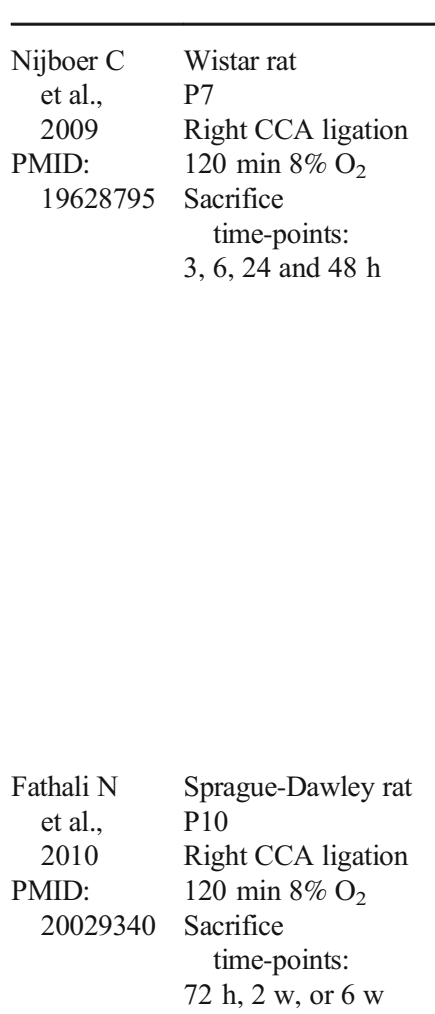

\section{TAT-NBD, IKK/NF-KB inhibitor; TAT-JBD, JNK inhibitor; and etanercept, TNF- $\alpha$} inhibitor

TAT-NBD, mutant TAT-NBD or TAT-JBD

Route: i.p.

Dose: $20 \mathrm{mg} / \mathrm{kg}$ for TAT-NBD peptides and $10 \mathrm{mg} / \mathrm{kg}$ for TAT-JBD

Treatment protocol: administered 0 and $3 \mathrm{~h}$ after HI

Etanercept (a fusion protein of TNF-R2 and human $\left.\operatorname{IgG}_{1}\right)$ :

Route: i.p.

Dose: $5 \mathrm{mg} / \mathrm{kg}$

Treatment protocol:

In the acute phase post-HI

administered directly after $\mathrm{HI}$ alone or with TAT-NBD

In clinical use for other conditions: etanercept is used for treating some autoimmune diseases (e.g. rheumatoid arthritis); the other compounds are experimental only

NS398, selective cyclooxygenase-2 (COX-2) inhibitor

Route: i.p.

Dose: 2 dosage regimens, either $10 \mathrm{mg} / \mathrm{kg}$ (NS-10 group), or $30 \mathrm{mg} / \mathrm{kg}$ (NS-30 group)

Treatment protocol:

In the acute and subacute phase post-HI

six injections $(1,6,24,36,48$, and $60 \mathrm{~h})$ after hypoxia

In clinical use for other conditions: going out of clinic due to adverse cardiac events
Degree of neuroprotection ${ }^{\dagger}$, neuroinflammation, conclusion (s)

Degree of neuroprotection

$48 \mathrm{~h}$ post-HI, measurement of CL and IL areas on MAP2 stained brain slices:

- NBD: $75-88 \%$ (***).

-JBD: $25 \%(*)$.

- NBD+JBD: $50 \%$ (***).

- Etanercept: $25 \%(*)$.

- NBD+Etanercept: 44\% (* vs NBD).

Cerebral inflammation post-treatment

- Combined NF-KB inhibition and JNK/AP-1 prevents HI-induced TNF- $\alpha$ production and reduces neuroprotection.

- Etanercept alone has a significant neuroprotective effect, but not as great as that provided by NF- $\mathrm{kB}$ inhibition.

- Etanercept treatment reduces the protective effect of TAT-NBD.

Conclusion

JNK/AP-1 inhibition and TNF- $\alpha$ inhibition reduce the neuroprotective effect of NF- $\mathrm{KB}$ inhibition: after $\mathrm{HI}$ is mediated in part by JNK/AP-1 activity and TNF- $\alpha$ production.

Degree of neuroprotection

2 and $6 \mathrm{w}$ post-HI, measurement of IL/CL weight ratio:

- NS-10 group: $63 \%$ at $2 \mathrm{w}(*)$ and $57 \%\left(^{*}\right)$ at $6 \mathrm{w}$.

- NS-30 group: $79 \%$ at $2 \mathrm{w}(*)$ and $75 \%(*)$ at $6 \mathrm{w}$.

$6 \mathrm{w}$ post-HI, behavior analysis:

improvement in, or restoration of many HI-induced neurobehavioral deficits in NS-10 and NS-30 treated animals.

Cerebral inflammation post-treatment

- COX-2 immunopositive signals (western blotting and IHC staining of ipsilateral brain) are significantly reduced in NS398 treated HI animals in comparison to HI-vehicle animals.

- At $72 \mathrm{~h}$ post-HI, IL-6 staining and concentration in ipsilateral brain is increased in HI-vehicle exposed rats, and significantly reduced by NS-30. Qualitative evaluation of single immunofluorescent staining for Iba1, CD68 and MPO in ipsilateral brain indicates that NS30 attenuates significantly HI-induced increase in these markers.

Conclusion

COX-2 inhibition is neuroprotective; effects may be mediated by anti-inflammatory actions, through IL- 6 reduction, decreased activation of microglia and of infiltration of macrophages and neutrophils.

Degree of neuroprotection

2 and $9 \mathrm{~d}$ post-HI, scoring of damage on MAP2 stained brain slices:

- P9 neonatal brain: $73 \%\left(^{*}\right)$ and $87 \%(*)$ protection at 2 and 9 d post-HI.

- P30 juvenile brain: no protection at both days; of note, $\mathrm{HI}$-induced brain damage less severe at $\mathrm{P} 30$ than at $\mathrm{P} 9$.

Brain atrophy at 9 and $60 \mathrm{~d}$ post-HI by T2-weighted MRI:

- P9 neonatal brain: no significant impact on volume loss at both days.

- P30 juvenile brain: no significant impact on volume loss at 9 $\mathrm{d}$, but a slight impact at $60 \mathrm{~d}$.

Hippocampal learning by Morris water maze test:

- P9 neonatal brain: no amelioration in HI-induced learning deficits.

- P30 juvenile brain: significant improvement.

Cerebral inflammation post-treatment 
Table 3 (continued)

Reference Species and Model Immune-related treatment of $\mathrm{HI}$

Degree of neuroprotection $^{\dagger}$, neuroinflammation, conclusion (s)

Impact of minocycline on total counts of microglia $\left(\mathrm{CD} 11 \mathrm{~b}^{+} / \mathrm{CD} 45^{+}\right)$

- Significantly suppresses HI-induced increase in microglia counts in the IL hippocampus from P9 and P30 brains 2 and $9 \mathrm{~d}$ post-HI; this is also observed in the cortex and striatum from $\mathrm{P} 9$ brains, but less in the same regions from P30 brains.

Impact of minocycline on percentage of activated microglia (CD45 $5^{\text {med }} /$ total microglia)

- $2 \mathrm{~d}$ post-HI, in the IL hippocampus, induces $\sim 70 \%$ reduction in the proportion of activated microglia in both neonatal and juvenile brains.

$-9 \mathrm{~d}$ post-HI in the IL cortex and striatum

- P9 neonatal brain: significant decrease in the percentage of activated microglia

- P30 juvenile brain: no impact of minocycline on $\mathrm{HI}$-induced late microglia activation

Conclusion

Minocycline has different neurological outcome depending on the age at which HI-injury is induced. Early improvements in neurologic injury do not necessarily predict long-term improvements in neurologic function.

Herz J et al., C57BL/6 J mice $2018 \quad$ P9

PMID: Right CCA ligation

3012778260 min $10 \% \mathrm{O}_{2}$ Sacrifice time-points:

$1 \mathrm{w}(\mathrm{P} 16)$
FTY720 (Fingolimod), a sphingosin-1-phosphate analog that reduces peripheral lymphocytes

Route: i.p.

Dose: $1 \mathrm{mg} / \mathrm{kg}$ body weight

Treatment protocol:

In the acute phase post-HI

single injection within $20 \mathrm{~min}$ after hypoxia In clinical use for other conditions: yes, for multiple sclerosis
Degree of neuroprotection

$1 \mathrm{w}$ post-HI, scoring of injury in cresyl violet stained brain slices:

- Significant worsening of neuropathology in FTY720-treated animals versus saline-exposed mice. Cerebral inflammation post-treatment

- FTY720 treatment induces a slight but not significant increase in Ibal protein levels (assessed by western blot). - Despite FTY720 induced depletion of circulating T cells, the total cerebral leukocyte infiltration assessed qualitatively by IHC is unaffected by FTY720. This is explained by an increased infiltration of innate immune cells, mainly neutrophils and inflammatory macrophages. Conclusion

Pharmacological mediated $\mathrm{T}$ cell depletion increases HI-induced brain injury; this contrasts with the neuroprotective effect of FTY720 observed in adult models of stroke. Thus, neonatal $\mathrm{T}$ cells may promote endogenous neuroprotection.

All sacrifice time-points are given in post-HI

H\&E: hematoxylin-eosin

BBB: Blood brain barrier

$\dagger$ Percent neuroprotection was either reported by study authors, either calculated by reviewers using the formula $100 *(1-\%$ damage in treated animals/ $\%$ damage in vehicle treated animals), as in [146]. The significance is that reported by authors, and unless indicated, represents the significance of HI drugtreated animals versus $\mathrm{HI}$ vehicle-treated animals. Significance values $* P<0.05 ; * * P<0.01 ; * * * P<0.001 ; * * * * P<0.0001$

$\S$ Various rhEPO treatment protocols have been tested in the P7 rodent model of neonatal HI (for a review, see [143]). This study is included in the table because it is the only one that reports on CD68 immunostaining in the ipsilateral hemisphere from HI-exposed animals. The study authors attribute CD68 staining to infiltrating leukocytes, but it could also be microglia/macrophages

signaling pathway remains currently unclear and requires further investigation.

Is the microglial phenotype modulated by immune related treatments and does it correlate with neuroprotection?
Among the 14 studies listed in Table 3, five examined the phenotype of microglia, but the depth of examination varied widely between studies. The data described below present results observed in the ipsilateral hemisphere from treated versus untreated HI-exposed animals. The injection of 
Fig. 1 (A) Main experimental steps within which individual factors can eventually complicate interpretation of results between different studies. Charts displaying (B) type and $(\mathbf{C})$ origin of transplanted SCs used in studies listed in Table 4
A
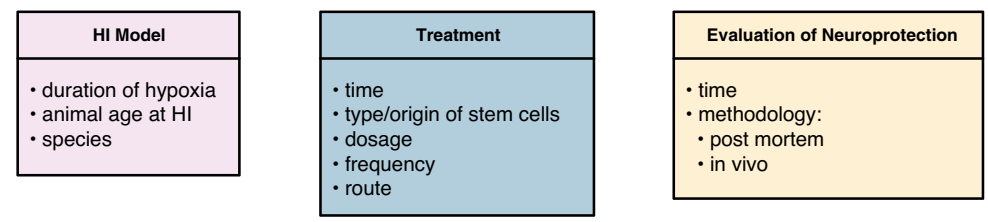

B Type of transplanted Stem Cells

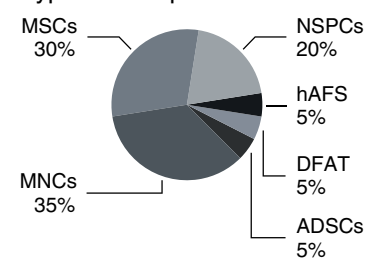

C Origin

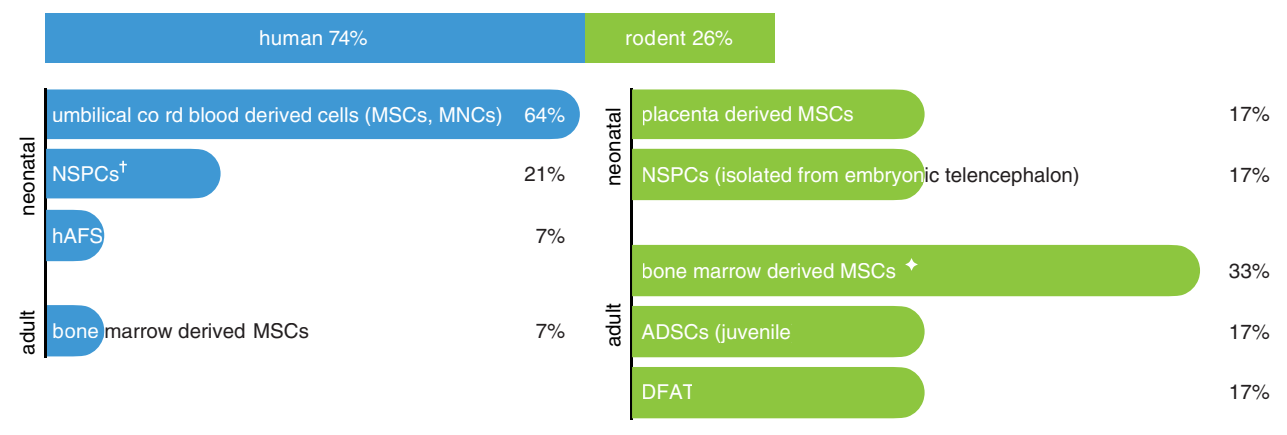

doxycycline before or within $3 \mathrm{~h}$ of $\mathrm{HI}$ reduced neuronal loss by $70 \%$ as measured with NeuN immunoreactivity in the hippocampus at seven days post-HI, and concomitantly the number of ED1 (CD68) positive cells declined in the ipsilateral hippocampus, thalamus and cortex [148]. Administration of cromolyn, a mast cell stabilizer curtailed significantly brain damage score at one, two and four weeks post-HI (by roughly $70 \%$ as measured with Fluoro-Jade B) and a significant reduction in the number of OX-42 (CD11b) positive cells was noted in the ipsilateral thalamus at the same time points [13]. Administration of the COX-2 inhibitor NS398 diminished significantly brain atrophy (assessed via ipsi:contralateral brain weight ratio, degree of neuroprotection ranging between 57 and $79 \%$ (two and six weeks post-HI), restored some HI-induced neurobehavioral defects and those effects were associated with a qualitative reduction in single Ibal and CD68 immunoreactivities in the ipsilateral cerebral cortex at three days post-HI [146]. The exacerbation of neonatal HI-induced brain injury reported after treatment with Fingolimod did not affect significantly Iba1 protein levels one-week post-HI [21]. Cikla et al. [108] carried out the most detailed examination of the microglial phenotype after minocycline treatment using a combination of flow cytometric and immunohistochemical analyses. Mice, subjected to HI at either P9 (mouse model of neonatal HI) or P30 (mouse model of juvenile $\mathrm{HI}$ ), were injected twice with minocycline at two and $24 \mathrm{~h}$ after surgery. In the HI-exposed neonatal mice, the total microglial count (CD11b/CD45 double positive cells) and the percent of activated microglia (CD $45^{\mathrm{med}+} /$ total $)$ increased in the ipsilateral hippocampus two days post-HI, and then in the ipsilateral cortex and striatum nine days post-HI. The same spatio-temporal rise in microglia was observed in HI-exposed juvenile mice, although not as strong as that observed in HI-exposed neonatal mice. In the mouse model of neonatal HI, minocycline reduced microglial counts (total and percent activated) at both days post-surgery in all regions considered; in the mouse model of juvenile HI, minocycline also impacted microglial counts in the hippocampus two days post-HI, but not at nine days post-HI in cortex and striatum. Surprisingly, long-term neuroprotection was only observed in HI-exposed juvenile mice, but not in HI-exposed neonates. Authors hypothesized that this differential response to treatment was linked to the persistent microglial activation observed in the striatum and cortex of treated $\mathrm{HI}$ juvenile mice, thereby suggesting a positive correlation between microglial activation and beneficial outcome. Thus, while the four aforementioned studies suggest a correlation between treatment-associated neuroprotection and a decline in the number of microglia in the ipsilateral hemisphere from treated animals in comparison to that from untreated animals, the latter study actually proposes a link between neuroprotection and persisting microglial activation. The role of microglia in the early phase after neonatal HI was recently addressed in murine models of neonatal HI using genetic and pharmacological based tools to deplete microglia [149, 150]. In [149], microglia depleted male mice (generated by conditional 
deletion of $\mathrm{Cx} 3 \mathrm{cr} 1$ induced by tamoxifen) subjected to $\mathrm{HI}$ at P10 displayed an aggravated neuropathology and astrocyte reaction three days after injury, and overall lower levels of TGF- $\beta$ and IL-10 in the ipsilateral hemispheres. These data suggest that microglia and specific cytokines play a neuroprotective role in the early phase post-injury. In contrast, in [150], PLX3397 (Plexxikon) was administered orally from P4 to $\mathrm{P} 11$, and mouse neonates were subjected to $\mathrm{HI}$ at P9. Two days after HI, a significant amelioration in neuropathology was observed, accompanied by a reduction in brain infiltration of circulating immune cells and an improved sensorimotor function, overall suggesting that in the early phase post HI, CSF1R mediated pathways exert a detrimental role in the pathogenesis of the disorder. Reasons underlying such opposing results are unclear but may be linked to differences in HI model (P10 mice, $1 \mathrm{~h}$ hypoxia in [149] versus P9 CD1 mice, 30 min hypoxia in [150]) and to the fact that CSF1R inhibition has unspecific effects, as reported in [151]. Another recently reported issue associated with the use of PLX3397 is the actual silencing of typical microglial genes such as Ibal and $\mathrm{Cx} 3 \mathrm{cr}$ l, rather than a depletion of or a reduction in microglial density [152]. Additional microglia targeting agents to be tested include gadolinium chloride $\left(\mathrm{GdCl}_{3}\right)$, a drug that reportedly can deplete selectively pro-inflammatory microglia [153], as well as others potential depletion tools, such as lipid nanocapsules, or polyamidoamine dendrimers as reported in [154].

\section{Therapeutic Benefit of Stem Cell Transplantation in the Rodent Model of Neonatal HIE: Is Microglia Involved?}

Immune modulation is often put forward as a major mechanism of SC mediated therapeutic benefit. We could find 19 studies - from 12 distinct research laboratories - that reported on SC transplantation in the rodent model of neonatal HI and examined changes in neuroinflammation or in peripheral inflammation post-treatment (see Table 4). A quick glimpse at the table indicates that each study used its own experimental protocol, thus rendering comparison of results between studies difficult. The only common point between these studies is that a single injection of stem cells was used. Variability is otherwise detected at all experimental steps, starting from the rodent model of neonatal HI, through the treatment (type/source, dose and route of SC transplantation), and to the evaluation of neuroinflammation and neuroprotection, as depicted in Figs. 1, 2 and 3. Even when the same treatment protocol is used, variation in other parameters eventually can lead to contrasting outcomes, as illustrated in the two following studies by the same group. In the study of McDonald et al. [155] duration of hypoxia was $180 \mathrm{~min}$ and readout endpoint was seven days post-HI, while in the study of Penny [156] these parameters were 90 min and 43 days post-HI. Perhaps mainly due to longer exposure to hypoxia in the first study, deficits in the negative geotaxis test were observed seven days post-HI in the untreated $\mathrm{HI}$-injured neonates, but not in the second study at 43 days post-HI. Stem cell treatment (one million human UCB mononuclear cells transplanted i.p. $24 \mathrm{~h}$ after $\mathrm{HI}$ ) almost fully protected animals from brain damage in the first study, and this was accompanied by an improvement in negative geotaxis test and a significant reduction in the number of Ibal+ cells in the frontal motor cortex. In the second report, stem cell treatment did not limit HI-induced brain damage and an increase in the number of Ibal activated microglia was observed in the somatosensory cortex, but not in the motor cortex. Thus, experimental variability eventually complicates interpretation.

Does stem cell therapy change the microglial phenotype after neonatal HI? If so, how? Is it correlated with neuroprotection and functional outcome?

Six studies reported a reduction in Iba1-related immunohistochemical parameters - such as number of activated cells, immunointensity and proliferation - in the cortex, the frontal motor cortex, the penumbra of the cortex, the hippocampus, the thalamus at 1-, 5-, 6-, 10-, 14-, 18- and 21 days post-transplantation. This observation was not correlated with a particular cell type, dose, route or time of transplantation (rat/ mouse/human bone marrow-BM derived mesenchymal stem cells-MSCs, human amniotic fluid stem cells, mouse neural stem cells, human umbilical cord blood-UCB derived mononuclear cells, T regulatory cells-Tregs, endothelial progenitor cells-EPCs and monocytes, injected i.p., i.v., i.c. or i.n., doses of $13^{\prime} 333$ or $66^{\prime} 667$ cells per gBW and 333'333-666'667-1' $666^{\prime} 667$ cells per g brain weight-BrW, injected either $24 \mathrm{~h}$, three or ten days post-HI). Behavioral outcome was evaluated in five studies, and significant improvements in sensorimotor function were reported (assessed in the cylinder rearing test or negative geotaxis test), with some nuances: for instance, amelioration in sensorimotor function was found transient in one report, being detected at three weeks post-HI but not at ten weeks post-HI [157]. Also, the individual cell subtypes of human UCB had differential ability to affect HI-induced deficits in the negative geotaxis test, with UCB derived monocytes being ineffective, in contrast to UCB derived EPCs [155]. The degrees of neuroprotection (assessed with cresyl violet, H\&E, MAP2 stainings, ipsi/contra area ratios) were variable, ranging from none to $42 \%, 58 \%, 70 \%$ to almost full neuroprotection.

Six studies reported a reduction in the CD68 microglia/ macrophage activation marker (levels in whole ipsilateral hemisphere, number of positive cells or immunointensity) in the cortex, temporal cortex, hippocampus and dentate gyrus, penumbra area at 1-, 7- and 35 days post-HI. This was again independent of a particular cell type, dose, route or time of transplantation (human UCB derived mononuclear cells and MSCs, or rat dedifferentiated fat cells, injected i.p., i.v. or i.c. 


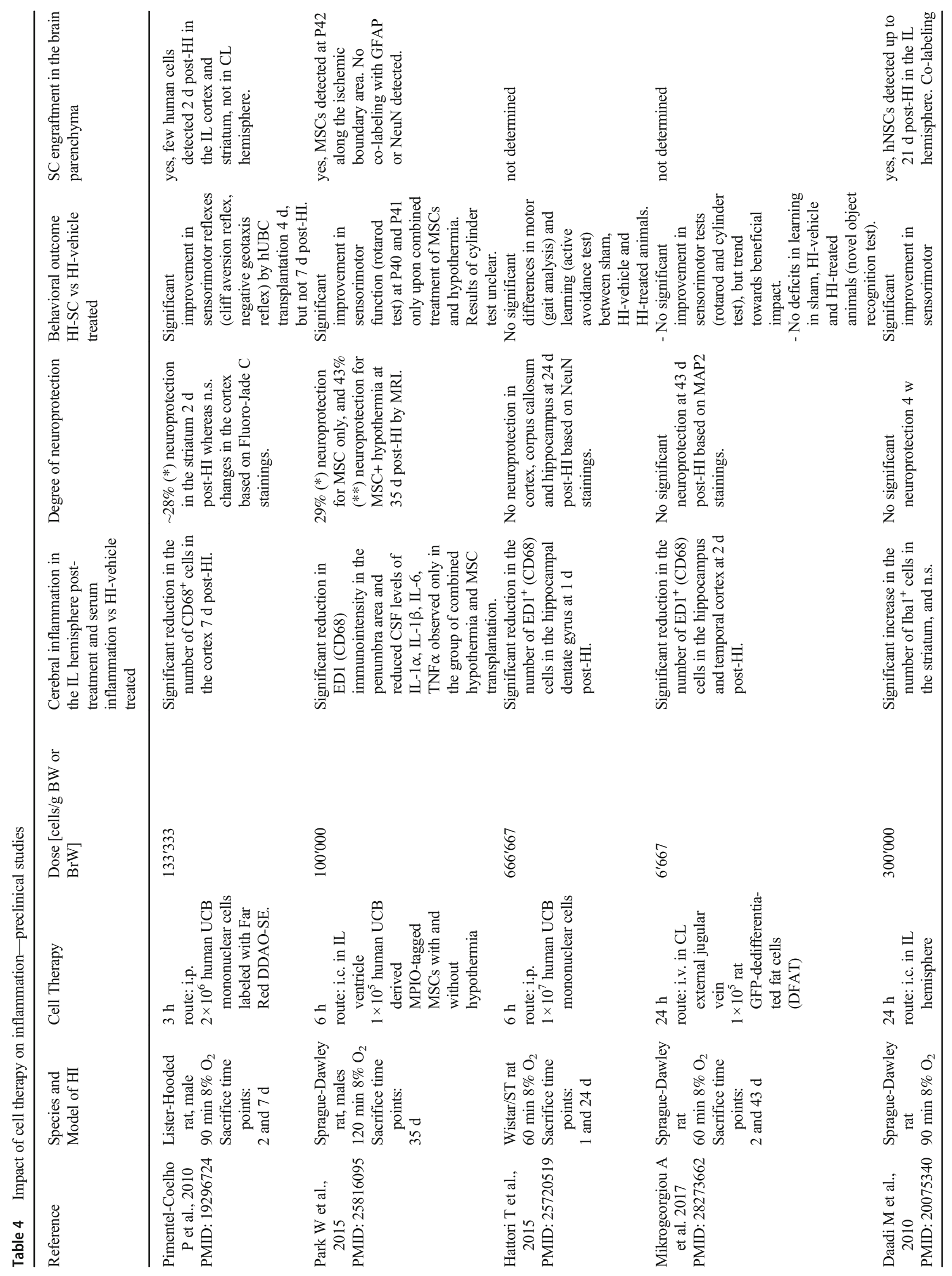




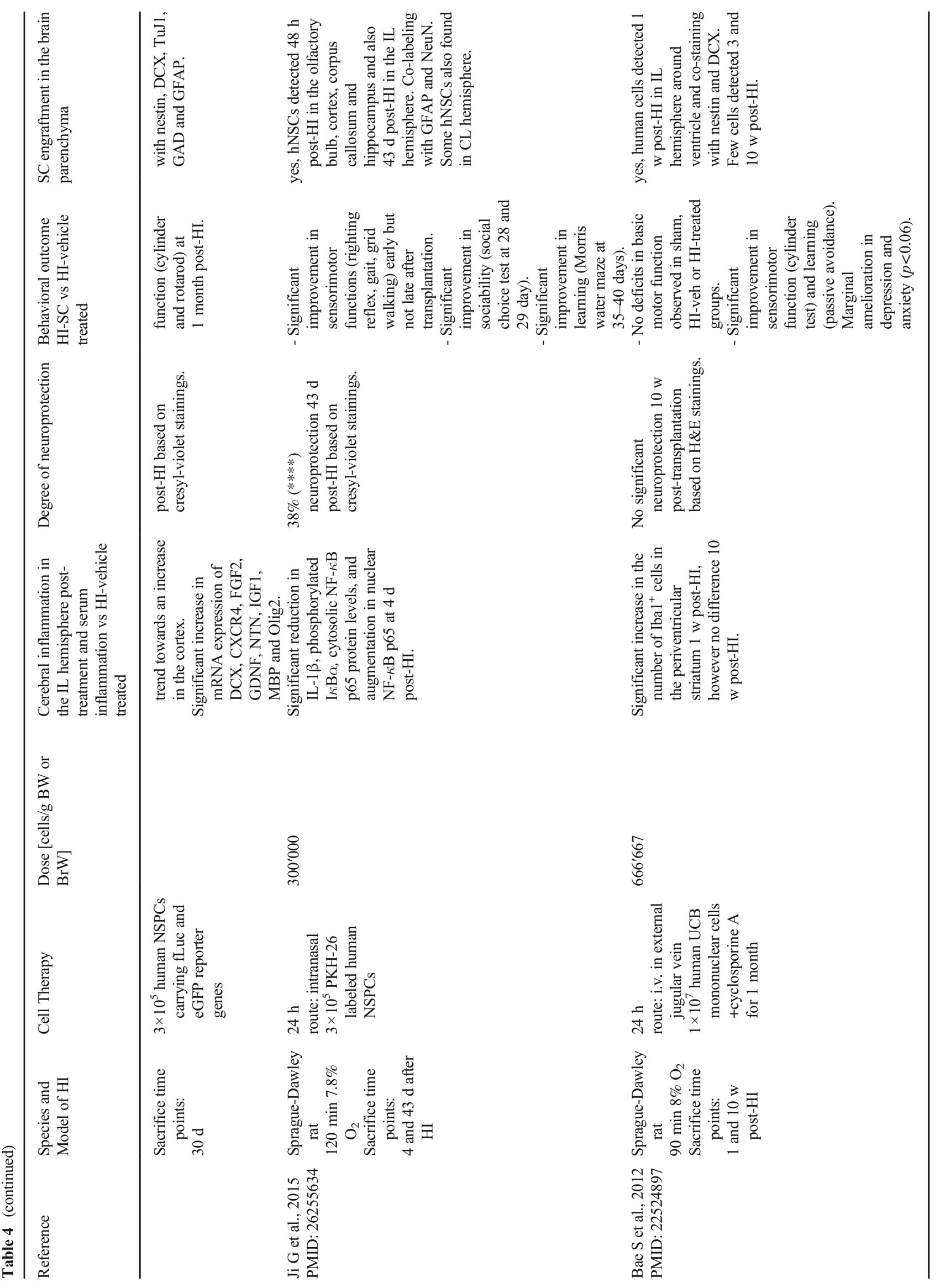




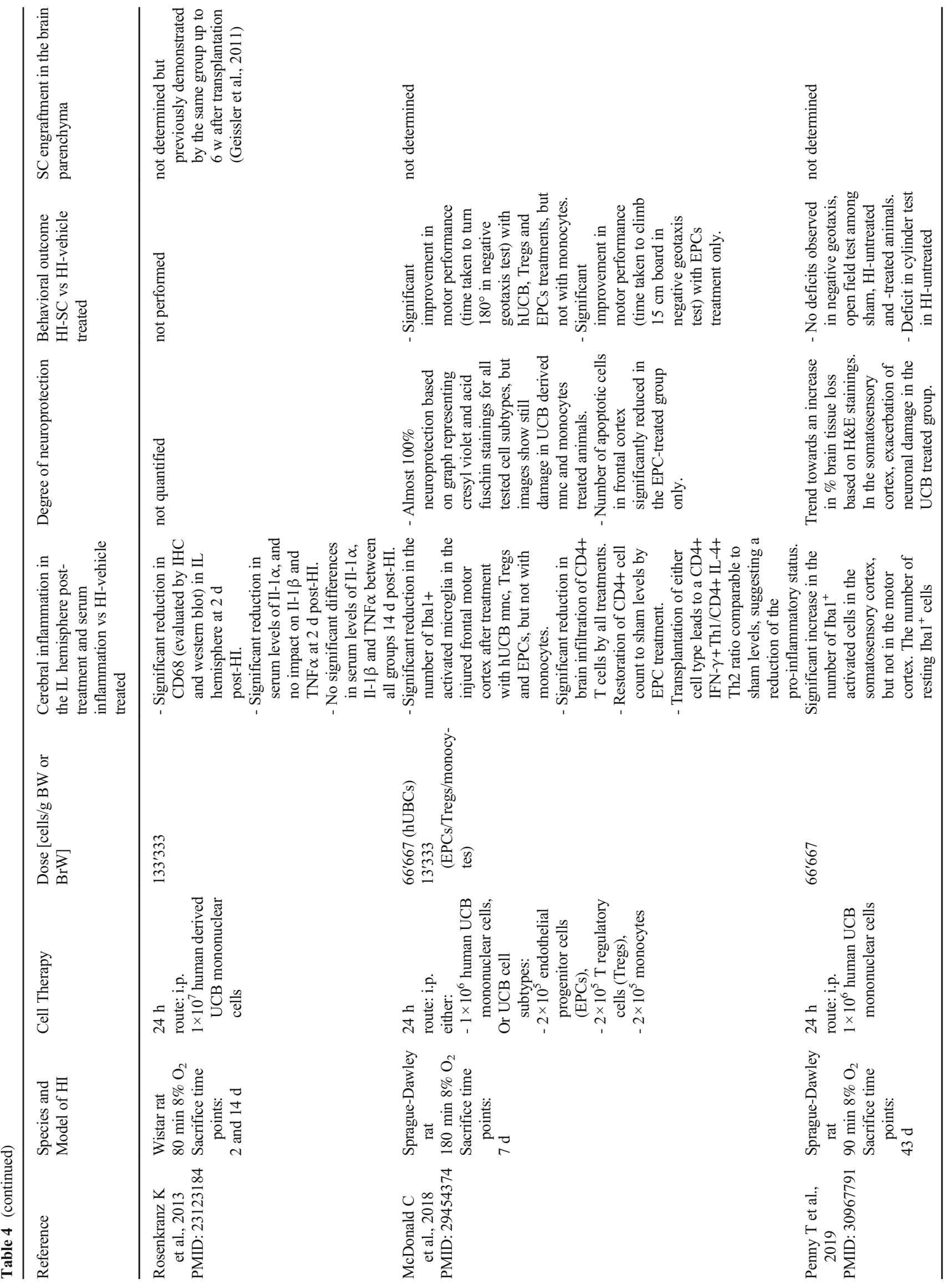




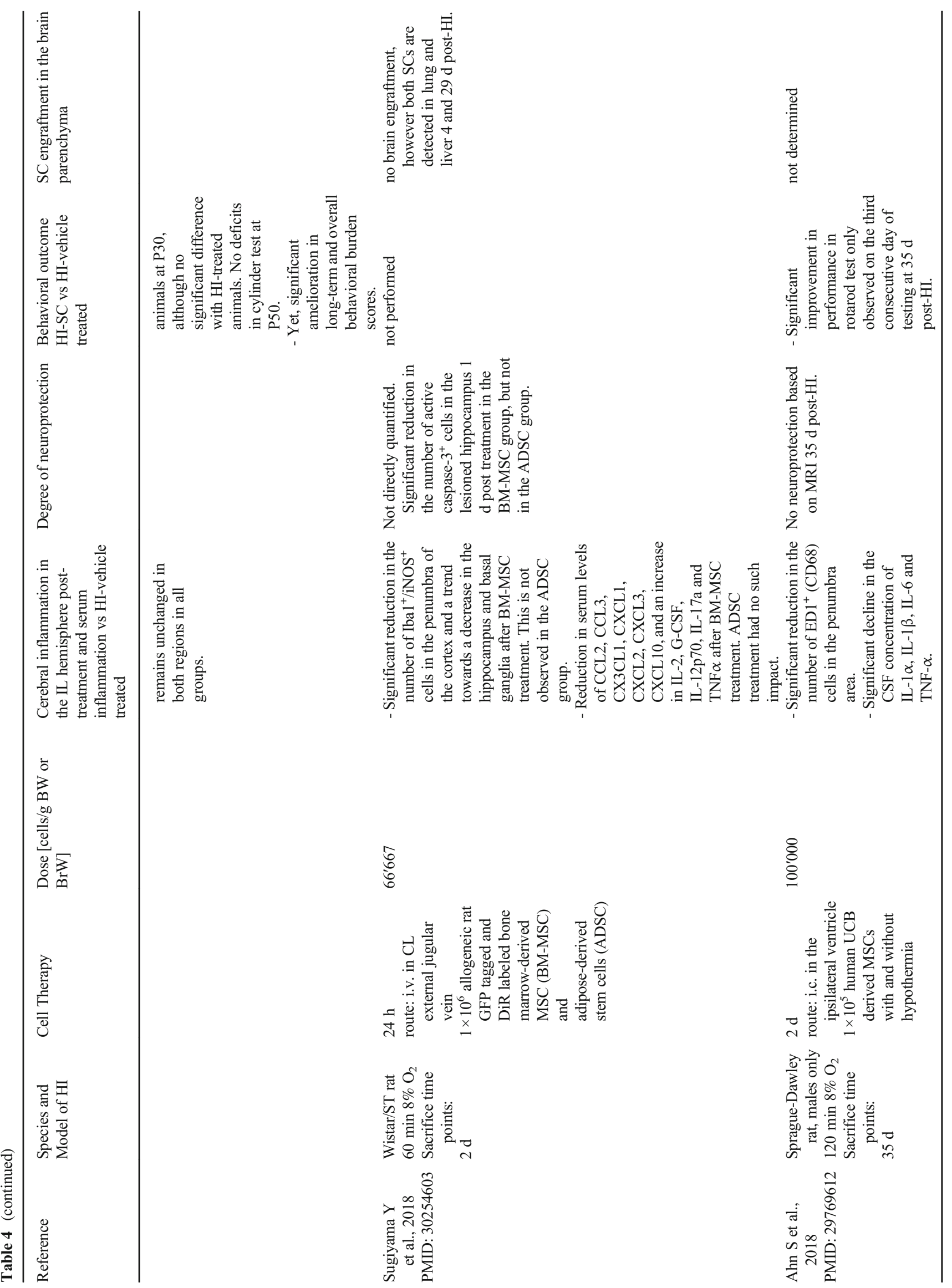




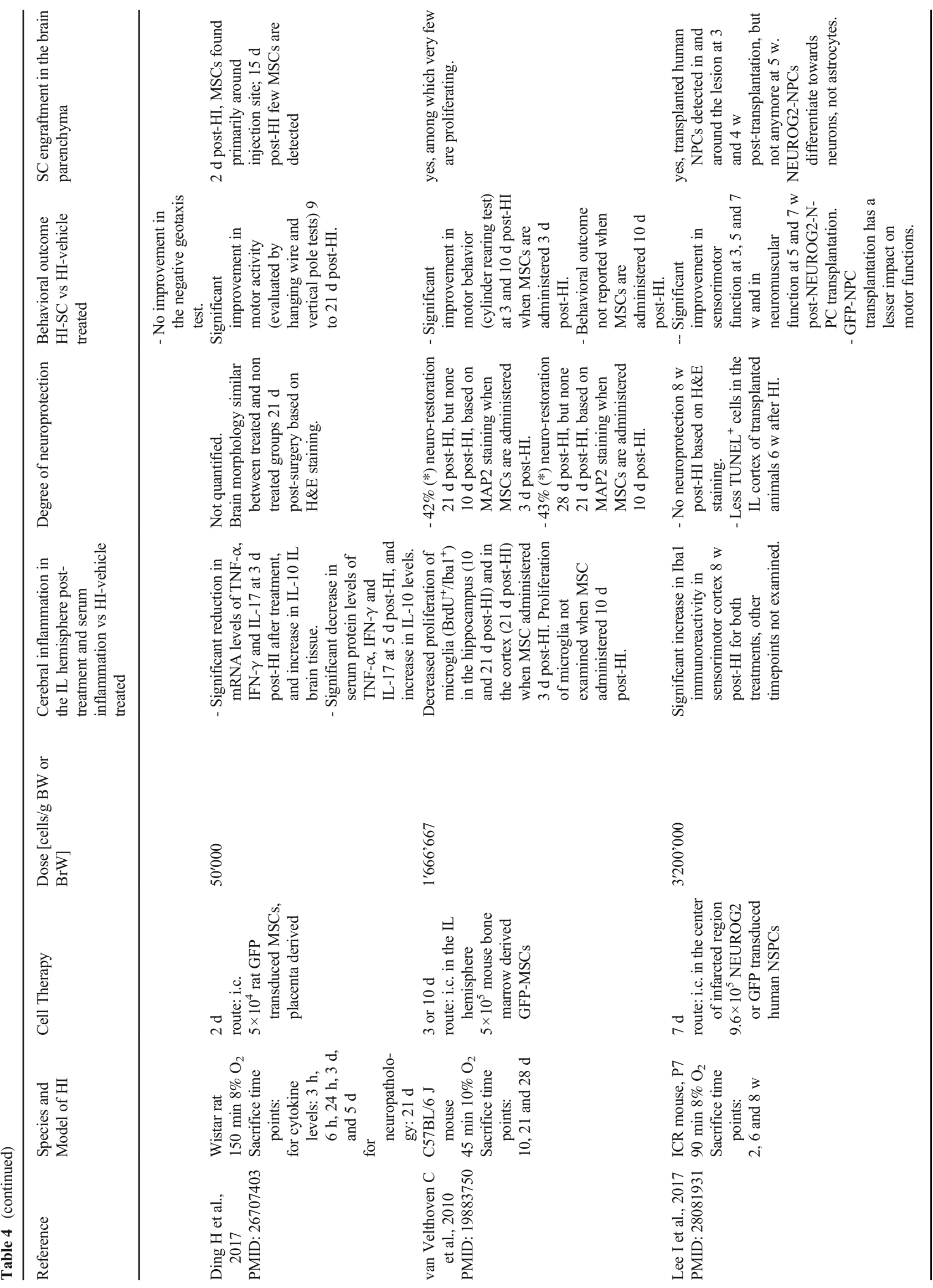




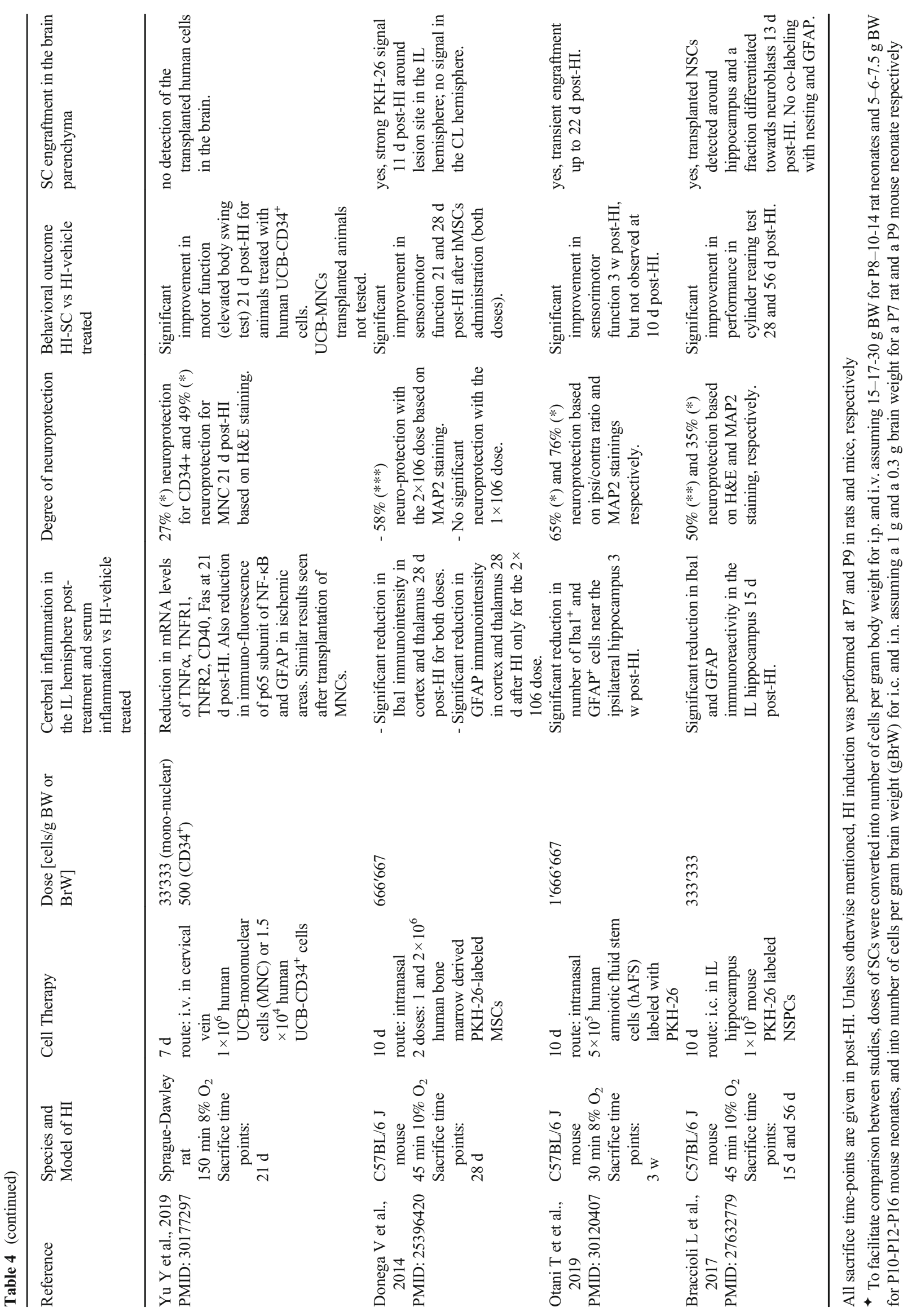




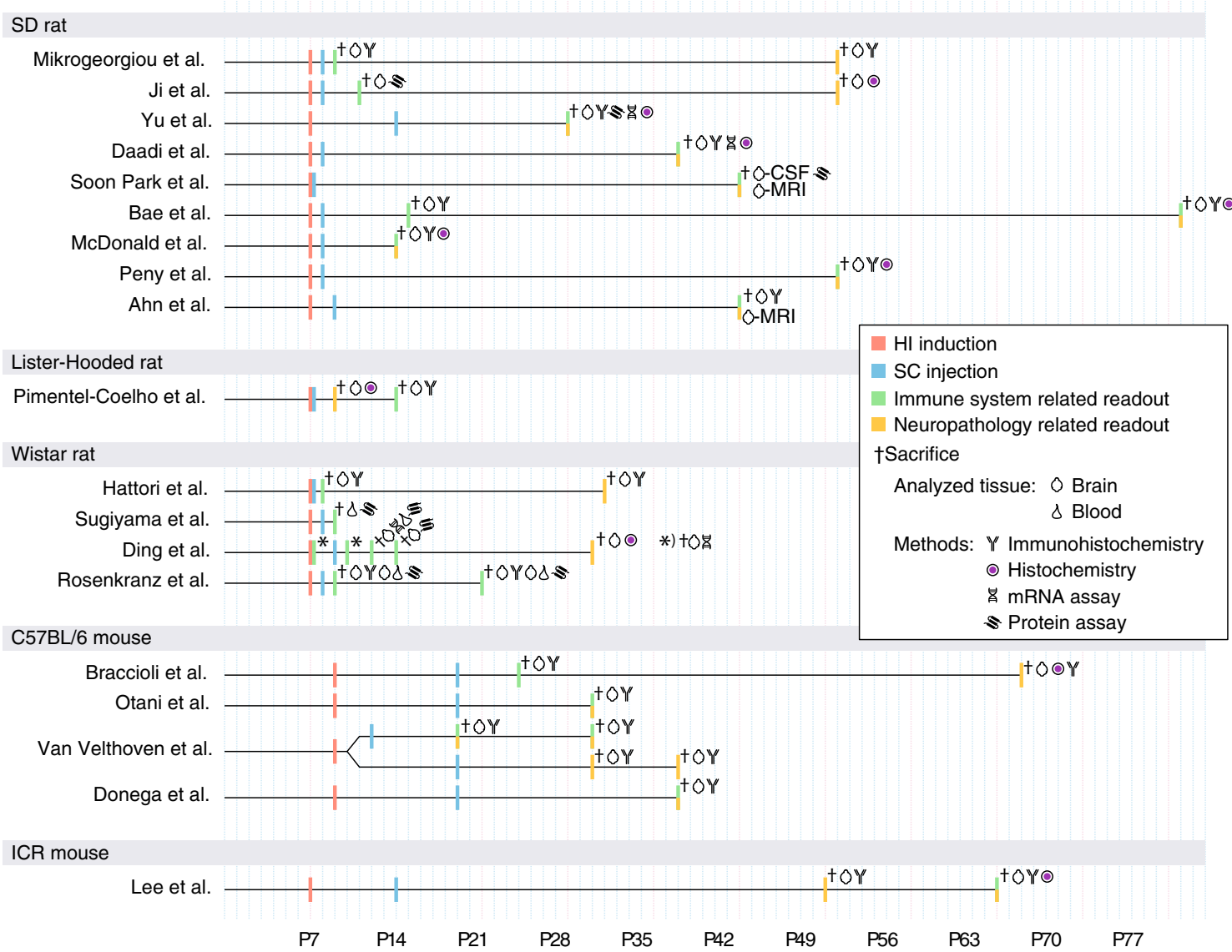

Fig. 2 Study designs summarized from Table 4, illustrating large variability in time points of SC transplantation and neuroinflammation related readouts

either three, six and $24 \mathrm{~h}$ post-HI at doses of 6' $667,133^{\prime} 333$ or $666^{\prime} 667$ cells/gBW and 6'667 cells/gBrW). Assessment of
A

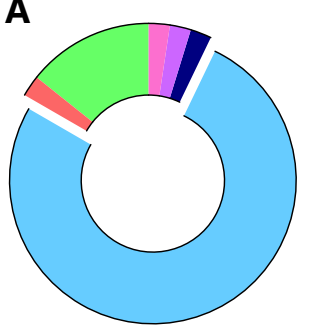

$\square$ Histochemistry / Immunohistochemistry, $76.19 \%$

$\square$ Flow Cytometry, $14.29 \%$

$\square$ Genetically modified mouse, $2.38 \%$

$\square$ Gene expression analysis, $2.38 \%$

In situ hybridization, $2.38 \%$

$\square$ Western Blot, $2.38 \%$
B Markers of Histochemistry / Immunohistochemistry
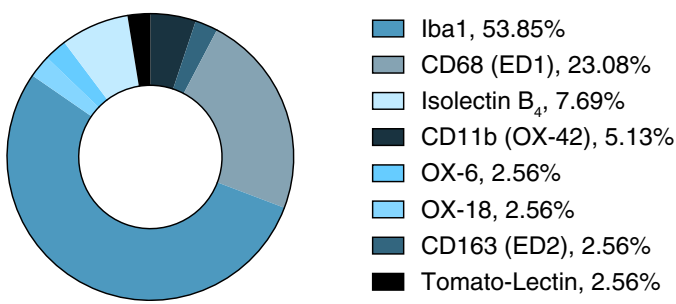

Fig. 3 Microglial phenotype-Tools and markers used in the rodent model of neonatal HIE, based on all studies in Tables 1, 2, 3 and 4. Pie charts showing (A) the frequency of technical approaches, in percentage of all methodologies and (B) the immunohistochemical markers used for the detection of microglia, in percentage of all markers. Of note stainings behavior, performed in four studies, revealed significant improvement in sensorimotor function (cliff aversion and

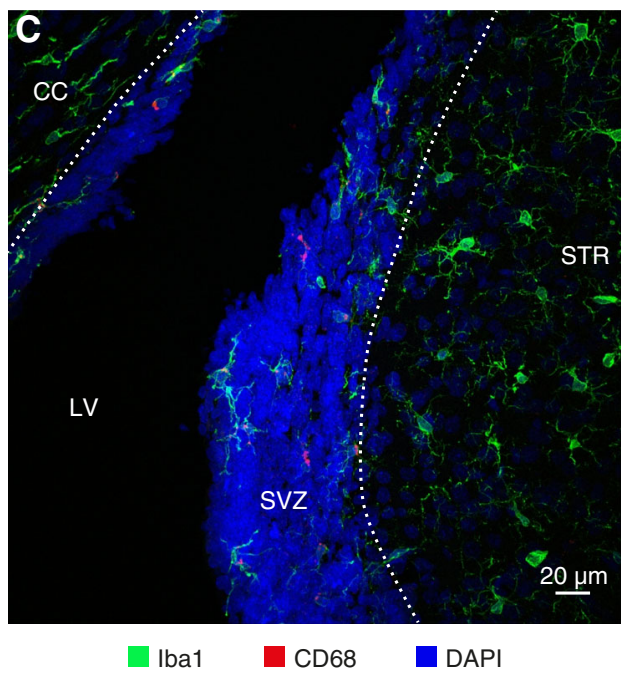

with Iba1 include single or double stainings (e.g. Iba1 with CD68 or with iNOS). (C) maximum image projection from a P30 rat exposed to $\mathrm{HI}$ and WJ-MSC treatment as an example of Iba1 and CD68 double immunostaining. CC: corpus callosum, LV: lateral ventricle, SVZ: subventricular zone, STR: striatum, dotted line marks SVZ area 
negative geotaxis reflex) in only one study, but this effect was transient, being observed four days post-HI, but not seven days post-HI [158]. In two studies, either sensorimotor function was not improved [159], or only trended towards improvement [160]. In two studies, HI-untreated animals did not show any deficits in motor function (gait analysis) [161], or learning (active avoidance test and novel object recognition test), thus rendering the assessment of therapeutic benefit of SC unattainable $[160,161]$. Absence of obvious deficits among HI untreated animals versus their sham counterparts was also anecdotally reported in [156], suggesting that some tests may be insensitive or that $\mathrm{HI}$ animals could be less affected. Neuroprotection was either detected and significant $[158,159]$, although in one report restricted to the striatum [158], or absent [160,161].

Conversely, four studies reported a significant elevation in Iba1-related immunohistochemical measurements (immunoreactivity/overall cell count of cells or of activated cells) in the striatum, periventricular striatum, somatosensory cortex at 7-, 29-, 43- and 49 days post-transplantation. In two independent studies, this elevation was reported to be transient [162], and region-specific [156]. Variability in sources, (human/ mouse NSCs or human UCB derived mononuclear cells) routes, i.c. (two studies), i.v. (one study) and i.p. (one study), timing of transplantation, $24 \mathrm{~h}$ (three studies) or seven days (one study) post-HI, and doses (66' 667 or $666^{\prime} 667$ cells/gBW for i.p. and i.v. and $300^{\prime} 000$ or 3'200'000 cells/gBrW for i.c. route) excludes a relation between microglial phenotype after SC treatment and any of these factors. Concomitantly, a significant improvement in sensorimotor functions was clearly observed in three studies, the report of Penny [156] being peculiar because HI-untreated animals did not show deficits in individual tests but the calculation of an overall behavioral burden score did reveal an improvement in the HI SC treated group. A common finding between these four studies is that neuroprotection, based on $\mathrm{H} \& \mathrm{E}$ or cresyl violet brain stainings, was not observed. In [156], an exacerbation of neuronal damage was even observed in the sensorimotor cortex after SC treatment. Nevertheless, the number of studies is too low to conclude on a relationship between an increase in Iba1-related measurements and SC associated amelioration in sensorimotor function.

Finally, three studies reported absence of modulation of Iba1-associated measures, such as count $[155,163]$, or CD68 immunointensity [159] after stem cell transplantation performed at either six or $24 \mathrm{~h}$ post-HI. In [163], rat adipose derived stem cells injected i.v. $24 \mathrm{~h}$ post-HI did not impact Iba1 microglial count or activation status in the cortex, hippocampus, and basal ganglia or serum chemokine/cytokine levels. The treatment also did not affect the number of apoptotic cells in the hippocampus, and was actually associated with an increased mortality, thus demonstrating a detrimental effect of these particular cells. In [155], i.p. transplantation of human UCB derived mononuclear cells or individual cell subtypes (at $24 \mathrm{~h}$ post-HI) show that transplantation of monocytes did not impact the number of activated Ibal cells in the cortex, and neither neuroprotection nor behavioral improvement were detected. I.c. transplantation of human UCB derived MSCs at $6 \mathrm{~h}$ post-HI was not associated with changes in CD68 immunointensity in the HI penumbra area, but neuroprotection was observed and HI-induced deficits in sensorimotor function remained. Nevertheless, combination of this treatment with hypothermia led to a reduction in CD68 immunointensity, together with a better neuroprotection and significant behavioral improvement [159].

Altogether, twelve studies reported a reduction in the activation of microglia upon SC administration, accompanied or not by a concomitant reduction in other cerebral or serum inflammation parameters. In some reports, but not all, this observation was accompanied by some degree of neuroprotection and/or improvement in behavioral outcome. In contrast, four studies reported an increase in these parameters typically accompanied by an improvement in behavioral outcome but not associated with significant neuroprotection. Absence of microglia modulation was also associated with absence of therapeutic benefit. Thus, overall the phenotype of microglia is modulated by SC transplantation, but bothlessened or augmented activation - phenotypes can be associated with a therapeutic benefit. Nonetheless, a major caveat in these studies is that the evaluation of the microglial phenotype relied mostly on single immunohistochemical stainings, which remains insufficient to fully capture the complexity of microglial response after treatment. Future studies could address it more precisely (using a combination of double immunostainings, and/or additional techniques i.e. flow cytometric, genomic and proteomic approaches) taking into account different developmental times and specific regions. The absence of a standardized methodology to assess changes in the microglial phenotype together with the multiplicity of experimental designs prevent for now any definitive conclusion.

\section{Transplanted SCs, microglia and neuroprotection/regeneration: mechanisms of the crosstalk}

Benefits of SC transplantation are currently mainly attributed to paracrine (over a short distance, i.e. within the damaged brain) and endocrine-like (over a long distance, i.e. from outside the injured brain) signaling, since evidence for cell differentiation and replacement remains scarce. SCs can migrate and home to the damaged brain (Table 4), as they express receptors for chemotactic cues such as stromal cell-derived factor-1 (SDF-1), but homing in the injured site may not be required to elicit benefits. SCs released factors, soluble or present in extracellular vesicles (EVs, e.g. exosomes, 
microvesicles) are thought to have pleiotropic activities in the host, including immunomodulatory, antiapoptotic, angiogenic, and neurotrophic effects. A particular interest in the role of EVs shed by exogenous SCs on endogenous microglia has recently emerged, as microglia appear crucial "EV recipient cells" in comparison to other cell types in the brain [164-166]. Until now three studies have investigated the therapeutic potential of bone marrow MSCs derived EVs (administration routes were either i.p., intranasal or intracardiac) in the murine model of neonatal HI, and all reported a reduction in microglial activation, with two studies also reporting functional benefits [167-169], similar to findings of studies using actual MSCs (Table 4). Thus, overall, a complex crosstalk between exogenous SCs, endogenous microglia and neuronal cells mediated by EVs may explain in part their therapeutic potential. A question remains though whether the EVs released by SCs after transplantation are of the same nature of those collected from in vitro cultured and expanded cells, as the diseased environment of the host may impact SCs secretion profile.

\section{Is Inflammation in HIE and CP Modulated by Stem Cell Treatment? Knowledge from Clinical Studies}

The tools allowing to evaluate the immune-system associated changes in living humans after cell-therapy are mainly the measurement of cytokine levels in plasma/serum or cerebrospinal fluid (CSF). Modern imaging techniques listed hereafter may also be useful, although with limitations. Positron emission tomography-computed tomography with the radiotracer ${ }^{18} \mathrm{~F}$-fluorodeoxyglucose $\left({ }^{18} \mathrm{FDG}\right.$ PET-CT $)$, which measures glucose metabolism, is a valuable tool, as inflammatory cells are highly glycolytic and foci of increased uptake of ${ }^{18} \mathrm{FDG}$ in the brain may be interpreted as sites of inflammation. Brain magnetic resonance imaging with diffusion tensor imaging sequences (MRI-DTI) provide relevant information on brain connectivity, indicative of white matter pathologies. Single-photon emission computed tomography (SPECT) can answer questions on inflammation, and on cerebral blood flow and blood brain barrier injury. These three imaging techniques are nevertheless not specific for immune-related changes, and therefore caution in data interpretation is warranted. In the past decade, clinical trials have investigated mainly safety, feasibility, and efficacy of cell-based therapies in HIE and CP (Table 5). Up to now, among 25 trials, we found three studies reporting on cytokine levels after SC transplantation, two in plasma $[170,171]$ of $\mathrm{CP}$ patients, and one in the CSF of intracerebral hemorrhage (IVH) patients [172]. ${ }^{18} \mathrm{FDG}$ PET-CT imaging was also performed in $[170,173]$ and three additional studies [174-176]; brain MRI-DTI data were reported in $[173,174,177,178]$ and SPECT data in [177]. To the best of our knowledge, studies using PET radioligands targeting the $18 \mathrm{kDa}$ translocator protein (TSPO), a surrogate marker of neuroinflammation (e.g. activated microglia and astrocytes), have not been performed in infants diagnosed with $\mathrm{CP}$ or an early HI brain injury. Promising studies in rodent models of adult stroke and in human stroke patients have been reported [179-181]; nevertheless, questions on cellular specificity persist, and insufficient binding affinity of these radioligands is documented in patients harboring polymorphisms in TSPO [182].

\section{General Considerations on SCs Used in Clinical Trials}

In clinical trials, umbilical cord blood (UCB) derived cells (i.e. total nucleated cells-TNCs, mononuclear cells-MNCs and MSCs) are the most frequently used cells (Fig. 4). SCs from neonatal tissue may display improved features in comparison to those isolated from adults, for instance MSCs derived from neonatal tissue display improved capacity for proliferation, expansion and engraftment in comparison to adult MSCs [183]. Cells from birth related tissue (UC, placenta) also raise no ethical issues; practically, they can be easily harvested and banked and are therefore rapidly available for both autologous or allogenic use in human patients. Alternative strategies for endogenous brain repair also include the mobilization of endogenous BM derived SCs to the bloodstream; this is typically achieved with granulocyte colony stimulating factor (G-CSF) but additional methods are being tested, for instance co-injection of NOx-12, a compound that acts in a similar fashion to G-CSF, with SDF-1 to promote recruitment of the cells and favor paracrine effects at site of injury, as reported in a model of retinal degeneration [184].

\section{Immune related findings in clinical trials}

Allogenic infusion of UCB-TNCs in CP patients resulted in elevated levels of plasma pentraxin 3 (PTX3), interleukin-8 (IL-8) and in an increased number of blood cells expressing Toll-like receptor 4 (TLR4) during a consecutive short period after infusion. The elevation in PTX3, IL-8 and TLR4 levels correlated with a better Gross Motor Function Measure (GMPM) outcome up to six months after treatment [170]. The role of the cytokine PTX3 is not fully understood but several studies suggest an anti-inflammatory, protective effect in various conditions [185-187]. IL-8 is a chemokine that promotes chemotaxis towards the injured area and was shown to have an angiogenic effect [188]. A study further investigating the role of PTX and TLR4 after allogenic UCB infusion in CP is currently pending (NCT03130816). In that same study, two weeks after treatment, a decreased activity in ${ }^{18} \mathrm{FDG}$ PET-CT in the white matter of the occipital and temporal areas was detected. The authors interpreted this finding as an anti-inflammatory effect of UCB-TNC, as these areas are 


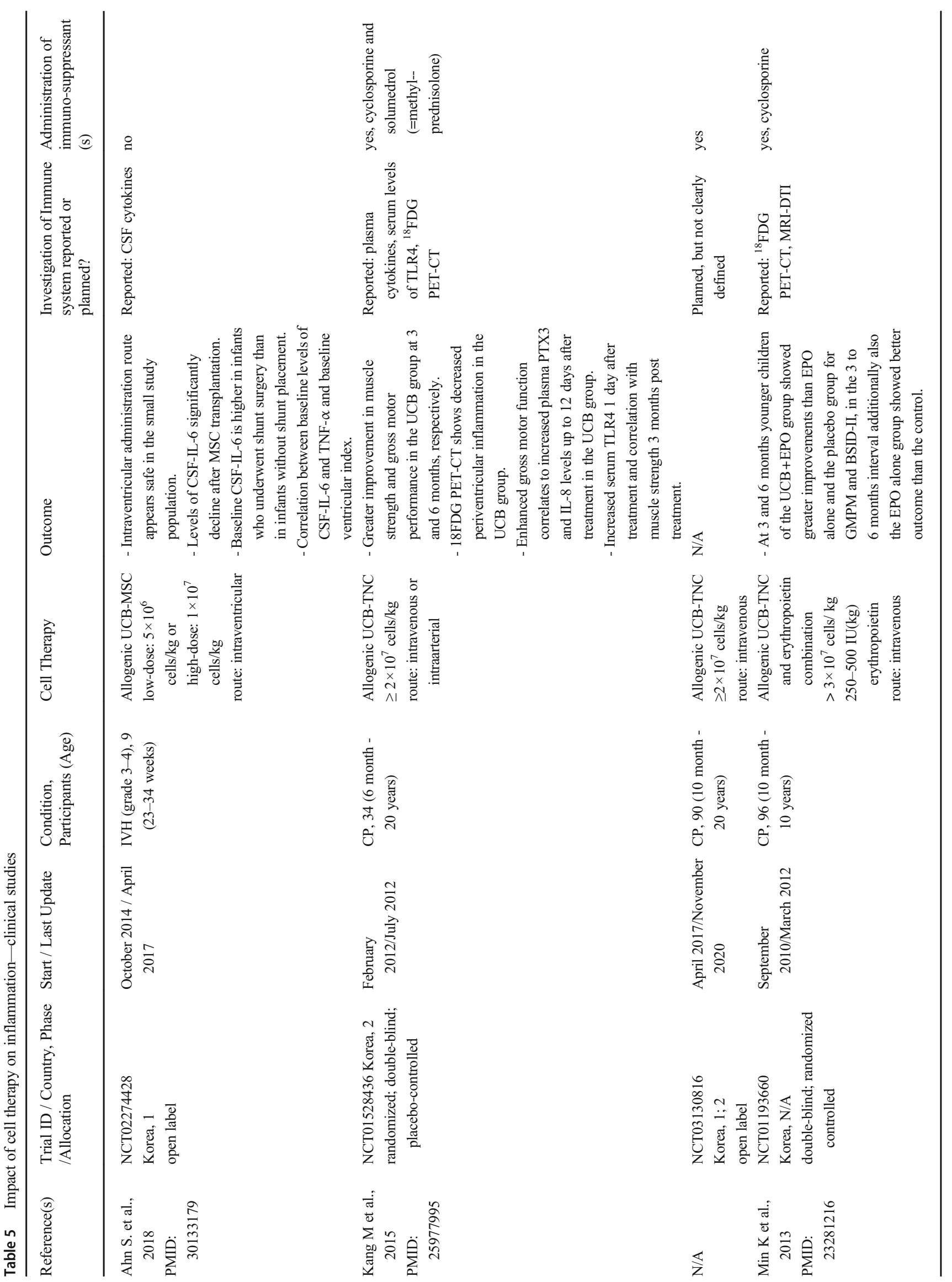




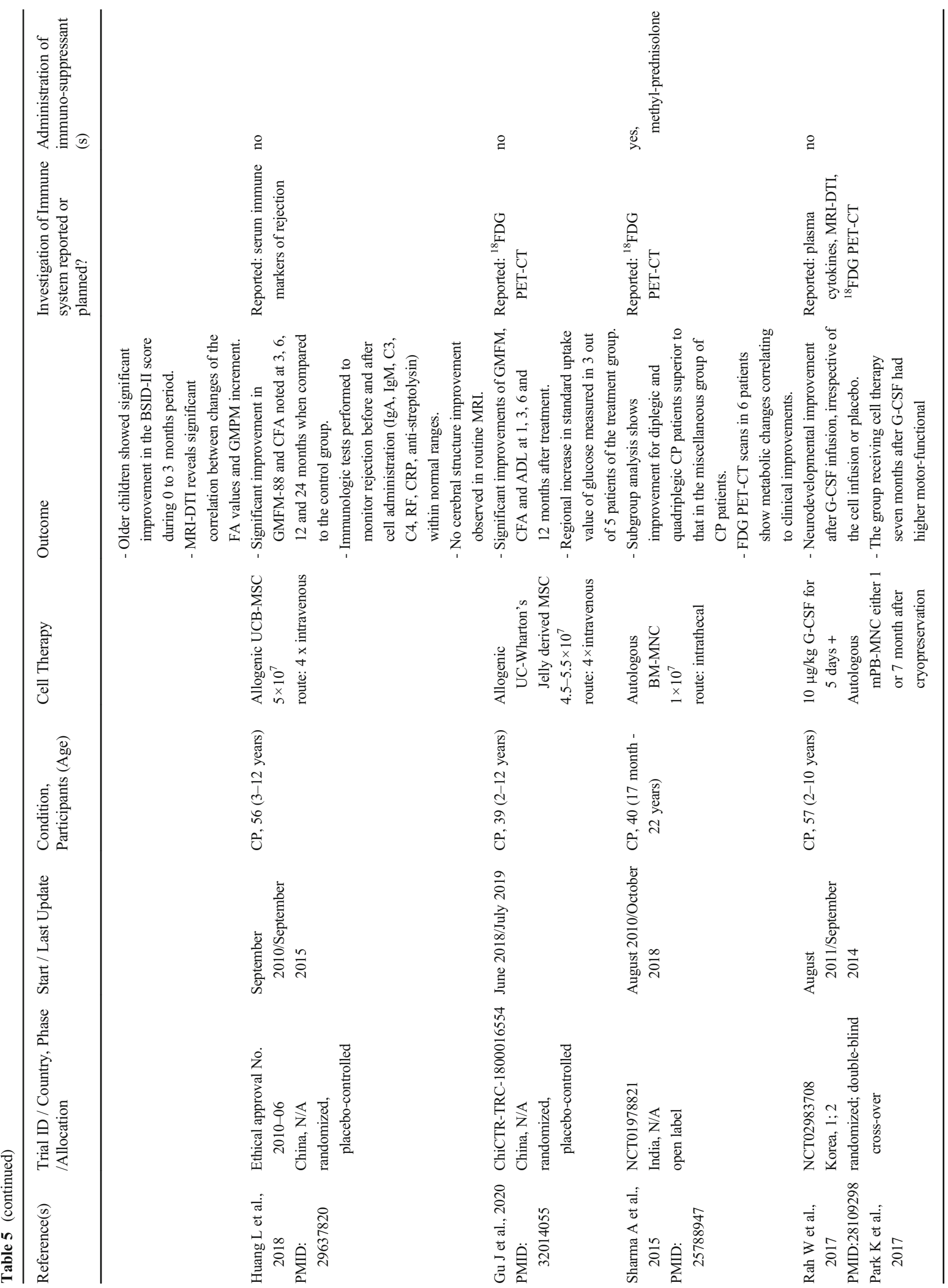




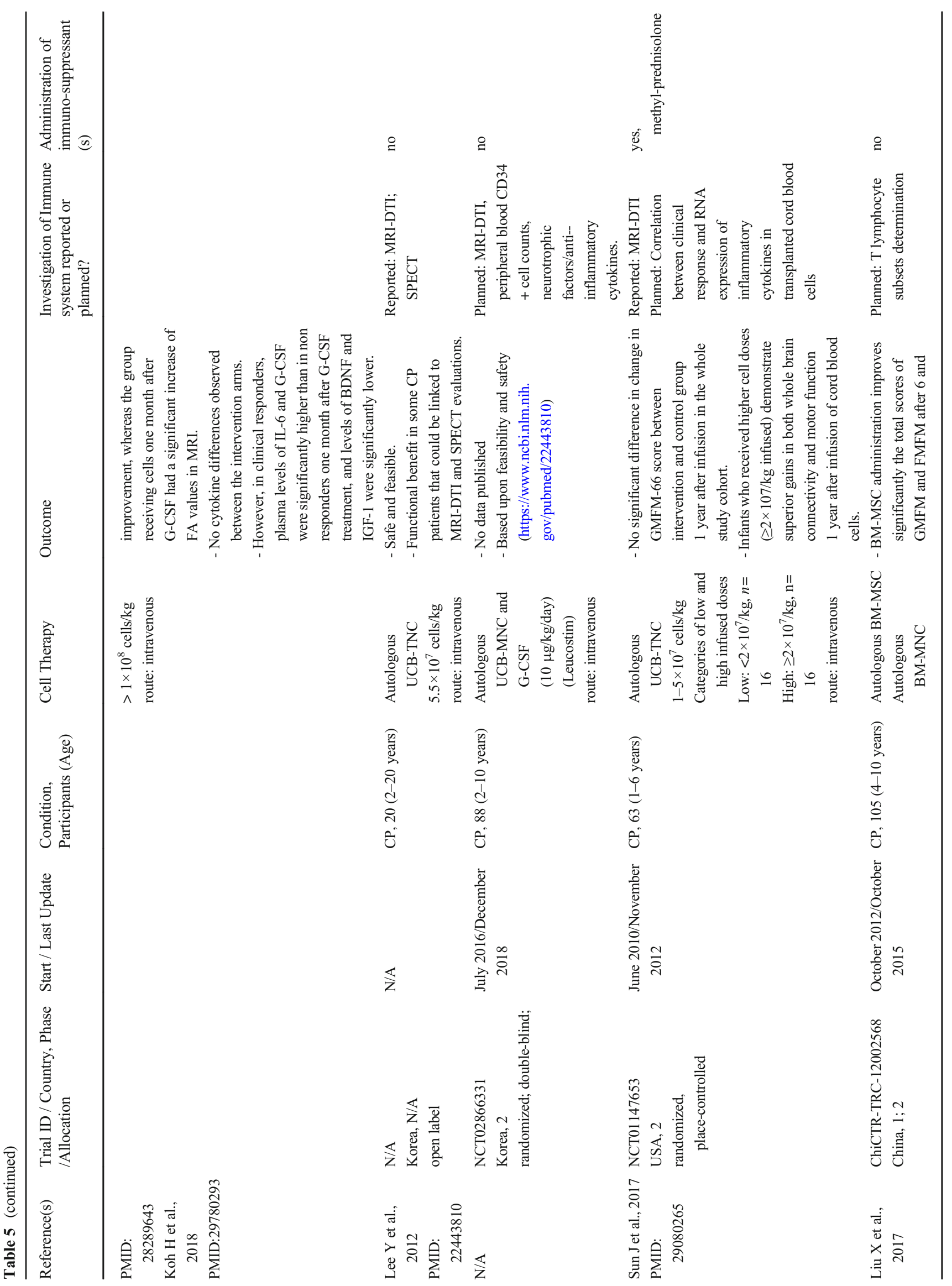




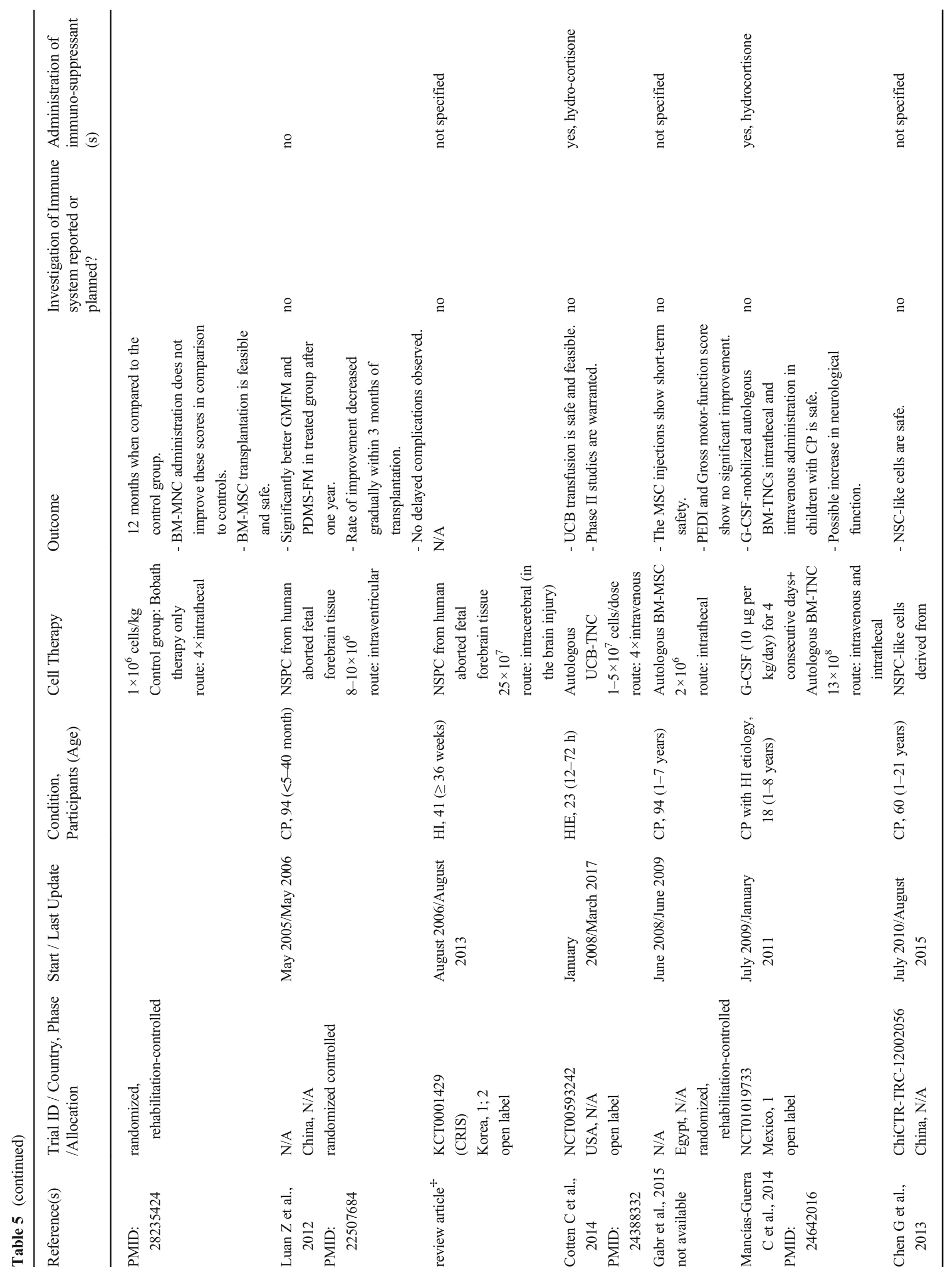




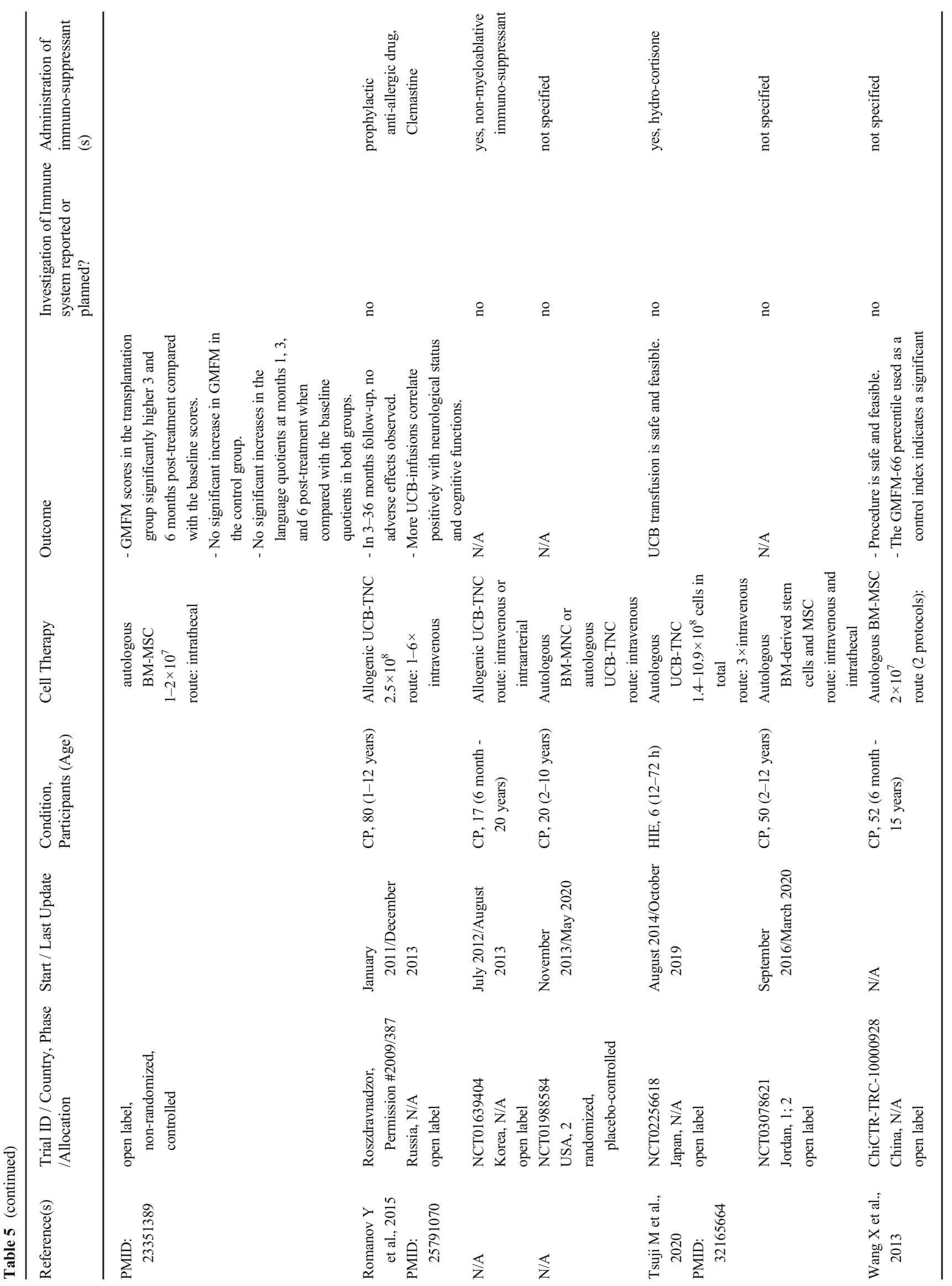




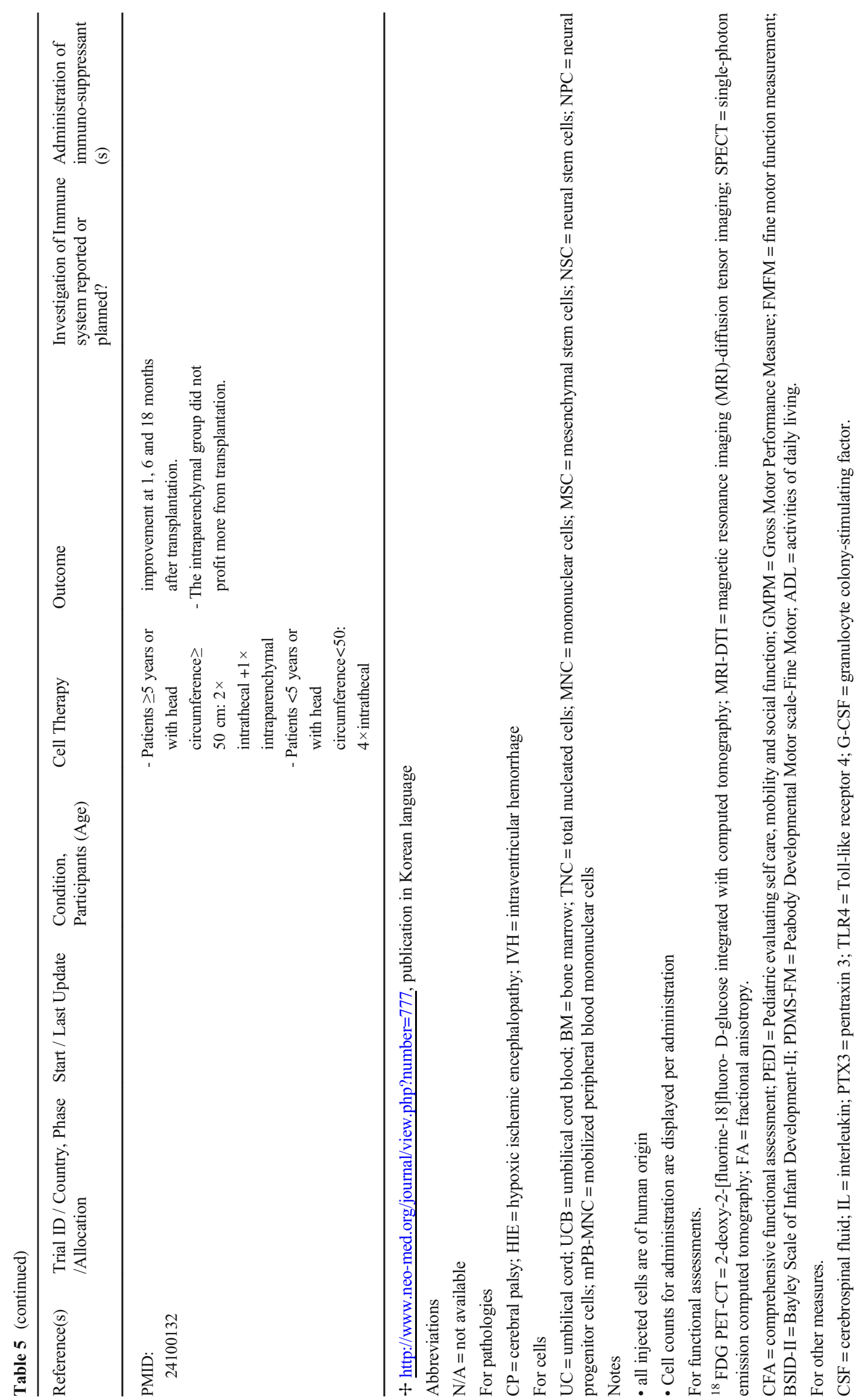


A Type of transplanted Stem Cells

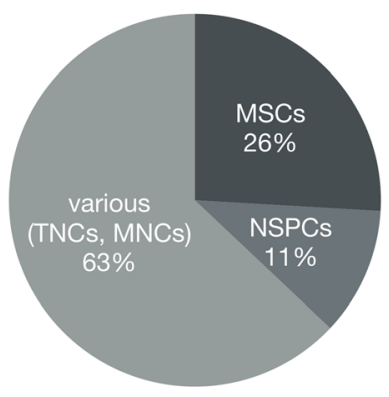

B Origin

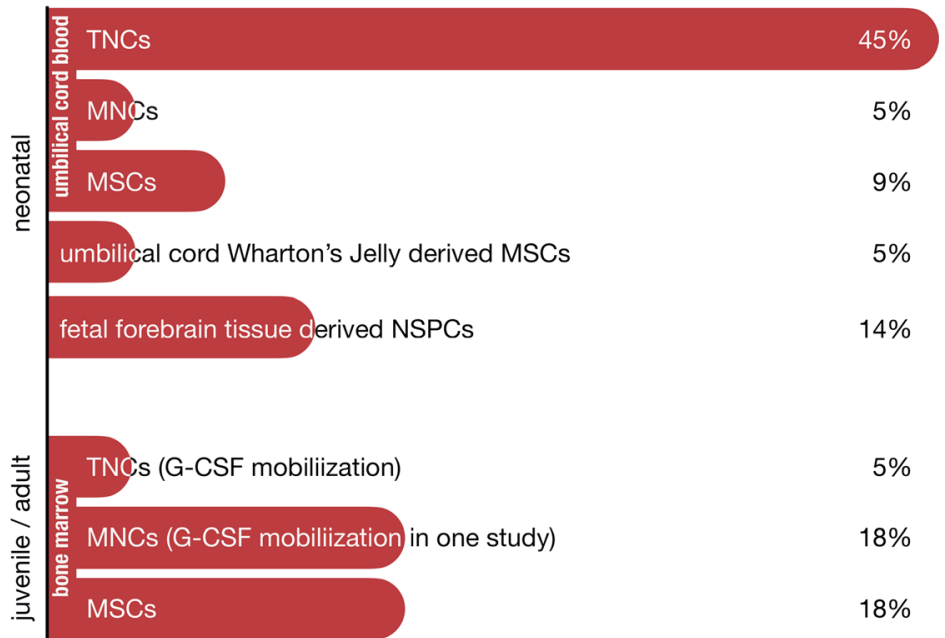

Fig. 4 Umbilical cord blood derived cells are most frequently used in human clinical trials. (A) Pie chart showing percentage of the types of stem cells tested in trials. (B) Bar graph displaying origin of the transplanted stem cells and corresponding percentages. For both charts, percentages were calculated from all studies listed in Table 5

period of reinfusion of cells. Overall, no significant difference in plasma levels of the following factors, i.e. G-CSF, brain-derived neurotrophic factor (BDNF), vascular endothelial growth factor (VEGF), insulin-like growth factor IGF-1, IL-6, IL-8, IL-10 was observed between the intervention arms. However, in clinical responders, plasma levels of IL-6 and G-CSF were higher one month after G-CSF infusion, and levels of IGF-1 and BDNF were lower, suggesting that these cytokines may be used as prognostic factors in G-CSF trials and that they may be associated with the G-CSF driven neurological improvements. MRI-DTI showed significantly higher FA-values in patients who received cell therapy one month after G-CSF treatment in comparison to those who received it seven months later, suggesting a possible synergetic effect if mPB-MNC are infused shortly after G-CSF, although ${ }^{18}$ FDG-PET did not show the expected differences [171, 173, 192]. In another study enrolling $18 \mathrm{CP}$ patients, mPB-MNC were considered safe for combined intrathecal/ intravenous administration with possible benefit on neurological function at six months after infusion. In that study the collection and reinfusion of cells were performed on the same day, four days after G-CSF mobilization [193]. Since G-CSF is an immune system stimulating factor, its contribution to positive effects cannot be ruled out; a clinical trial including a study arm with G-CSF alone is registered (NCT02866331, last updated 2016).

In a clinical study assessing the effect of intraventricular administration of allogenic UBC derived MSC in nine preterm infants with severe intracerebral hemorrhage (IVH), the CSF levels of IL- $1 \beta$, IL- 6 , TNF- $\alpha$, VEGF, TGF- $\beta 1 / 2$, BDNF and fibroblast growth factor (FGF) were investigated before and after MSC transplantation [172]. Results showed that the concentration of IL-6 significantly declined after transplantation, 
while that of other cytokines or growth factors also tended to decline, but not significantly. Of note, the baseline levels of IL-6 were significantly higher in infants with shunt surgery than in infants without, which may confound the results observed after MSC transplantation. A correlation between baseline CSF levels of IL- 6 and TNF- $\alpha$ and ventricular index was observed. Authors suggest that these cytokines may be used as markers of early neuronal injury, but also acknowledge the small sample size and the need for further studies. In a trial using autologous BM derived MSC in $40 \mathrm{CP}$ patients, ${ }^{18} \mathrm{FDG}$ PET-CT changes were observed correlating to clinical improvement after intrathecal administration [175]. A safety study comparing an intraparenchymal with intrathecal administration of autologous BM-MSCs did not find a superior effect of intraparenchymal versus intrathecal administration, supporting again the hypothesis of paracrine signaling for SC-mediated positive outcome. Of note, the invasive intraparenchymal access was also considered safe [194]. In contrast, one study also testing autologous BM derived MSC in $94 \mathrm{CP}$ patients showed no functional short-term improvements [195]. Allogenic MSC derived from UCB or UC Wharton's Jelly were also tested in two Chinese studies and showed motor-functional improvements during twelve [176] and 24 months [196] of follow up, respectively. Improvements in cerebral structure could not be observed in MRI-DTI, but ${ }^{18}$ FDG-PET revealed increased glucose uptake in some patients of the treatment group which could support functional improvements, since lowered glucose metabolism can be found in CP patients [197].

Overall, the efficacy of stem cells via the modulation of the immune system at this stage remains hypothetical given the limited number of studies. Immunosuppressive or stimulating growth factors like cyclosporine and G-CSF may play a role in the inflammatory status of the brain or other organs which eventually could confound the results.

\section{Conclusion}

Stem cell-based therapies hold promise as alternative or complementary neuroprotective/regenerative therapeutic strategies for infants diagnosed with neonatal HIE or CP. In a context where these therapies are being advertised by uncontrolled institutes, and understandably, families are eager to offer treatment to their children to ameliorate the persisting neurological disabilities, it is crucial to improve our basic understanding of their mechanism of action to eventually optimize and advance the clinical development of SC protocols.

Our review of the preclinical literature indicates that stem cell treatments can modulate the microglial phenotype after neonatal HI, but a causal link between this immune-related modulation and neuroprotection is difficult to establish, due partly to a limited number of studies, caveats in methodology and highly heterogenous experimental designs. The concept that microglia may be a therapeutic target is appealing [152], but in its current state, requires further research. Clinical data on immunomodulation after SC transplantation in HIE and $\mathrm{CP}$ patients remain anecdotical and hold considerable uncertainties that also call for further investigations. Collaborative efforts between researchers and medical practitioners from different fields (neurodevelopment, neuroimmunology, neurobehavior, pediatry, neurosurgery) as well as general guidelines as to how to characterize microglia -similar to those established for macrophages- and various immune related parameters, would advance our understanding of the link between the cerebral immune system, microglia and neuroprotection.

Acknowledgements The authors thank Simona Falbo for helping to prepare Table 5 on clinical trials of stem cell therapy for cerebral palsy, HIE and IVH patients.

Authors' Contributions $\mathrm{CB}$ and RG discussed and established the plan of the manuscript. $\mathrm{CB}, \mathrm{BS}$ and $\mathrm{BR}$ conducted the literature search, analyzed the literature, and prepared the figures and Tables. CB wrote the draft with input of all authors. RG revised the final manuscript. All authors approved the submitted version.

Funding Open Access funding provided by Universität Basel (Universitätsbibliothek Basel). This research was supported by the Neurosurgery department and the Department of Biomedicine of the University Hospital Basel.

Availability of Data and Material Not applicable.

Code Availability Not applicable.

\section{Declarations}

Conflicts of Interest/Competing Interests Not applicable.

Ethics Approval Not applicable.

Consent to Participate Not applicable.

Consent for Publication Not applicable.

Open Access This article is licensed under a Creative Commons Attribution 4.0 International License, which permits use, sharing, adaptation, distribution and reproduction in any medium or format, as long as you give appropriate credit to the original author(s) and the source, provide a link to the Creative Commons licence, and indicate if changes were made. The images or other third party material in this article are included in the article's Creative Commons licence, unless indicated otherwise in a credit line to the material. If material is not included in the article's Creative Commons licence and your intended use is not permitted by statutory regulation or exceeds the permitted use, you will need to obtain permission directly from the copyright holder. To view a copy of this licence, visit http://creativecommons.org/licenses/by/4.0/. 


\section{References}

1. Parker, S. J., Kuzniewicz, M., Niki, H., \& Wu, Y. W. (2018). Antenatal and intrapartum risk factors for hypoxic-ischemic encephalopathy in a US birth cohort. Journal of Pediatrics, 203, 163-169.

2. Kurinczuk, J. J., White-Koning, M., \& Badawi, N. (2010). Epidemiology of neonatal encephalopathy and hypoxicischaemic encephalopathy. Early Human Development, 86(6), 329-338.

3. Lawn, J. E., Cousens, S., Zupan, J., \& Lancet Neonatal Survival Steering, T. (2005). 4 million neonatal deaths: when? Where? Why? Lancet, 365(9462), 891-900.

4. Mwaniki, M. K., Atieno, M., Lawn, J. E., \& Newton, C. R. J. C. (2012). Long-term neurodevelopmental outcomes after intrauterine and neonatal insults: A systematic review. The Lancet, 379, $445-452$.

5. Jacobs, S. E., Berg, M., Hunt, R., Tarnow-Mordi, W. O., Inder, T. E., \& Davis, P. G. (2013). Cooling for newborns with hypoxic ischaemic encephalopathy. Cochrane Database of Systematic Reviews(1), CD003311.

6. Lee, J. H., Zhang, J., \& Yu, S. P. (2017). Neuroprotective mechanisms and translational potential of therapeutic hypothermia in the treatment of ischemic stroke. Neural Regeneration Research, 12(3), 341-350.

7. Daadi, M. M., Davis, A. S., Arac, A., Li, Z., Maag, A. L., Bhatnagar, R., Jiang, K., Sun, G., Wu, J. C., \& Steinberg, G. K. (2010). Human neural stem cell grafts modify microglial response and enhance axonal sprouting in neonatal hypoxic-ischemic brain injury. Stroke, 41, 516-523.

8. de Paula, S., Greggio, S., Marinowic, D. R., Machado, D. C., \& DaCosta, J. C. (2012). The dose-response effect of acute intravenous transplantation of human umbilical cord blood cells on brain damage and spatial memory deficits in neonatal hypoxia-ischemia. Neuroscience, 210, 431-441.

9. Ashwal, S., Ghosh, N., Turenius, C. I., Dulcich, M., Denham, C. M., Tone, B., Hartman, R., Snyder, E. Y., \& Obenaus, A. (2014). Reparative effects of neural stem cells in neonatal rats with hypoxic-ischemic injury are not influenced by host sex. Pediatric Research, 75, 603-611.

10. Braccioli, L., Heijnen, C. J., Coffer, P. J., \& Nijboer, C. H. (2017). Delayed administration of neural stem cells after hypoxiaischemia reduces sensorimotor deficits, cerebral lesion size, and neuroinflammation in neonatal mice. Pediatric Research, 81, 127-135.

11. Eggenberger, S., Boucard, C., Schoeberlein, A., Guzman, R., Limacher, A., Surbek, D., \& Mueller, M. (2019). Stem cell treatment and cerebral palsy: Systemic review and meta-analysis. World J Stem Cells, 11(10), 891-903.

12. Jin, Y., Silverman, A. J., \& Vannucci, S. J. (2007). Mast cell stabilization limits hypoxic-ischemic brain damage in the immature rat. Developmental Neuroscience, 29(4-5), 373-384.

13. Jin, Y., Silverman, A. J., \& Vannucci, S. J. (2009). Mast cells are early responders after hypoxia-ischemia in immature rat brain. Stroke; A Journal of Cerebral Circulation, 40, 3107-3112.

14. Umekawa, T., Osman, A. M., Han, W., Ikeda, T., \& Blomgren, K. (2015). Resident microglia, rather than blood-derived macrophages, contribute to the earlier and more pronounced inflammatory reaction in the immature compared with the adult hippocampus after hypoxia-ischemia. Glia, 63, 2220-2230.

15. Smith, P. L. P., Mottahedin, A., Svedin, P., Mohn, C. J., Hagberg, H., Ek, J., \& Mallard, C. (2018). Peripheral myeloid cells contribute to brain injury in male neonatal mice. Journal of Neuroinflammation, 15, 301.
16. Hudome, S., Palmer, C., Roberts, R. L., Mauger, D., Housman, C., \& Towfighi, J. (1997). The role of neutrophils in the production of hypoxic-ischemic brain injury in the neonatal rat. Pediatric Research, 41(5), 607-616.

17. Bona, E., Andersson, A. L., Blomgren, K., Gilland, E., PukaSundvall, M., Gustafson, K., \& Hagberg, H. (1999). Chemokine and inflammatory cell response to hypoxia-ischemia in immature rats. Pediatric Research, 45, 500-509.

18. Palmer, C., Roberts, R. L., \& Young, P. I. (2004). Timing of neutrophil depletion influences long-term neuroprotection in neonatal rat hypoxic-ischemic brain injury. Pediatric Research, 55(4), 549-556.

19. Fathali, N., Ostrowski, R. P., Hasegawa, Y., Lekic, T., Tang, J., \& Zhang, J. H. (2013). Splenic immune cells in experimental neonatal hypoxia-ischemia. Translational Stroke Research, 4(2), 208219.

20. Winerdal, M., Winerdal, M. E., Kinn, J., Urmaliya, V., Winqvist, O., \& Ådén, U. (2012). Long lasting local and systemic inflammation after cerebral hypoxic ischemia in newborn mice. PLoS One, 7, e36422.

21. Herz, J., Köster, C., Crasmöller, M., Abberger, H., Hansen, W. Felderhoff-Müser, U., \& Bendix, I. (2018). Peripheral T cell depletion by FTY720 exacerbates hypoxic-ischemic brain injury in neonatal mice. Frontiers in Immunology, 9, 1696.

22. Ratajczak, M. Z., Mack, A., Bujko, K., Domingues, A., Pedziwiatr, D., Kucia, M., Ratajczak, J., Ulrich, H., KucharskaMazur, J., \& Samochowiec, J. (2019). ATP-N1rp3 Inflammasome-complement Cascade Axis in sterile brain inflammation in psychiatric patients and its impact on stem cell trafficking. Stem Cell Reviews and Reports, 15(4), 497-505.

23. Szaflarski, J., Burtrum, D., \& Silverstein, F. S. (1995). Cerebral hypoxia-ischemia stimulates cytokine gene expression in perinatal rats. Stroke, 26, 1093-1100.

24. Hagberg, H., Gilland, E., Bona, E., Hanson, L. Å., Hahn-Zoric, M., Blennow, M., Holst, M., McRae, A., \& Söder, O. (1996). Enhanced expression of interleukin (IL)-1 and IL-6 messenger RNA and bioactive protein after hypoxia-ischemia in neonatal rats. Pediatric Research, 40, 603-609.

25. Ivacko, J., Szaflarski, J., Malinak, C., Flory, C., Warren, J. S., \& Silverstein, F. S. (1997). Hypoxic-ischemic injury induces monocyte chemoattractant protein-1 expression in neonatal rat brain. Journal of Cerebral Blood Flow and Metabolism, 17(7), 759-770.

26. Xu, H., Barks, J. D. E., Schielke, G. P., \& Silverstein, F. S. (2001). Attenuation of hypoxia-ischemia-induced monocyte chemoattractant protein-1 expression in brain of neonatal mice deficient in interleukin-1 converting enzyme. Molecular Brain Research, 90, 57-67.

27. Cowell, R. M., Xu, H., Galasso, J. M., \& Silverstein, F. S. (2002) Hypoxic-ischemic injury induces macrophage inflammatory protein- $1 \alpha$ expression in immature rat brain. Stroke, 33, 795-801.

28. Hedtjärn, M., Leverin, A. L., Eriksson, K., Blomgren, K., Mallard, C., \& Hagberg, H. (2002). Interleukin-18 involvement in hypoxicischemic brain injury. Journal of Neuroscience, 22, 5910-5919.

29. Hedtjärn, M., Mallard, C., Iwakura, Y., \& Hagberg, H. (2005). Combined deficiency of IL-1 $\beta 18$, but not IL- $1 \alpha \beta$, reduces susceptibility to hypoxia-ischemia in the immature brain. Developmental Neuroscience, 27, 143-148.

30. Van Den Tweel, E. R. W., Kavelaars, A., Lombardi, M. S., Nijboer, C. H. A., Groenendaal, F., Van Bel, F., \& Heijnen, C. J. (2006). Bilateral molecular changes in a neonatal rat model of unilateral hypoxic-ischemic brain damage. Pediatric Research, 59, 434-439.

31. Bonestroo, H. J. C., Nijboer, C. H. A., Van Velthoven, C. T. J., Kavelaars, A., Hack, C. E., Van Bel, F., \& Heijnen, C. J. (2013). Cerebral and hepatic inflammatory response after neonatal 
hypoxia-ischemia in newborn rats. Developmental Neuroscience, 35, 197-211.

32. Furukawa, S., Sameshima, H., Yang, L., Harishkumar, M., \& Ikenoue, T. (2014). Regional differences of microglial accumulation within 72 hours of hypoxia-ischemia and the effect of acetylcholine receptor agonist on brain damage and microglial activation in newborn rats. Brain Research, 1562, 52-58.

33. Hagberg, H., Mallard, C., Ferriero, D. M., Vannucci, S. J., Levison, S. W., Vexler, Z. S., \& Gressens, P. (2015). The role of inflammation in perinatal brain injury. Nature Reviews. Neurology, 11(4), 192-208.

34. Li, B., Concepcion, K., Meng, X., \& Zhang, L. (2017). Brainimmune interactions in perinatal hypoxic-ischemic brain injury. Progress in Neurobiology, 159, 50-68.

35. Ziemka-Nalecz, M., Jaworska, J., \& Zalewska, T. (2017). Insights into the Neuroinflammatory responses after neonatal hypoxia-ischemia. Journal of Neuropathology and Experimental Neurology, 76(8), 644-654.

36. Li, Q., \& Barres, B. A. (2018). Microglia and macrophages in brain homeostasis and disease. Nature Reviews. Immunology, 18(4), 225-242.

37. Rosenbaum, P., Paneth, N., Leviton, A., Goldstein, M., Bax, M., Damiano, D., Dan, B., \& Jacobsson, B. (2007). A report: the definition and classification of cerebral palsy April 2006. Developmental Medicine and Child Neurology. Supplement, 109, 8-14.

38. Quinn, J. A., Munoz, F. M., Gonik, B., Frau, L., Cutland, C., Mallett-Moore, T., Kissou, A., Wittke, F., Das, M., Nunes, T., Pye, S., Watson, W., Ramos, A. M. A., Cordero, J. F., Huang, W. T., Kochhar, S., \& Buttery, J. (2016). Preterm birth: Case definition \& guidelines for data collection, analysis, and presentation of immunisation safety data. Vaccine, 34, 6047-6056.

39. Reddy, U. M., Bettegowda, V. R., Dias, T., Yamada-Kushnir, T., Ko, C. W., \& Willinger, M. (2011). Term pregnancy: A period of heterogeneous risk for infant mortality. Obstetrics and Gynecology, 117, 1279-1287.

40. Committee opinion no 579. (2013). Definition of term pregnancy. Obstetrics and Gynecology, 122, 1139-1140.

41. Schneider, M. (2013). Adolescence as a vulnerable period to alter rodent behavior. Cell and Tissue Research, 354(1), 99-106.

42. Jackson, S. J., Andrews, N., Ball, D., Bellantuono, I., Gray, J., Hachoumi, L., Holmes, A., Latcham, J., Petrie, A., Potter, P., Rice, A., Ritchie, A., Stewart, M., Strepka, C., Yeoman, M., \& Chapman, K. (2017). Does age matter? The impact of rodent age on study outcomes. Laboratory Animals, 51, 160-169.

43. Johnston, M. V. (1998). Selective vulnerability in the neonatal brain. Annals of Neurology, 44, 155-156.

44. Johnston, M. V., \& Hoon, J. (2000). Possible mechanisms in infants for selective basal ganglia damage from asphyxia, kernicterus, or mitochondrial encephalopathies. Journal of Child Neurology, 15, 588-591.

45. Fleiss, B., \& Gressens, P. (2012). Tertiary mechanisms of brain damage: a new hope for treatment of cerebral palsy? Lancet Neurology, 11(6), 556-566.

46. Rice, J. E., Vannucci, R. C., \& Brierley, J. B. (1981). The influence of immaturity on hypoxic-ischemic brain damage in the rat. Annals of Neurology, 9, 131-141.

47. Ditelberg, J. S., Sheldon, R. A., Epstein, C. J., \& Ferriero, D. M. (1996). Brain injury after perinatal hypoxia-ischemia is exacerbated in copper/zinc superoxide dismutase transgenic mice. Pediatric Research, 39, 204-208.

48. Ferriero, D. M., Holtzman, D. M., Black, S. M., \& Sheldon, R. A. (1996). Neonatal mice lacking neuronal nitric oxide synthase are less vulnerable to hypoxic-ischemic injury. Neurobiology of Disease, 3, 64-71.
49. Dwyer, B. E., Nishimura, R. N., \& Fujikawa, D. G. (1988). Cerebral hypoxia-ischemia in immature rats: Methodological considerations. Experimental Neurology, 99, 772-777.

50. Hylton, C. M., Pesenson, M. A., \& Welsh, F. A. (1995). Adaptive preservation of ATP and tolerance to hypoxia following carotid artery ligation in the immature rat. Journal of Cerebral Blood Flow and Metabolism, 15, 1137-1140.

51. Coyle, P., \& Panzenbeck, M. J. (1990). Collateral development after carotid artery occlusion in fischer 344 rats. Stroke, 21, 316 321.

52. Bronner, G., Mitchell, K., \& Welsh, F. A. (1998). Cerebrovascular adaptation after unilateral carotid artery ligation in the rat: Preservation of blood flow and ATP during forebrain ischemia. Journal of Cerebral Blood Flow and Metabolism, 18, 118-121.

53. Rakhade, S. N., Klein, P. M., Huynh, T., Hilario-Gomez, C., Kosaras, B., Rotenberg, A., \& Jensen, F. E. (2011). Development of later life spontaneous seizures in a rodent model of hypoxia-induced neonatal seizures. Epilepsia, 52, 753-765.

54. Rodriguez-Alvarez, N., Jimenez-Mateos, E. M., Dunleavy, M., Waddington, J. L., Boylan, G. B., \& Henshall, D. C. (2015). Effects of hypoxia-induced neonatal seizures on acute hippocampal injury and later-life seizure susceptibility and anxiety-related behavior in mice. Neurobiology of Disease, 83, 100-114.

55. Liu, X. H., Kwon, D., Schielke, G. P., Yang, G. Y., Silverstein, F. S., \& Barks, J. D. E. (1999). Mice deficient in interleukin-1 converting enzyme are resistant to neonatal hypoxic-ischemic brain damage. Journal of Cerebral Blood Flow and Metabolism, 19, 1099-1108.

56. Patel, S. D., Pierce, L., Ciardiello, A., Hutton, A., Paskewitz, S., Aronowitz, E., Voss, H. U., Moore, H., \& Vannucci, S. J. (2015). Therapeutic hypothermia and hypoxia-ischemia in the termequivalent neonatal rat: Characterization of a translational preclinical model. Pediatric Research, 78, 264-271.

57. Brégère, C., Fisch, U., Sailer, M. H., Lieb, W. S., Chicha, L., Goepfert, F., Kremer, T., \& Guzman, R. (2017). Neonatal hypoxia-ischemia in rat increases doublecortin concentration in the cerebrospinal fluid. The European Journal of Neuroscience, 46(2), 1758-1767.

58. Ten, V. S., Bradley-Moore, M., Gingrich, J. A., Stark, R. I., \& Pinsky, D. J. (2003). Brain injury and neurofunctional deficit in neonatal mice with hypoxic-ischemic encephalopathy. Behavioural Brain Research, 145, 209-219.

59. Jansen, E. M., \& Low, W. C. (1996). Long-term effects of neonatal ischemic-hypoxic brain injury on sensorimotor and locomotor tasks in rats. Behavioural Brain Research, 78, 189-194.

60. Bona, E., Johansson, B. B., \& Hagberg, H. (1997). Sensorimotor function and neuropathology five to six weeks after hypoxiaischemia in seven-day-old rats. Pediatric Research, 42, 678-683.

61. Ikeda, T., Mishima, K., Yoshikawa, T., Iwasaki, K., Fujiwara, M., Xia, Y. X., \& Ikenoue, T. (2001). Selective and long-term learning impairment following neonatal hypoxic-ischemic brain insult in rats. Behavioural Brain Research, 118, 17-25.

62. Grow, J. L., Liu, Y. Q., \& Barks, J. D. (2003). Can lateralizing sensorimotor deficits be identified after neonatal cerebral hypoxiaischemia in rats? Developmental Neuroscience, 25(6), $394-402$.

63. Dobbing, J., \& Sands, J. (1979). Comparative aspects of the brain growth spurt. Early Human Development, 3, 79-83.

64. Romijn, H. J., Hofman, M. A., \& Gramsbergen, A. (1991). At what age is the developing cerebral cortex of the rat comparable to that of the full-term newborn human baby? Early Human Development, 26, 61-67.

65. Craig, A., Luo, N. L., Beardsley, D. J., Wingate-Pearse, N., Walker, D. W., Hohimer, A. R., \& Back, S. A. (2003). Quantitative analysis of perinatal rodent oligodendrocyte lineage progression and its correlation with human. Experimental Neurology, 181, 231-240. 
66. Neonatal encephalopathy. (2014). Pre-clinical studies in neuroprotection (Vol. 42, pp. 564-568). Portland Press Ltd.

67. Clancy, B., Darlington, R. B., \& Finlay, B. L. (2001). Translating developmental time across mammalian species. Neuroscience, $105,7-17$.

68. Workman, A. D., Charvet, C. J., Clancy, B., Darlington, R. B., \& Finlay, B. L. (2013). Modeling transformations of neurodevelopmental sequences across mammalian species. Journal of Neuroscience, 33, 7368-7383.

69. Ohmura, Y., \& Kuniyoshi, Y. (2017). A translational model to determine rodent's age from human foetal age. Scientific Reports, 7, 17248.

70. Volpe, J. J. (2009). The encephalopathy of prematurity-brain injury and impaired brain development inextricably intertwined. Seminars in Pediatric Neurology 16(4), 167-178.

71. Towfighi, J., Mauger, D., Vannucci, R. C., \& Vannucci, S. J. (1997). Influence of age on the cerebral lesions in an immature rat model of cerebral hypoxia-ischemia: A light microscopic study. Developmental Brain Research, 100, 149-160.

72. Back, S. A., Han, B. H., Luo, N. L., Chricton, C. A., Xanthoudakis, S., Tam, J., Arvin, K. L., \& Holtzman, D. M. (2002). Selective vulnerability of late oligodendrocyte progenitors to hypoxia-ischemia. Journal of Neuroscience, 22, 455-463.

73. McQuillen, P. S., Sheldon, R. A., Shatz, C. J., \& Ferriero, D. M. (2003). Selective vulnerability of subplate neurons after early neonatal hypoxia-ischemia. The Journal of Neuroscience, 23(8), 3308-3315.

74. Sizonenko, S. V., Kiss, J. Z., Inder, T., Gluckman, P. D., \& Williams, C. E. (2005). Distinctive neuropathologic alterations in the deep layers of the parietal cortex after moderate ischemichypoxic injury in the P3 immature rat brain. Pediatric Research, 57, 865-872.

75. Quairiaux, C., Sizonenko, S. V., Mégevand, P., Michel, C. M., \& Kiss, J. Z. (2010). Functional deficit and recovery of developing sensorimotor networks following neonatal hypoxic-ischemic injury in the rat. Cerebral Cortex, 20(9), 2080-2091.

76. Alexander, M., Garbus, H., Smith, A. L., Rosenkrantz, T. S., \& Fitch, R. H. (2014). Behavioral and histological outcomes following neonatal $\mathrm{HI}$ injury in a preterm (P3) and term (P7) rodent model. Behavioural Brain Research, 259, 85-96.

77. Potter, M., Rosenkrantz, T., \& Fitch, R. H. (2018). Behavioral and neuroanatomical outcomes in a rat model of preterm hypoxicischemic brain injury: Effects of caffeine and hypothermia. International Journal of Developmental Neuroscience, 70, 46-55.

78. Eklind, S., Mallard, C., Arvidsson, P., \& Hagberg, H. (2005). Lipopolysaccharide induces both a primary and a secondary phase of sensitization in the developing rat brain. Pediatric Research, 58(1), 112-116.

79. Brochu, M. E., Girard, S., Lavoie, K., \& Sébire, G. (2011). Developmental regulation of the neuroinflammatory responses to LPS and/or hypoxia-ischemia between preterm and term neonates: An experimental study. Journal of Neuroinflammation, 8, 55.

80. Dammann, O., \& Leviton, A. (1997). Maternal intrauterine infection, cytokines, and brain damage in the preterm newborn. Pediatric Research, 42(1), 1-8.

81. Gilles, F., Gressens, P., Dammann, O., \& Leviton, A. (2018). Hypoxia-ischemia is not an antecedent of most preterm brain damage: The illusion of validity. Developmental Medicine and Child Neurology, 60(2), 120-125.

82. Tai, W. C., Burke, K. A., Dominguez, J. F., Gundamraj, L., \& Turman Jr., J. E. (2009). Growth deficits in a postnatal day 3 rat model of hypoxic-ischemic brain injury. Behavioural Brain Research, 202(1), 40-49.

83. Misumi, S., Ueda, Y., Nishigaki, R., Suzuki, M., Ishida, A., Jung, C. G., \& Hida, H. (2016). Dysfunction in motor coordination in neonatal White matter injury model without apparent neuron loss. Cell Transplantation, 25(7), 1381-1393.

84. Durán-Carabali, L. E., Sanches, E. F., Marques, M. R., Aristimunha, D., Pagnussat, A., \& Netto, C. A. (2017). Longer hypoxia-ischemia periods to neonatal rats causes motor impairments and muscular changes. Neuroscience, 340, 291-298.

85. Durán-Carabali, L. E., Sanches, E. F., Odorcyk, F. K., Nicola, F., Mestriner, R. G., Reichert, L., Aristimunha, D., Pagnussat, A. S., \& Netto, C. A. (2019). Tissue injury and astrocytic reaction, but not cognitive deficits, are dependent on hypoxia duration in very immature rats undergoing neonatal hypoxia-ischemia. Neurochemical Research, 44(11), 2631-2642.

86. McCutcheon, J. E., \& Marinelli, M. (2009). Age matters. The European Journal of Neuroscience, 29(5), 997-1014.

87. Dobbing, J., \& Sands, J. (1973). Quantitative growth and development of human brain. Archives of Disease in Childhood, 48(10), 757-767.

88. Paolicelli, R. C., Bolasco, G., Pagani, F., Maggi, L., Scianni, M., Panzanelli, P., Giustetto, M., Ferreira, T. A., Guiducci, E., Dumas, L., Ragozzino, D., \& Gross, C. T. (2011). Synaptic pruning by microglia is necessary for normal brain development. Science, 333(6048), 1456-1458.

89. Schafer, D. P., Lehrman, E. K., Kautzman, A. G., Koyama, R., Mardinly, A. R., Yamasaki, R., Ransohoff, R. M., Greenberg, M. E., Barres, B. A., \& Stevens, B. (2012). Microglia sculpt postnatal neural circuits in an activity and complement-dependent manner. Neuron, 74(4), 691-705.

90. Erblich, B., Zhu, L., Etgen, A. M., Dobrenis, K., \& Pollard, J. W. (2011). Absence of colony stimulation factor-1 receptor results in loss of microglia, disrupted brain development and olfactory deficits. PLoS One, 6(10), e26317.

91. Cunningham, C. L., Martinez-Cerdeno, V., \& Noctor, S. C. (2013). Microglia regulate the number of neural precursor cells in the developing cerebral cortex. The Journal of Neuroscience, 33(10), 4216-4233.

92. Squarzoni, P., Oller, G., Hoeffel, G., Pont-Lezica, L., Rostaing, P., Low, D., Bessis, A., Ginhoux, F., \& Garel, S. (2014). Microglia modulate wiring of the embryonic forebrain. Cell Reports, 8(5), 1271-1279.

93. Shigemoto-Mogami, Y., Hoshikawa, K., Goldman, J. E., Sekino, Y., \& Sato, K. (2014). Microglia enhance neurogenesis and oligodendrogenesis in the early postnatal subventricular zone. The Journal of Neuroscience, 34(6), 2231-2243.

94. McRae, A., Gilland, E., Bona, E., \& Hagberg, H. (1995). Microglia activation after neonatal hypoxic-ischemia. Developmental Brain Research, 84, 245-252.

95. Ivacko, J. A., Sun, R., \& Silverstein, F. S. (1996). Hypoxicischemic brain injury induces an acute microglial reaction in perinatal rats. Pediatric Research, 39, 39-47.

96. Ferrazzano, P., Chanana, V., Uluc, K., Fidan, E., Akture, E., Kintner, D. B., Cengiz, P., \& Sun, D. (2013). Age-dependent microglial activation in immature brains after hypoxia- ischemia. CNS \& Neurological Disorders - Drug Targets, 12, 338-349.

97. Erkenstam, N. H., Smith, P. L. P., Fleiss, B., Nair, S., Svedin, P., Wang, W., Boström, M., Gressens, P., Hagberg, H., Brown, K. L., Sävman, K., \& Mallard, C. (2016). Temporal characterization of microglia/macrophage phenotypes in a mouse model of neonatal hypoxic-ischemic brain injury. Frontiers in Cellular Neuroscience, 10, 286.

98. Fisch, U., Brégère, C., Geier, F., Chicha, L., \& Guzman, R. (2020). Neonatal hypoxia-ischemia in rat elicits a region-specific neurotrophic response in SVZ microglia. Journal of Neuroinflammation, 17, 26.

99. Holtman, I. R., Raj, D. D., Miller, J. A., Schaafsma, W., Yin, Z., Brouwer, N., Wes, P. D., Moller, T., Orre, M., Kamphuis, W., Hol, E. M., Boddeke, E. W., \& Eggen, B. J. (2015). Induction of 
a common microglia gene expression signature by aging and neurodegenerative conditions: A co-expression meta-analysis. Acta Neuropathologica Communications, 3, 31.

100. Keren-Shaul, H., Spinrad, A., Weiner, A., Matcovitch-Natan, O., Dvir-Szternfeld, R., Ulland, T. K., David, E., Baruch, K., LaraAstaiso, D., Toth, B., Itzkovitz, S., Colonna, M., Schwartz, M., \& Amit, I. (2017). A unique microglia type associated with restricting development of Alzheimer's disease. Cell, 169(7), 1276-1290 e1217.

101. Deczkowska, A., Keren-Shaul, H., Weiner, A., Colonna, M., Schwartz, M., \& Amit, I. (2018). Disease-associated microglia: A universal immune sensor of neurodegeneration. Cell, 173(5), 1073-1081.

102. Gerrits, E., Heng, Y., Boddeke, E., \& Eggen, B. J. L. (2020). Transcriptional profiling of microglia; current state of the art and future perspectives. Glia, 68(4), 740-755.

103. Masuda, T., Sankowski, R., Staszewski, O., \& Prinz, M. (2020). Microglia heterogeneity in the single-cell era. Cell Reports, 30(5), 1271-1281.

104. Mittelbronn, M. (2014). The M1/M2 immune polarization concept in microglia: A fair transfer? Neuroimmunology and Neuroinflammation, 1, 6-7.

105. Ransohoff, R. M. (2016). A polarizing question: Do M1 and M2 microglia exist? Nature Neuroscience, 19(8), 987-991.

106. Matcovitch-Natan, O., Winter, D. R., Giladi, A., Vargas Aguilar, S., Spinrad, A., Sarrazin, S., Ben-Yehuda, H., David, E., Zelada Gonzalez, F., Perrin, P., Keren-Shaul, H., Gury, M., Lara-Astaiso, D., Thaiss, C. A., Cohen, M., Bahar Halpern, K., Baruch, K., Deczkowska, A., Lorenzo-Vivas, E., Itzkovitz, S., Elinav, E., Sieweke, M. H., Schwartz, M., \& Amit, I. (2016). Microglia development follows a stepwise program to regulate brain homeostasis. Science, 353(6301), aad8670

107. Hammond, T. R., Marsh, S. E., \& Stevens, B. (2019). Immune Signaling in Neurodegeneration. Immunity, 50(4), 955-974.

108. Cikla, U., Chanana, V., Kintner, D. B., Covert, L., Dewall, T., Waldman, A., Rowley, P., Cengiz, P., \& Ferrazzano, P. (2016). Suppression of microglia activation after hypoxia-ischemia results in age-dependent improvements in neurologic injury. Journal of Neuroimmunology, 291, 18-27.

109. Mackaness, G. B. (1962). Cellular resistance to infection. The Journal of Experimental Medicine, 116, 381-406.

110. Mackaness, G. B. (1964). The immunological basis of acquired cellular resistance. The Journal of Experimental Medicine, 120, 105-120.

111. Mackaness, G. B. (1969). The influence of immunologically committed lymphoid cells on macrophage activity in vivo. The Journal of Experimental Medicine, 129(5), 973-992.

112. Mackaness, G. B. (1970). The monocyte in cellular immunity. Seminars in Hematology, 7(2), 172-184.

113. Van Epps, H. L. (2005). Macrophage activation unveiled. The Journal of Experimental Medicine, 202(7), 884.

114. Nathan, C. F., Murray, H. W., Wiebe, M. E., \& Rubin, B. Y. (1983). Identification of interferon-gamma as the lymphokine that activates human macrophage oxidative metabolism and antimicrobial activity. The Journal of Experimental Medicine, 158(3), 670 689

115. Stein, M., Keshav, S., Harris, N., \& Gordon, S. (1992). Interleukin 4 potently enhances murine macrophage mannose receptor activity: A marker of alternative immunologic macrophage activation. The Journal of Experimental Medicine, 176(1), 287-292.

116. Doyle, A. G., Herbein, G., Montaner, L. J., Minty, A. J., Caput, D., Ferrara, P., \& Gordon, S. (1994). Interleukin-13 alters the activation state of murine macrophages in vitro: Comparison with interleukin-4 and interferon-gamma. European Journal of Immunology, 24(6), 1441-1445.
117. Coffman, R. L., \& Carty, J. (1986). A T cell activity that enhances polyclonal IgE production and its inhibition by interferon-gamma. Journal of Immunology, 136(3), 949-954.

118. Mosmann, T. R., Cherwinski, H., Bond, M. W., Giedlin, M. A., \& Coffman, R. L. (1986). Two types of murine helper T cell clone. I. Definition according to profiles of lymphokine activities and secreted proteins. J Immunol, 136(7), 2348-2357.

119. Liew, F. Y. (2002). T(H)1 and T(H)2 cells: A historical perspective. Nature Reviews. Immunology, 2(1), 55-60.

120. Coffman, R. L. (2006). Origins of the T(H)1-T(H)2 model: A personal perspective. Nature Immunology, 7(6), 539-541.

121. Mills, C. D., Kincaid, K., Alt, J. M., Heilman, M. J., \& Hill, A. M. (2000). M-1/M-2 macrophages and the Th1/Th2 paradigm. Journal of Immunology, 164(12), 6166-6173.

122. Mills, C. D. (2012). M1 and M2 macrophages: Oracles of health and disease. Critical Reviews in Immunology, 32(6), 463-488.

123. Mills, C. D. (2015). Anatomy of a discovery: $\mathrm{m} 1$ and $\mathrm{m} 2$ macrophages. Frontiers in Immunology, 6, 212.

124. Mills, C. D., Harris, R. A., \& Ley, K. (2015). Macrophage polarization: Decisions that affect health. Journal of Clinical and Cellular Immunology, 6(5).

125. Murray, P. J., Allen, J. E., Biswas, S. K., Fisher, E. A., Gilroy, D. W., Goerdt, S., Gordon, S., Hamilton, J. A., Ivashkiv, L. B., Lawrence, T., Locati, M., Mantovani, A., Martinez, F. O., Mege, J. L., Mosser, D. M., Natoli, G., Saeij, J. P., Schultze, J. L., Shirey, K. A., Sica, A., Suttles, J., Udalova, I., van Ginderachter, J. A., Vogel, S. N., \& Wynn, T. A. (2014). Macrophage activation and polarization: Nomenclature and experimental guidelines. Immunity, 41(1), 14-20.

126. Mantovani, A., Sica, A., Sozzani, S., Allavena, P., Vecchi, A., \& Locati, M. (2004). The chemokine system in diverse forms of macrophage activation and polarization. Trends in Immunology, 25(12), 677-686.

127. Duluc, D., Delneste, Y., Tan, F., Moles, M. P., Grimaud, L., Lenoir, J., Preisser, L., Anegon, I., Catala, L., Ifrah, N., Descamps, P., Gamelin, E., Gascan, H., Hebbar, M., \& Jeannin, P. (2007). Tumor-associated leukemia inhibitory factor and IL-6 skew monocyte differentiation into tumor-associated macrophage-like cells. Blood, 110(13), 4319-4330.

128. Ferrante, C. J., \& Leibovich, S. J. (2012). Regulation of macrophage polarization and wound healing. Adv Wound Care (New Rochelle), 1(1), 10-16.

129. Bleriot, C., Chakarov, S., \& Ginhoux, F. (2020). Determinants of resident tissue macrophage identity and function. Immunity, 52(6), 957-970.

130. Murray, P. J. (2020). On macrophage diversity and inflammatory metabolic timers. Nature Reviews. Immunology, 20(2), 89-90.

131. Martinez, F. O., \& Gordon, S. (2014). The M1 and M2 paradigm of macrophage activation: Time for reassessment. F1000Prime Rep, 6, 13.

132. Deng, W., Mandeville, E., Terasaki, Y., Li, W., Holder, J., Chuang, A. T., Ning, M., Arai, K., Lo, E. H., \& Xing, C. (2020). Transcriptomic characterization of microglia activation in a rat model of ischemic stroke. J Cereb blood flow Metab, 40(1_suppl), S34-S48.

133. Wang, H., Li, Y., Ryder, J. W., Hole, J. T., Ebert, P. J., Airey, D. C., Qian, H. R., Logsdon, B., Fisher, A., Ahmed, Z., Murray, T. K., Cavallini, A., Bose, S., Eastwood, B. J., Collier, D. A., Dage, J. L., Miller, B. B., Merchant, K. M., O'Neill, M. J., \& Demattos, R. B. (2018). Genome-wide RNAseq study of the molecular mechanisms underlying microglia activation in response to pathological tau perturbation in the $\mathrm{rTg} 4510$ tau transgenic animal model. Molecular Neurodegeneration, 13(1), 65.

134. Sobue, A., Komine, O., Hara, Y., Endo, F., Mizoguchi, H., Watanabe, S., Murayama, S., Saito, T., Saido, T. C., Sahara, N., Higuchi, M., Ogi, T., \& Yamanaka, K. (2021). Microglial gene 
signature reveals loss of homeostatic microglia associated with neurodegeneration of Alzheimer's disease. Acta Neuropathologica Communications, 9(1), 1.

135. Olah, M., Menon, V., Habib, N., Taga, M. F., Ma, Y., Yung, C. J., Cimpean, M., Khairallah, A., Coronas-Samano, G., Sankowski, R., Grun, D., Kroshilina, A. A., Dionne, D., Sarkis, R. A., Cosgrove, G. R., Helgager, J., Golden, J. A., Pennell, P. B., Prinz, M., Vonsattel, J. P. G., Teich, A. F., Schneider, J. A., Bennett, D. A., Regev, A., Elyaman, W., Bradshaw, E. M., \& De Jager, P. L. (2020). Single cell RNA sequencing of human microglia uncovers a subset associated with Alzheimer's disease. Nature Communications, 11(1), 6129.

136. Zhou, Y., Song, W. M., Andhey, P. S., Swain, A., Levy, T., Miller, K. R., Poliani, P. L., Cominelli, M., Grover, S., Gilfillan, S., Cella, M., Ulland, T. K., Zaitsev, K., Miyashita, A., Ikeuchi, T., Sainouchi, M., Kakita, A., Bennett, D. A., Schneider, J. A., Nichols, M. R., Beausoleil, S. A., Ulrich, J. D., Holtzman, D. M., Artyomov, M. N., \& Colonna, M. (2020). Human and mouse single-nucleus transcriptomics reveal TREM2-dependent and TREM2-independent cellular responses in Alzheimer's disease. Nature Medicine, 26(1), 131-142.

137. Fukui, O., Kinugasa, Y., Fukuda, A., Fukuda, H., Tskitishvili, E., Hayashi, S., Song, M., Kanagawa, T., Hosono, T., Shimoya, K., \& Murata, Y. (2006). Post-ischemic hypothermia reduced IL-18 expression and suppressed microglial activation in the immature brain. Brain Research, 1121(1), 35-45.

138. Xiong, M., Yang, Y., Chen, G. Q., \& Zhou, W. H. (2009). Postischemic hypothermia for $24 \mathrm{~h}$ in $\mathrm{P} 7$ rats rescues hippocampal neuron: Association with decreased astrocyte activation and inflammatory cytokine expression. Brain Research Bulletin, 79(6), 351-357.

139. Yuan, X., Ghosh, N., McFadden, B., Tone, B., Bellinger, D. L., Obenaus, A., \& Ashwal, S. (2014). Hypothermia modulates cytokine responses after neonatal rat hypoxic-ischemic injury and reduces brain damage. ASN Neuro, 6(6), 175909141455841.

140. Suresh, S., Rajvanshi, P. K., \& Noguchi, C. T. (2019). The many facets of erythropoietin physiologic and metabolic response. Frontiers in Physiology, 10, 1534.

141. Strauss, K. I. (2008). Antiinflammatory and neuroprotective actions of COX2 inhibitors in the injured brain. Brain, Behavior, and Immunity, 22(3), 285-298.

142. Sapadin, A. N., \& Fleischmajer, R. (2006). Tetracyclines: Nonantibiotic properties and their clinical implications. Journal of the American Academy of Dermatology, 54(2), 258-265.

143. Oorschot, D. E., Sizemore, R. J., \& Amer, A. R. (2020). Treatment of neonatal hypoxic-ischemic encephalopathy with erythropoietin alone, and erythropoietin combined with hypothermia: History, current status, and future research. International Journal of Molecular Sciences, 21(4)

144. Arvin, K. L., Han, B. H., Du, Y., Lin, S. Z., Paul, S. M., \& Holtzman, D. M. (2002). Minocycline markedly protects the neonatal brain against hypoxic-ischemic injury. Annals of Neurology, 52(1), 54-61.

145. Martin, D., Chinookoswong, N., \& Miller, G. (1994). The interleukin-1 receptor antagonist (rhIL-1 ra) protects against cerebral infarction in a rat model of hypoxia-ischemia. Experimental Neurology, 130(2), 362-367.

146. Fathali, N., Ostrowski, R. P., Lekic, T., Jadhav, V., Tong, W., Tang, J., \& Zhang, J. H. (2010). Cyclooxygenase-2 inhibition provides lasting protection against neonatal hypoxic-ischemic brain injury. Critical Care Medicine, 38(2), 572-578.

147. Liu, X. H., Eun, B. L., Silverstein, F. S., \& Barks, J. D. (1996). The platelet-activating factor antagonist BN 52021 attenuates hypoxic-ischemic brain injury in the immature rat. Pediatric Research, 40(6), 797-803.
148. Jantzie, L. L., Cheung, P. Y., \& Todd, K. G. (2005). Doxycycline reduces cleaved caspase-3 and microglial activation in an animal model of neonatal hypoxia-ischemia. Journal of Cerebral Blood Flow and Metabolism, 25(3), 314-324.

149. Tsuji, S., Di Martino, E., Mukai, T., Tsuji, S., Murakami, T., Harris, R. A., Blomgren, K., \& Åden, U. (2020). Aggravated brain injury after neonatal hypoxic ischemia in microglia-depleted mice. Journal of Neuroinflammation, 17(1), 111.

150. Zhang, B., Ran, Y., Wu, S., Zhang, F., Huang, H., Zhu, C., Zhang, S., \& Zhang, X. (2021). Inhibition of Colony stimulating factor 1 receptor suppresses Neuroinflammation and neonatal hypoxicischemic brain injury. Frontiers in Neurology, 12, 607370.

151. Lei, F., Cui, N., Zhou, C., Chodosh, J., Vavvas, D. G., \& Paschalis, E. I. (2020). CSF1R inhibition by a small-molecule inhibitor is not microglia specific; affecting hematopoiesis and the function of macrophages. Proceedings of the National Academy of Sciences of the United States of America, 117(38), 23336-23338.

152. Fleiss, B., Van Steenwinckel, J., Bokobza, C., K Shearer, I., RossMunro, E., \& Gressens, P. (2021). Microglia-Mediated Neurodegeneration in Perinatal Brain Injuries. Biomolecules, 11(1), 99.

153. Van Steenwinckel, J., Schang, A. L., Krishnan, M. L., Degos, V., Delahaye-Duriez, A., Bokobza, C., Csaba, Z., Verdonk, F., Montane, A., Sigaut, S., Hennebert, O., Lebon, S., Schwendimann, L., Le Charpentier, T., Hassan-Abdi, R., Ball, G., Aljabar, P., Saxena, A., Holloway, R. K., Birchmeier, W., Baud, O., Rowitch, D., Miron, V., Chretien, F., Leconte, C., Besson, V. C., Petretto, E. G., Edwards, A. D., Hagberg, H., Soussi-Yanicostas, N., Fleiss, B., \& Gressens, P. (2019). Decreased microglial Wnt/beta-catenin signalling drives microglial pro-inflammatory activation in the developing brain. Brain, 142(12), 3806-3833.

154. McNamara, N. B., \& Miron, V. E. (2020). Microglia in developing white matter and perinatal brain injury. Neuroscience Letters, 714,134539

155. McDonald, C. A., Penny, T. R., Paton, M. C. B., Sutherland, A. E., Nekkanti, L., Yawno, T., Castillo-Melendez, M., Fahey, M. C., Jones, N. M., Jenkin, G., \& Miller, S. L. (2018). Effects of umbilical cord blood cells, and subtypes, to reduce neuroinflammation following perinatal hypoxic-ischemic brain injury. Journal of Neuroinflammation, 15, 47.

156. Penny, T. R., Sutherland, A. E., Mihelakis, J. G., Paton, M. C. B., Pham, Y., Lee, J., Jones, N. M., Jenkin, G., Fahey, M. C., Miller, S. L., \& McDonald, C. A. (2019). Human umbilical cord therapy improves long-term behavioral outcomes following neonatal hypoxic ischemic brain injury. Frontiers in Physiology, 10, 283.

157. Otani, T., Ochiai, D., Masuda, H., Abe, Y., Fukutake, M., Matsumoto, T., Miyakoshi, K., \& Tanaka, M. (2019). The neurorestorative effect of human amniotic fluid stem cells on the chronic phase of neonatal hypoxic-ischemic encephalopathy in mice. Pediatric Research, 85, 97-104.

158. Pimentel-Coelho, P. M., Magalhães, E. S., Lopes, L. M., Deazevedo, L. C., Santiago, M. F., \& Mendez-Otero, R. (2010). Human cord blood transplantation in a neonatal rat model of hypoxic-ischemic brain damage: Functional outcome related to neuroprotection in the striatum. Stem Cells and Development, 19, 351-358.

159. Park, W. S., Sung, S. I., Ahn, S. Y., Yoo, H. S., Sung, D. K., Im, G. H., Choi, S. J., \& Chang, Y. S. (2015). Hypothermia augments neuroprotective activity of mesenchymal stem cells for neonatal hypoxic-ischemic encephalopathy. PLoS One, 10, e 0120893.

160. Mikrogeorgiou, A., Sato, Y., Kondo, T., Hattori, T., Sugiyama, Y., Ito, M., Saito, A., Nakanishi, K., Tsuji, M., Kazama, T., Kano, K., Matsumoto, T., \& Hayakawa, M. (2017). Dedifferentiated fat cells as a novel source for cell therapy to target neonatal hypoxic- 
ischemic encephalopathy. Developmental Neuroscience, 39, 273 286.

161. Hattori, T., Sato, Y., Kondo, T., Ichinohashi, Y., Sugiyama, Y., Yamamoto, M., Kotani, T., Hirata, H., Hirakawa, A., Suzuki, S., Tsuji, M., Ikeda, T., Nakanishi, K., Kojima, S., Blomgren, K., \& Hayakawa, M. (2015). Administration of umbilical cord blood cells transiently decreased hypoxic-ischemic brain injury in neonatal rats. Developmental Neuroscience, 37, 95-104.

162. Bae, S. H., Kong, T. H., Lee, H. S., Kim, K. S., Hong, K. S., Chopp, M., Kang, M. S., \& Moon, J. (2012). Long-lasting paracrine effects of human cord blood cells on damaged neocortex in an animal model of cerebral palsy. Cell Transplantation, 21, 2497-2515.

163. Sugiyama, Y., Sato, Y., Kitase, Y., Suzuki, T., Kondo, T., Mikrogeorgiou, A., Horinouchi, A., Maruyama, S., Shimoyama, Y., Tsuji, M., Suzuki, S., Yamamoto, T., \& Hayakawa, M. (2018). Intravenous administration of bone marrow-derived mesenchymal stem cell, but not adipose tissue-derived stem cell, ameliorated the neonatal hypoxic-ischemic brain injury by changing cerebral inflammatory state in rat. Frontiers in Neurology, 9, 757.

164. Fitzner, D., Schnaars, M., van Rossum, D., Krishnamoorthy, G., Dibaj, P., Bakhti, M., Regen, T., Hanisch, U. K., \& Simons, M. (2011). Selective transfer of exosomes from oligodendrocytes to microglia by macropinocytosis. Journal of Cell Science, 124(Pt 3), 447-458.

165. Morton, M. C., Neckles, V. N., Seluzicki, C. M., Holmberg, J. C., \& Feliciano, D. M. (2018). Neonatal subventricular zone neural stem cells release extracellular vesicles that act as a microglial morphogen. Cell Reports, 23(1), 78-89.

166. Spellicy, S. E., \& Stice, S. L. (2021). Tissue and stem cell sourced extracellular vesicle communications with microglia. Stem Cell Reviews and Reports, 17(2), 357-368.

167. Kaminski, N., Köster, C., Mouloud, Y., Börger, V., FelderhoffMüser, U., Bendix, I., Giebel, B., \& Herz, J. (2020). Mesenchymal stromal cell-derived extracellular vesicles reduce Neuroinflammation, promote neural cell proliferation and improve oligodendrocyte maturation in neonatal hypoxic-ischemic brain injury. Frontiers in Cellular Neuroscience, 14, 601176.

168. Sisa, C., Kholia, S., Naylor, J., Herrera Sanchez, M. B., Bruno, S., Deregibus, M. C., Camussi, G., Inal, J. M., Lange, S., \& Hristova, M. (2019). Mesenchymal stromal cell derived extracellular vesicles reduce hypoxia-Ischaemia induced perinatal brain injury. Frontiers in Physiology, 10, 282.

169. Xin, D., Li, T., Chu, X., Ke, H., Yu, Z., Cao, L., Bai, X., Liu, D., \& Wang, Z. (2020). Mesenchymal stromal cell-derived extracellular vesicles modulate microglia/macrophage polarization and protect the brain against hypoxia-ischemic injury in neonatal mice by targeting delivery of miR-21a-5p. Acta Biomaterialia, 113, 597613.

170. Kang, M., Min, K., Jang, J., Kim, S. C., Kang, M. S., Jang, S. J., Lee, J. Y., Kim, S. H., Kim, M. K., An, S. A., \& Kim, M. (2015). Involvement of immune responses in the efficacy of Cord blood cell therapy for cerebral palsy. Stem Cells and Development, 24(19), 2259-2268.

171. Koh, H., Rah, W. J., Kim, Y. J., Moon, J. H., Kim, M. J., \& Lee, Y. H. (2018). Serial changes of cytokines in children with cerebral palsy who received intravenous granulocyte-colony stimulating factor followed by autologous mobilized peripheral blood mononuclear cells. Journal of Korean Medical Science, 33(21), e102.

172. Ahn, S. Y., Chang, Y. S., Sung, S. I., \& Park, W. S. (2018). Mesenchymal stem cells for severe intraventricular hemorrhage in preterm infants: Phase I dose-escalation clinical trial. Stem Cells Translational Medicine, 7(12), 847-856.

173. Rah, W. J., Lee, Y. H., Moon, J. H., Jun, H. J., Kang, H. R., Koh, H., Eom, H. J., Lee, J. Y., Lee, Y. J., Kim, J. Y., Choi, Y. Y., Park, K., Kim, M. J., \& Kim, S. H. (2017). Neuroregenerative potential of intravenous G-CSF and autologous peripheral blood stem cells in children with cerebral palsy: A randomized, double-blind, cross-over study. Journal of Translational Medicine, 15(1), 16.

174. Min, K., Song, J., Kang, J. Y., Ko, J., Ryu, J. S., Kang, M. S., Jang, S. J., Kim, S. H., Oh, D., Kim, M. K., Kim, S. S., \& Kim, M. (2013). Umbilical cord blood therapy potentiated with erythropoietin for children with cerebral palsy: A double-blind, randomized, placebo-controlled trial. Stem Cells, 31(3), 581-591.

175. Sharma, A., Sane, H., Gokulchandran, N., Kulkarni, P., Gandhi, S., Sundaram, J., Paranjape, A., Shetty, A., Bhagwanani, K., Biju, H., \& Badhe, P. (2015). A clinical study of autologous bone marrow mononuclear cells for cerebral palsy patients: A new frontier. Stem Cells International, 2015, 905874.

176. Gu, J., Huang, L., Zhang, C., Wang, Y., Zhang, R., Tu, Z., Wang, H., Zhou, X., Xiao, Z., Liu, Z., Hu, X., Ke, Z., Wang, D., \& Liu, L. (2020). Therapeutic evidence of umbilical cord-derived mesenchymal stem cell transplantation for cerebral palsy: A randomized, controlled trial. Stem Cell Research \& Therapy, 11(1), 43.

177. Lee, Y. H., Choi, K. V., Moon, J. H., Jun, H. J., Kang, H. R., Oh, S. I., Kim, H. S., Um, J. S., Kim, M. J., Choi, Y. Y., Lee, Y. J., Kim, H. J., Lee, J. H., Son, S. M., Choi, S. J., Oh, W., \& Yang, Y. S. (2012). Safety and feasibility of countering neurological impairment by intravenous administration of autologous cord blood in cerebral palsy. Journal of Translational Medicine, 10, 58.

178. Sun, J. M., Song, A. W., Case, L. E., Mikati, M. A., Gustafson, K. E., Simmons, R., Goldstein, R., Petry, J., McLaughlin, C., WatersPick, B., Chen, L. W., Wease, S., Blackwell, B., Worley, G., Troy, J., \& Kurtzberg, J. (2017). Effect of autologous Cord blood infusion on motor function and brain connectivity in Young children with cerebral palsy: A randomized, placebo-controlled trial. Stem Cells Translational Medicine, 6(12), 2071-2078.

179. Lartey, F. M., Ahn, G. O., Ali, R., Rosenblum, S., Miao, Z., Arksey, N., Shen, B., Colomer, M. V., Rafat, M., Liu, H., Alejandre-Alcazar, M. A., Chen, J. W., Palmer, T., Chin, F. T., Guzman, R., Loo Jr., B. W., \& Graves, E. (2014). The relationship between serial [(18) F]PBR06 PET imaging of microglial activation and motor function following stroke in mice. Molecular Imaging and Biology, 16(6), 821-829.

180. Lartey, F. M., Ahn, G. O., Shen, B., Cord, K. T., Smith, T., Chua, J. Y., Rosenblum, S., Liu, H., James, M. L., Chernikova, S., Lee, S. W., Pisani, L. J., Tirouvanziam, R., Chen, J. W., Palmer, T. D., Chin, F. T., Guzman, R., Graves, E. E., \& Loo Jr., B. W. (2014). PET imaging of stroke-induced neuroinflammation in mice using [18F]PBR06. Molecular Imaging and Biology, 16(1), 109-117.

181. Evans, N. R., Tarkin, J. M., Buscombe, J. R., Markus, H. S., Rudd, J. H. F., \& Warburton, E. A. (2017). PET imaging of the neurovascular interface in cerebrovascular disease. Nature Reviews. Neurology, 13(11), 676-688.

182. Zhang, L., Hu, K., Shao, T., Hou, L., Zhang, S., Ye, W., Josephson, L., Meyer, J. H., Zhang, M. R., Vasdev, N., Wang, J., Xu, H., Wang, L., \& Liang, S. H. (2021). Recent developments on PET radiotracers for TSPO and their applications in neuroimaging. Acta Pharmaceutica Sinica B, 11(2), 373-393.

183. Serrenho, I., Rosado, M., Dinis, A., M Cardoso, C., Grãos, M., Manadas, B., \& Baltazar, G. (2021). Stem Cell Therapy for Neonatal Hypoxic-Ischemic Encephalopathy: A Systematic Review of Preclinical Studies. International Journal of Molecular Sciences, 22(6).

184. Enzmann, V., Lecaudé, S., Kruschinski, A., \& Vater, A. (2017). CXCL12/SDF-1-dependent retinal migration of endogenous bone marrow-derived stem cells improves visual function after pharmacologically induced retinal degeneration. Stem Cell Reviews and Reports, 13(2), 278-286.

185. Ravizza, T., Moneta, D., Bottazzi, B., Peri, G., Garlanda, C., Hirsch, E., Richards, G. J., Mantovani, A., \& Vezzani, A. (2001). Dynamic induction of the long pentraxin PTX3 in the 
CNS after limbic seizures: Evidence for a protective role in seizure-induced neurodegeneration. Neuroscience, 105(1), 43-53.

186. Han, B., Haitsma, J. J., Zhang, Y., Bai, X., Rubacha, M., Keshavjee, S., Zhang, H., \& Liu, M. (2011). Long pentraxin PTX3 deficiency worsens LPS-induced acute lung injury. Intensive Care Medicine, 37(2), 334-342.

187. Kunes, P., Mandak, J., Holubcova, Z., Kolackova, M., \& Krejsek, J. (2013). The long pentraxin PTX3: A candidate antiinflammatory mediator in cardiac surgery. Perfusion, 28(5), 377-389.

188. Norrby, K. (1996). Interleukin-8 and de novo mammalian angiogenesis. Cell Proliferation, 29(6), 315-323.

189. Romanov, Y. A., Tarakanov, O. P., Radaev, S. M., Dugina, T. N., Ryaskina, S. S., Darevskaya, A. N., Morozova, Y. V., Khachatryan, W. A., Lebedev, K. E., Zotova, N. S., Burkova, A. S., Sukhikh, G. T., \& Smirnov, V. N. (2015). Human allogeneic $\mathrm{AB} 0 / \mathrm{Rh}$-identical umbilical cord blood cells in the treatment of juvenile patients with cerebral palsy. Cytotherapy, 17(7), 969978.

190. Tsuji, M., Sawada, M., Watabe, S., Sano, H., Kanai, M., Tanaka, E., Ohnishi, S., Sato, Y., Sobajima, H., Hamazaki, T., Mori, R., Oka, A., Ichiba, H., Hayakawa, M., Kusuda, S., Tamura, M., Nabetani, M., \& Shintaku, H. (2020). Autologous cord blood cell therapy for neonatal hypoxic-ischaemic encephalopathy: A pilot study for feasibility and safety. Scientific Reports, 10(1), 4603.

191. Cotten, C. M., Murtha, A. P., Goldberg, R. N., Grotegut, C. A., Smith, P. B., Goldstein, R. F., Fisher, K. A., Gustafson, K. E., Waters-Pick, B., Swamy, G. K., Rattray, B., Tan, S., \& Kurtzberg, J. (2014). Feasibility of autologous cord blood cells for infants with hypoxic-ischemic encephalopathy. $J$ Pediatr, 164(5), 973-979.e971.

192. Park, K. I., Lee, Y. H., Rah, W. J., Jo, S. H., Park, S. B., Han, S. H., Koh, H., Suh, J. Y., Um, J. S., Choi, E. H., Park, U. J., \& Kim, M. J. (2017). Effect of intravenous infusion of G-CSF-mobilized peripheral blood mononuclear cells on upper extremity function in cerebral palsy children. Annals of Rehabilitation Medicine, 41(1), 113-120.

193. Mancías-Guerra, C., Marroquín-Escamilla, A. R., GonzálezLlano, O., Villarreal-Martínez, L., Jaime-Pérez, J. C., GarcíaRodríguez, F., Valdés-Burnes, S. L., Rodríguez-Romo, L. N., Barrera-Morales, D. C., Sánchez-Hernández, J. J., CantúRodríguez, O. G., Gutiérrez-Aguirre, C. H., Gómez-De León, A., Elizondo-Riojas, G., Salazar-Riojas, R., \& GómezAlmaguer, D. (2014). Safety and tolerability of intrathecal delivery of autologous bone marrow nucleated cells in children with cerebral palsy: An open-label phase I trial. Cytotherapy, 16(6), 810-820.

194. Wang, X., Cheng, H., Hua, R., Yang, J., Dai, G., Zhang, Z., Wang, R., Qin, C., \& An, Y. (2013). Effects of bone marrow mesenchymal stromal cells on gross motor function measure scores of children with cerebral palsy: A preliminary clinical study. Cytotherapy, 15(12), 1549-1562.

195. Gabr, H., El-Kheir, W. A., Ghannam, O., El-Fiki, M. E., \& Salah, Y. (2015). Intrathecal autologous bone marrow derived MSC therapy in cerebral palsy: Safety and short term efficacy. American journal of bioscience and bioengineering 3(4-1), pp. 24-29.

196. Huang, L., Zhang, C., Gu, J., Wu, W., Shen, Z., Zhou, X., \& Lu, H. (2018). A randomized, placebo-controlled trial of human umbilical Cord blood mesenchymal stem cell infusion for children with cerebral palsy. Cell Transplantation, 27(2), 325-334.

197. Thorngren-Jerneck, K., Ohlsson, T., Sandell, A., Erlandsson, K., Strand, S. E., Ryding, E., \& Svenningsen, N. W. (2001). Cerebral glucose metabolism measured by positron emission tomography in term newborn infants with hypoxic ischemic encephalopathy. Pediatric Research, 49(4), 495-501.

Publisher's Note Springer Nature remains neutral with regard to jurisdictional claims in published maps and institutional affiliations. 